Key Words: Cesium, Illite In situ remediation

Wetlands

Soil amendment

Environmental impact

Turbidity

\title{
SHORT-TERM ENVIRONMENTAL IMPACTS OF ILLITE CLAYS WHEN USED AS AN IN SITU METHOD FOR REMEDIATING ${ }^{137}$ Cs- CONTAMINATED WETLANDS (U)
}

T. G. Hinton, Bon-Jun Koo, S. I. Watson, D. E. Fletcher, D. P. Coughlin, and M. M. Standora Savannah River Ecology Laboratory

The University of Georgia

Aiken, SC 29802

Phone: (803) $557-7454$

FAX: (803) $557-7342$

D. I. Kaplan

Savannah River Technology Center

Westinghouse Savannah River Company

Aiken, SC 29802

Phone: (803) $725-2363$

FAX: (803) $725-4704$ 
This document was prepared in conjunction with work accomplished under Contract No. DE-AC09-96SR18500 with the U. S. Department of Energy.

\section{DISCLAIMER}

This report was prepared as an account of work sponsored by an agency of the United States Government. Neither the United States Government nor any agency thereof, nor any of their employees, makes any warranty, express or implied, or assumes any legal liability or responsibility for the accuracy, completeness, or usefulness of any information, apparatus, product or process disclosed, or represents that its use would not infringe privately owned rights. Reference herein to any specific commercial product, process or service by trade name, trademark, manufacturer, or otherwise does not necessarily constitute or imply its endorsement, recommendation, or favoring by the United States Government or any agency thereof. The views and opinions of authors expressed herein do not necessarily state or reflect those of the United States Government or any agency thereof.

This report has been reproduced directly from the best available copy.

Available for sale to the public, in paper, from: U.S. Department of Commerce, National Technical Information Service, 5285 Port Royal Road, Springfield, VA 22161, phone: (800) 553-6847, fax: (703) 605-6900

email: orders@ntis.fedworld.gov

online ordering: http://www.ntis.gov/help/index.asp

Available electronically at http://www.osti.gov/bridge

Available for a processing fee to U.S. Department of Energy and its contractors, in paper, from: U.S. Department of Energy, Office of Scientific and Technical Information, P.O. Box 62, Oak Ridge, TN 37831-0062,

phone: (865)576-8401,

fax: (865)576-5728

email: $\underline{\text { reports@ adonis.osti.gov }}$ 
This page intentionally left blank 


\section{TABLE OF CONTENTS}

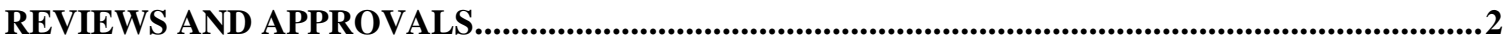

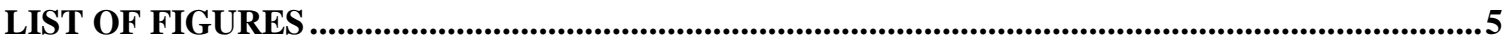

LIST OF TABLES .................................................................................................................................

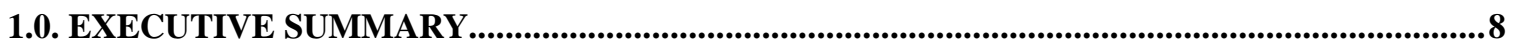

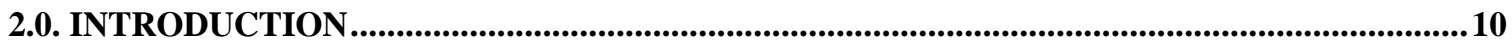

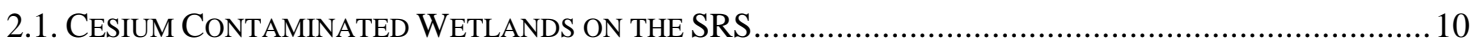

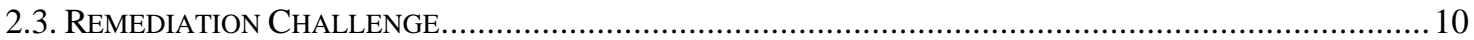

2.4. APPLICATION OF ILLITE TO SEQUESTER ${ }^{137}$ CS IN CONTAMINATED SEDIMENTS .................................. 11

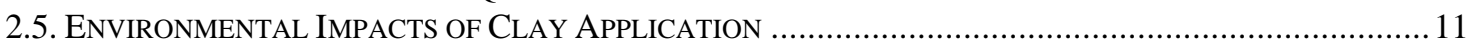

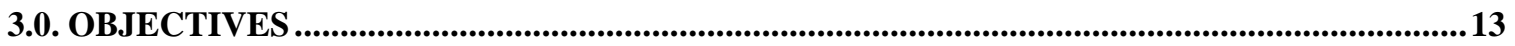

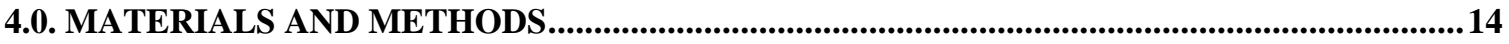

4.1. SETTLING BEHAVIOR AND CS AdSORPTION CAPACITY OF TODD Light ILLITES .............................. 14

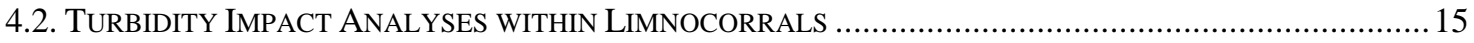

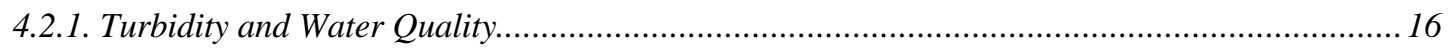

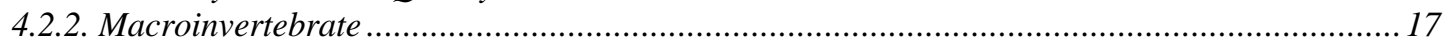

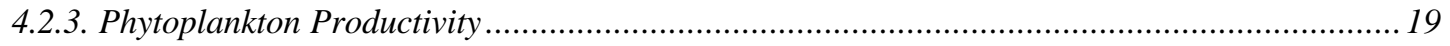

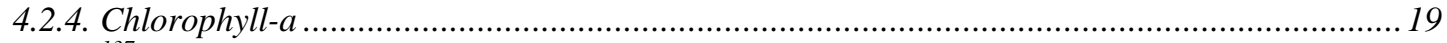

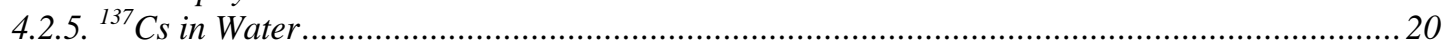

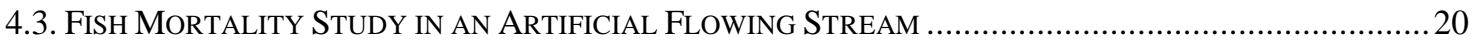

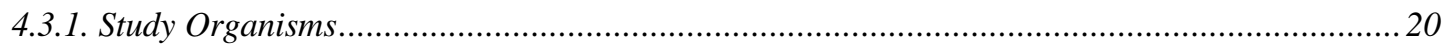

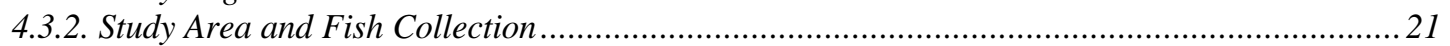

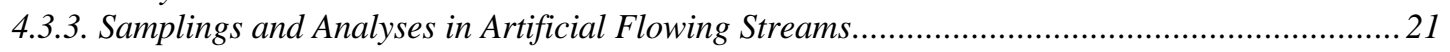

4.4. SURVEY OF POTENTIAL SRS LOCATIONS FOR FUTURE FIELD DEPLOYMENT …...............................2

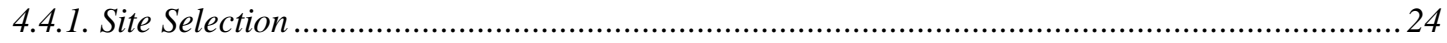

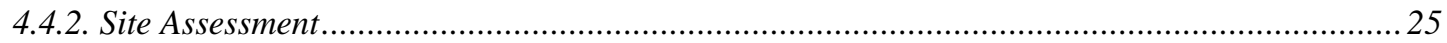

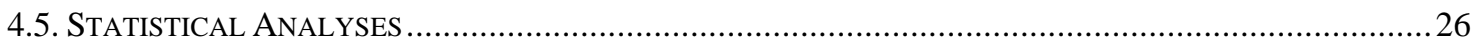

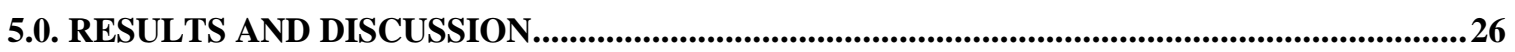

5.1. SETTLING BEHAVIOR AND Cs AdSORPTION CAPACITY OF TODd Light ILLITES ..............................26

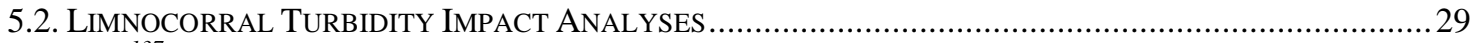

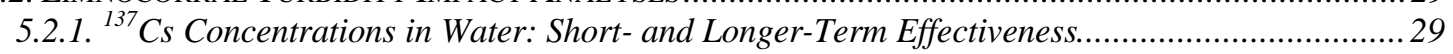

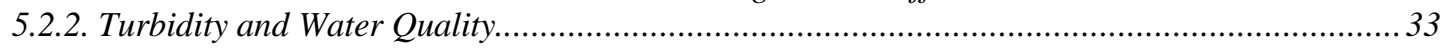

5.2.3. Macroinvertebrates, Phytoplankton Productivity, and Chlorophyll-a .................................... 35

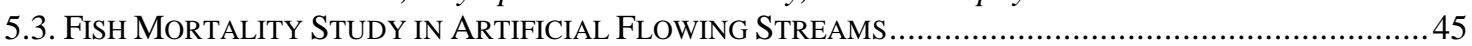

5.4. SURVEY OF POTENTIAL SRS LOCATIONS FOR FUTURE FIELD DEPLOYMENT …............................... 48

6.0. CONCLUSIONS AND IMPLICATIONS TO WSRC / DOE..........................................................51

7.0. ACKNOWLEDGEMENTS.....................................................................................................52

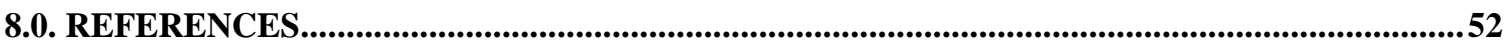

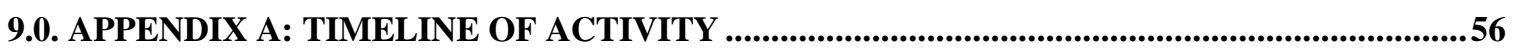

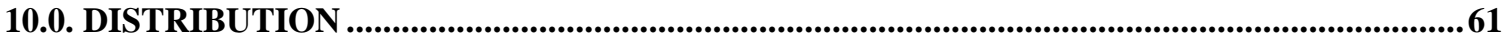


WSRC-TR-2004-00125

SREL-73; UC-66e

\section{LIST OF FIGURES}

Figure 1. Mean $\left( \pm\right.$ SE) activity of ${ }^{137} \mathrm{Cs}$ in water samples collected from controls and limnocorrals treated with two levels of illite $(0.25 \mathrm{~cm}$ and $2.5 \mathrm{~cm}$ of illite covering the pond sediments). Data show the reduction in ${ }^{137} \mathrm{Cs}$ concentrations within samples taken prior to the addition of the clay treatment (PRE) and on weeks 5, 12, 23, and 42 subsequent to the treatment. ${ }^{137} \mathrm{Cs}$ levels in the high clay treatment for week 42 were below limits of detection (from Hinton et al. 2002) ..........................................................

Figure 2. Reductions in mean ${ }^{137} \mathrm{Cs}$ concentrations in the stems and leaves of an aquatic plant species (Nymphae odorata), duckweed, and fish (Gambusia) following treatment of the water with two levels of illite $(0.25 \mathrm{~cm}$ and $2.5 \mathrm{~cm}$ of illite covering the pond sediments). Results are from replicated limnocorrals placed in Pond A and R-canal (from Hinton et al. 2002). . .11

Figure 3. Randomized locations of limnocorrals placed in R-Canal and Pond A on the Savannah River Site. Six limnocorrals were treated with enough clay to cover $0.25 \mathrm{~cm}$ of the sediment surface (Low clay application), six received a treatment 10 times that amount (2.5 $\mathrm{cm}$ on the sediment surface: High clay application), and four limnocorrals received no clay and served as untreated controls................................................

Figure 4. Limnocorral in foreground after receiving the high clay treatment, and a control, untreated limnocorral in the background..........................................

Figure 5. Hester-Dendy (H-D) multiplate samplers were placed in twelve (4 limnocorrals for each control, low clay, and high clay treatment) of the 16 limnocorrals located in R-Canal and Pond A to collect aquatic macroinvertebrates.

Figure 6. Map of the study area and three fish collection locations on Fourmile Branch .........22

Figure 7. Sampling method for site evaluation of clay application. Five replicate sediment samples were taken at every location, one in the center of the steam, one $1 \mathrm{~m}$ upstream and downstream of the center and $1 \mathrm{~m}$ to each side of the center..........................25

Figure 8. A comparison of mean $\left( \pm \mathrm{St} \mathrm{dev}\right.$. ${ }^{137} \mathrm{Cs}$ removal efficiencies of contaminated Pond B water samples treated with air-floated, semi-dry, and crude Todd Light Illites. ......................28

Figure 9. Mean ( \pm Stdev.) activity of ${ }^{137} \mathrm{Cs}$ in water samples collected from control and treated limnocorrals. Data show samples taken 112 weeks after the original treatment (BCA; 1 July 2003; post 112W, indicates on 1 May 2001) and two weeks after a re-application of the illite treatments (ACA; 17 July 2003; LCA: low clay application; HCA: high clay application). Within treatments (BCA and ACA) means followed by the same letter are not significantly different at $\mathrm{p}>.05$....

Figure 10. Changes in turbidity (NTU; mean \pm Stdev) are shown from before treatment (29 June, 2003) to nineteen days after treatment. Turbidity decreased exponentially following application (high clay: $\mathrm{y}=3227\left(\mathrm{e}^{-0.558 \mathrm{x}}\right), \mathrm{R}^{2}=0.95$; low clay: $\mathrm{y}=183.6\left(\mathrm{e}^{-0.583 \mathrm{x}}\right)$,

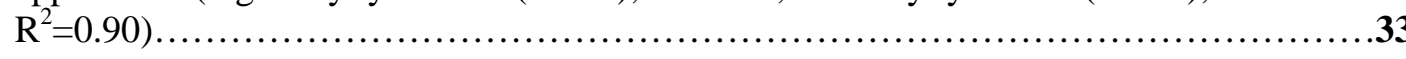

Figure 11. Temperature changes (mean \pm Stdev.) of limnocorrals from June 29 through July 21. Temperature of high clay amended limnocorrals drops below those levels of control and low clay amended limnocorrals briefly after clay application.........................34

Figure 12. Mean numbers of individuals of the aquatic insect families most commonly found in the Hester-Dendy samplers, one year after the first application (BCA) and seven days after

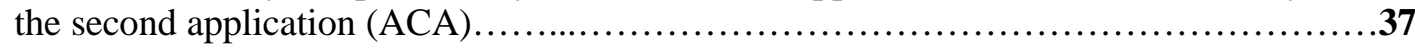

Figure 13. Comparison of factor scores of the first and second principal components. Polygons enclose all points for each treatment: control, low clay application, high clay application. A) BCA-before second clay application; B) ACA-after second clay application. ...........40 
Figure 14. Response of PC-I scores to clay treatment. Least squares means saved from ANOVA

\pm 1 standard error. A) mean scores before (BCA) and after (ACA) the second clay application with the effects of treatment controlled. B) Mean scores across treatments before the second clay application: no clay applied (control), low clay application (LCA) and high clay application (HCA). C) Mean scores across treatments after the second clay treatment. ...

Figure 15. Turbidity (mean \pm Stdev.; $n=3$ ) was measured in the raceways as a function of elapsed time after introducing Upper Three Runs water and prior to clay treatment. Turbidity

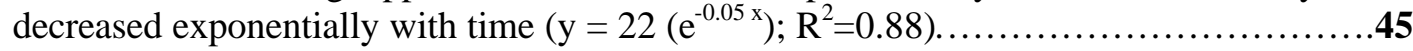

Figure 16. Mean ( \pm Stdev.) survivorship of yellowfin shiners collected from raceways. No significant differences $(\mathrm{p}>0.05)$ exist among treatments for the fish survivorship .........47

Figure 17. Concentration of ${ }^{137} \mathrm{Cs}$ (mean \pm Stdev.) in sediments and water in streams. A ranking of the ${ }^{137} \mathrm{Cs}$ concentrations in sediments and water in streams as chemical characteristics would be Fourmile Branch > Lower Three Runs > Pen Branch • Steel Creek..................49 
WSRC-TR-2004-00125

SREL-73; UC-66e

\section{LIST OF TABLES}

Table 1. Combined body weight of 50 yellowfin shiners and 20 tessellated darters measured on 24 July 2003. Fish were weighed in a tared beaker of water before being introduced into the experimental raceway.

Table 2. Selected physicochemical properties of illites used in the study (mean \pm Stdev; $n=3$ )..26

Table 3. Results of a particle settling and flocculation experiments using different types of Todd Light Illites (air-floated, semi-dry, and crude).

Table 4. Water quality measurements were taken once before clay application, July 1 , and several times after clay application, on July $7,10,15,17$, and 21 . Temperature, $\mathrm{pH}$, dissolved oxygen (DO), electrical conductivity, and oxidation-reduction potential (ORP) were recorded. Treatments: Control - no clay application; LCA - low clay application $(0.25 \mathrm{~cm}$ layer of clay on the bottom of the sediment); HCA - high clay application $(2.5 \mathrm{~cm}$ layer of clay on the bottom of the sediment).............................................

Table 5. Water samples were taken for chlorophyll-a analysis on July 21. Treatments: Control no clay application; LCA - low clay application $(0.25 \mathrm{~cm}$ layer of clay on the bottom of the sediment); HCA - high clay application $(2.5 \mathrm{~cm}$ layer of clay on the bottom of the

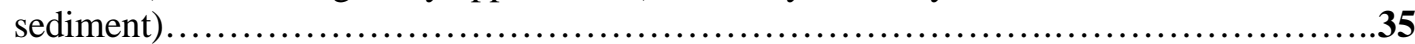

Table 6. Gross and net primary productivity and respiration of phytoplankton were measured on July 7, 15, and 21 using the dissolved oxygen method (Wetzel and Likens, 1991; Clesceri et al., 1998). Treatments: Control - no clay application; LCA - low clay application $(0.25 \mathrm{~cm}$ layer of clay on the bottom of the sediment $)$; HCA - high clay application $(2.5 \mathrm{~cm}$ layer of clay on the bottom of the sediment).

Table 7. Abundance of aquatic insects was measured before (BCA) and after the second clay application (ACA). Total numbers of insects and number of insects belonging to the most common taxa are presented. Taxonomic richness measured as the total number of families and orders of insects found in the Hester-Dendy samplers. Means and standard deviations are for the samplers; see Figure 12 for limnocoral means. Treatments: Control - no clay application; LCA - low clay application $(0.25 \mathrm{~cm}$ layer of clay on the bottom of the sediment); HCA - high clay application $(2.5 \mathrm{~cm}$ layer of clay on the bottom of the

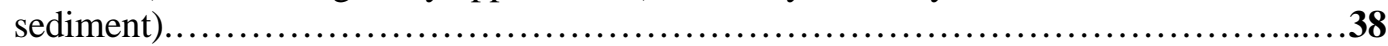

Table 8. Loadings of abundance of the 5 aquatic insect families collected in the Hester-Dendy samplers on the first 2 principal components

Table 9. Results of ANOVA of the effects of clay status (ACA vs. BCA) and treatment on each of the two principle components. Aquatic insect families with loadings of absolute value greater than 0.4 are listed beside the component heading ...

Table 10. Changes in turbidity (mean \pm Stdev.) for air-floated, semi-dry, and control treated raceways were measured before (BCA), during (DCA) and after clay application. Turbidity values were measured 1, 2, 4, 8, 24, 48, 96, and 168 hours after the clay application and at 2, 3, 4, 5, 6, and $7 \mathrm{~m}$ of raceways...

Table 11. Evaluation of potential sites for illite application. Results showed on a scale of 1-4 (1: being the best and 4: being the worst)

Table 12. Velocity, depth, and width (mean \pm Stdev.) at 3 locations on each stream were measured for comparison 


\subsection{EXECUTIVE SUMMARY}

Over 1,200 hectares (3,000 acres) of wetlands such as L-Lake; Par Pond; Ponds A, 2, 4, 5, and B; canals; and several creeks (e.g. Steel Creek, Lower Three Runs, and Pen Branch) on the Savannah River Site (SRS) are contaminated with 560 Ci of ${ }^{137} \mathrm{Cs}$ (Carlton et al., 1992). These environmentally sensitive wetlands pose a significant remediation challenge to the Department of Energy (DOE). A new technology is needed to avoid environmentally destructive remediation (Whicker et al., 2004). Current muck and truck technologies destroy the sensitive ecosystems, and may increase dose to workers.

Because of relatively low amount of clay and weak ${ }^{137} \mathrm{Cs}$ retention capabilities of kaolinitedominant sediments on the SRS, ${ }^{137} \mathrm{Cs}$ has a greater bioavailability here than at any other DOE site. We have previously shown that naturally occurring illite minerals, with a high complexing capability for ${ }^{137} \mathrm{Cs}$, can sequester ${ }^{137} \mathrm{Cs}$ and reduce its bioavailability when applied to ${ }^{137} \mathrm{Cs}$ contaminated wetlands. Previous research showed that an in situ remediation method using illite minerals reduced ${ }^{137} \mathrm{Cs}$ concentrations in the water 25 - to 30 -fold, in aquatic plants 3 - to 5-fold, and in fish 2- to 3-fold (Hinton et al. 1999, 2001, 2002).

During this funding period (Fy03) we re-sampled study sites in Pond A and R-Canal that had been treated in 2001 with illite clays. The data revealed that ${ }^{137} \mathrm{Cs}$ concentrations in water are still lower than untreated control sites, some 112 weeks later. This encouraging result indicates that the in situ remediation technique has a longer-term effectiveness than was previously reported. This positive finding occurred despite the study site experiencing a severe drought, as well as flooded conditions during the two-year period.

However, the application of large amounts of clay to the wetlands creates conditions of high turbidity, siltation, and sedimentation that could have environmental impacts of their own. Sedimentation and turbidity are common by-products of activities such as agriculture, forestry, mining, and road construction. Research reported herein examined the environmental impacts of the clay application in a pond habitat (R-Canal and Pond A), and a simulated stream habitat represented by an artificial stream at the Savannah River Ecology Laboratory's Aquatic Ecology Laboratory (AEL). We also began research on adapting the remediation technique originally designed for ponds and lakes, to stream environments.

Applying the illite clays caused water turbidity to increase by two to three orders-ofmagnitude. Although water clarity improved quickly at an exponential rate, with a half time of 1.2 days, some 100 days were required for the high clay treatments to return to the turbidity levels of control sites. The environmental impact of the turbid water was assessed by examining other 
WSRC-TR-2004-00125

SREL-73; UC-66e

water quality measurements, phytoplankton productivity, chlorophyll-a production, the abundance of macro-invertebrates, and fish mortality. No significant differences in $\mathrm{pH}$, electrical conductivity, dissolved oxygen or oxidation-reduction potential were found among treatments. Electrical conductivity values would be expected to decrease if the illites were absorbing ionic solutes from the water column, such as $\mathrm{K}_{\text {or }} \mathrm{NH}_{4}$. Thus, the clay application is not likely to decrease the availability of essential plant nutrients in treated waters. No significant differences were observed in phytoplankton productivity, chlorophyll-a levels. No difference in total numbers of macroinvertebrate insects was observed between controls and illite-treated limnocorrals. However, differences in species assemblages of macroinvertebrates were apparent, two years after the initial clay application, between controls and high clay application treatments. No difference was found between the low clay applications and controls. The divergence in species assemblages among treatments significantly increased after the second clay application. These results are very encouraging in that they suggest that although impacts did occur to the macroinvertebrate community, recovery was occurring and that the impacts are not permanent. When the illite was applied to flowing streams (raceways at the Aquatic Ecology Laboratory), water clarity returned within a matter of hours and fish mortality was not affected.

Analyses of particle settling and flocculation rates among three commercially available Todd Light Illites that differed in particle size and moisture content revealed the flexibility of the clay application method and the versatility of the Todd Light Illites to different remediation needs. Air-floated Todd Light Illites were found to disperse quickly throughout the water column and would be ideal for remediating lakes, or possibly long reaches of a contaminated stream. If, however, small localized contaminated hot spots within streams are the target of remediation, then the crude Todd Light Illite's more rapid settling characteristics would allow one to place the mineral specifically where needed, rather than broadly dispersing it within the stream. More work on field deployment methods for various contaminant dispersal scenarios would be useful.

Studies on the in situ application of illite minerals to ${ }^{137} \mathrm{Cs}$-contaminated wetlands continue to produce positive results. Additional measurements are needed, however, to determine the longterm effectiveness of the technique, and the environmental impacts on parameters not measured in this study. When coupled to the earlier work of Hinton et al. $(1999,2001,2002)$, the results reported herein support the use of illite applications to ${ }^{137} \mathrm{Cs}$-contaminated wetlands on the SRS as an attractive alternative to more environmentally destructive remediation methods. 


\subsection{INTRODUCTION}

\subsection{Cesium Contaminated Wetlands on the SRS}

Numerous aquatic systems on the Savannah River Site (SRS) such as L-Lake; Par Pond; Ponds A, 2, 4, 5 and B; several creeks (e.g., Steel Creek, Lower Three Runs, Fourmile Branch, and Pen Branch); as well as many kilometers of canals that connected the reactors to their cooling ponds are contaminated with ${ }^{137} \mathrm{Cs},{ }^{90} \mathrm{Sr}$, and isotopes of $\mathrm{Pu}$. Combined, these aquatic systems represent over 3,000 acres of wetlands.

Cesium-137 is often the radionuclide of primary concern in these systems because of its biological mobility and long half-life. Cesium's implication to human health was evident during the draw down of Par Pond. Exposure to ${ }^{137} \mathrm{Cs}$ comprised $95 \%$ of the lifetime fatal cancer risks to an adult farmer hypothetically living on the exposed sediments, while strontium's and plutonium's contribution to risks were 0.6 and 4.1\%, respectively (Whicker et al., 1993).

Inventories of ${ }^{137} \mathrm{Cs}$ within contaminated wetlands on SRS have been estimated at $560 \mathrm{Ci}$ (Carlton et al., 1992). The change in ${ }^{137} \mathrm{Cs}$ concentrations in site streams over time shows that peak releases occurred in the mid-1960s, with the highest median discharge of about $20 \mathrm{Ci}$ released in 1964. Of the total ${ }^{137} \mathrm{Cs}$ activities in SRS streams, Steel Creek, Lower Three Runs, Fourmile Branch, and Pen Branch, contained 54\%, 21\%, 14\%, and 11\%, respectively (RAC, 1999).

The problems of contaminated aquatic systems and their associated risks are heightened on the SRS because ${ }^{137} \mathrm{Cs}$ is more biologically available here than at any other DOE facility. Two main reasons for the enhanced mobility and bioavailability of ${ }^{137} \mathrm{Cs}$ in the aquatic systems on the SRS are the low percentage of clays in SRS soils and the fact that the existing clays are dominated by kaolinite and iron oxides. Kaolinite (a 1:1 clay) forms weak bonds with ${ }^{137} \mathrm{Cs}$. In contrast, 2:1 phyllosilicate minerals, such as illites and micas, form very strong bonds with ${ }^{137} \mathrm{Cs}$. Illite minerals can sorb ${ }^{137} \mathrm{Cs}$ almost irreversibly, meaning once the ${ }^{137} \mathrm{Cs}$ sorbs to the mineral it is held and will not readily desorb. Interestingly, SRS sediments have some mica-like minerals (Ruhe and Matney, 1980), but they are largely ineffective in forming strong bonds with ${ }^{137} \mathrm{Cs}$ (Seaman et al., 2001), presumably because of lower particle unit charge, due to extensive weathering.

\subsection{Remediation Challenge}

All sites contaminated with radionuclides on the SRS fall under the Environmental Protection Agency's (EPA) Comprehensive Environmental Response, Compensation, and Liability Act (CERCLA) regulations and thus may represent a remediation challenge to DOE. Remediation of 
wetlands is particularly problematic because current cleanup technology for aquatic systems is generally destructive to the ecosystem. If cleanup is required, then a likely scenario would entail draining the impoundment and either immobilizing the sediments, where $95 \%$ of the radionuclides reside (Whicker et al. 1990), with some form of grout, or hauling the sediments off to be buried. These methods would be expensive. Costs to remediate just the Old-R Discharge Canal have been estimated at over $\$ 117,000,000$ (ERD, 2002). Additionally, the traditional "muck and truck" methods would expose workers to inhalation doses, would destroy the associated ecosystems, and would likely invoke negative responses from stakeholders, South Carolina Department of Health and Environmental Control (SCDHEC), EPA, and National Environmental Policy Act (NEPA) regulators.

\subsection{Application of Illite to Sequester ${ }^{137} \mathrm{Cs}$ in Contaminated Sediments}

Because high Cs mobility on the SRS is due, in part, to a low adsorptive capability of the kaolinitic-dominated soils, we hypothesized that adding naturally occurring micaceous minerals to wetlands would sequester ${ }^{137} \mathrm{Cs}$ and reduce its bioavailability. We tested numerous minerals in the laboratory and found that the addition of illite minerals enhanced the adsorption and sequestration of ${ }^{137} \mathrm{Cs}$, even in the presence of competing ions such as ammonium (Hinton et al., 1999). We then applied the concept to a field demonstration in Pond A and R-canal using limnocorrals (Hinton et al., 2002), and found that the addition of illite minerals significantly reduced ${ }^{137} \mathrm{Cs}$ concentrations in the water (Fig. 1), as well as reduced the bioavailability of ${ }^{137} \mathrm{Cs}$ in aquatic plants and fish (Fig. 2).

\subsection{Environmental Impacts of Clay Application}

The addition of illite can sequester much of the ${ }^{137} \mathrm{Cs}$ in contaminated wetlands on the SRS and reduce the bioavailability of ${ }^{137} \mathrm{Cs}$ (Fig. 1 and Fig. 2). However, the application of large amounts of clay to the wetlands creates conditions of high turbidity, siltation, and sedimentation that could have environmental impacts of their own. Sedimentation and turbidity are common byproducts of activities such as agriculture, forestry, mining, and road construction (Henley et al., 2000). Increases in sedimentation and turbidity in aquatic ecosystems have been associated with impacts on phytoplankton (Grobbelar, 1985; Holz et al., 1997) and zooplankton, macrophyte biomass (Henley et al., 2000), and insects (Gray and Ward, 1982; Henley et al., 2000), fish (Newcombe and MacDonald, 1991), and filter-feeding bivalves (Ellis et al., 2002). 
WSRC-TR-2004-00125

SREL-73; UC-66e

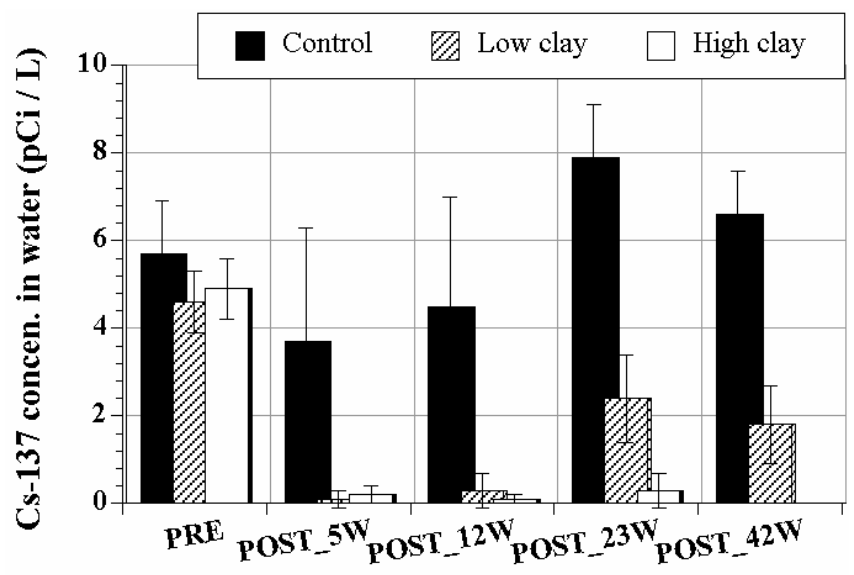

Figure 1. Mean ( \pm SE) activity of ${ }^{137}$ Cs in water samples collected from controls and limnocorrals treated with two levels of illite $10.25 \mathrm{~cm}$ and $2.5 \mathrm{~cm}$ of illite covering the pond sediments). Data show ${ }^{137}$ Cs concentrations prior to the addition of the clay treatment (PRE) and the reduction on weeks $5,12,23$, and 42 subsequent to the treatment. ${ }^{137}$ Cs levels in the high clay treatment for week 42 were below limits of detection (from Hinton et al. 2002).

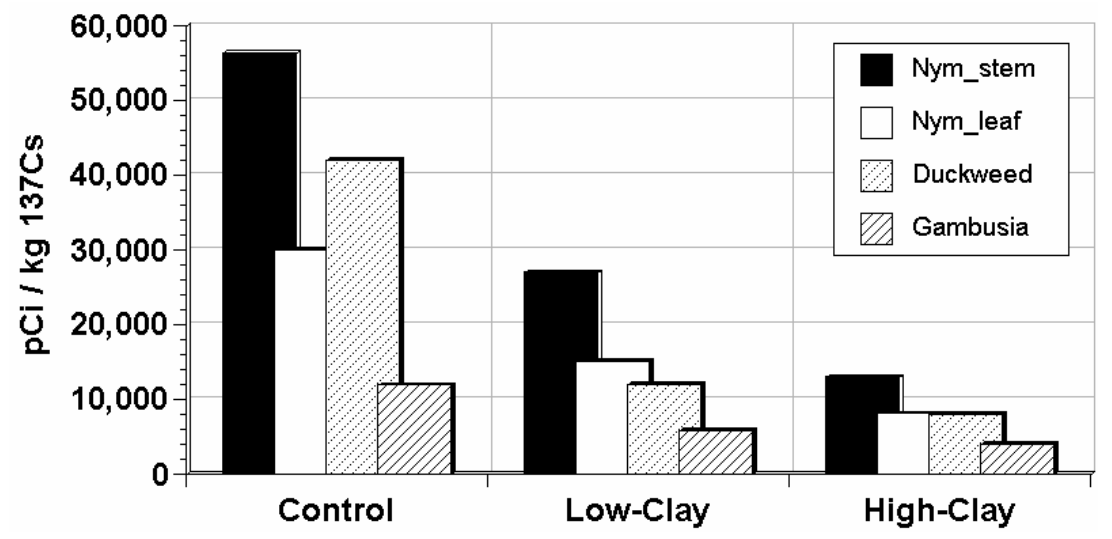

Figure 2. Reductions in mean ${ }^{137}$ Cs concentrations in the stems and leaves of an aquatic plant species (Nymphae odorata), duckweed, and fish (Gambusia) following treatment of the water with two levels of illite $(0.25 \mathrm{~cm}$ and $2.5 \mathrm{~cm}$ of illite covering the pond sediments). Results are from replicated limnocorrals placed in Pond A and R-canal (from Hinton et al. 2002).

Aquatic organisms are affected by increased turbidity, primarily from the limitation of light available to algae and macrophytes, and by reduced habitat due to siltation of small spaces. Phytoplankton productivity can suffer from light limitation, abundance of algae can decrease, and communities have been shown to shift from dominance by cyanophytes to flagellated chlorophytes under very turbid conditions (Holz et al., 1997). Decreases in algal productivity 
tend to lower concentrations of dissolved oxygen, harming insects and other organisms. Siltation of periphyton can lower the quality of food for snails and herbivorous insects (Hann et al., 2001), and an increase in suspended sediments can lower food quality for filter feeders such as mussels and clams (Ellis et al., 2002; Sobral and Widdows, 2000). Detrimental effects on some species of fish and frogs have also been observed (Newcombe and MacDonald, 1991; Dupuis and Steventon, 1999; Gillespie, 2002). The severity of damage to a wetland ecosystem from suspended sediments, however, depends on the duration of exposure to conditions of high turbidity and on the organisms that inhabit the area, as well as the concentration of suspended sediment (Newcombe and MacDonald, 1991).

\subsection{OBJECTIVES}

We previously conducted successful laboratory proof-of-concept studies (Hinton et al, 1999 and 2001) and a moderate-sized field demonstration of the in situ remediation method in R-Canal and Pond A (Hinton et al., 2002). For the current funding period FY03, we re-sampled our study sites 112 weeks after the initial clay application to examine their longer term effectiveness at reducing concentrations of ${ }^{137} \mathrm{Cs}$ in the water. We then reapplied illite minerals to R-Canal and Pond A limnocorrals to evaluate the short-term environmental impacts of turbidity caused from the clay application. In anticipation of transferring this remediation technology from a lake application to flowing streams, we also performed short-term mesocosm stream experiments at the Aquatic Ecology Laboratory (AEL) to observe the dynamics of clay and water in artificial streams, and to test for impacts to fish.

Our previous test of candidate minerals demonstrated that Todd Light Illite minerals had excellent qualities for remediating ${ }^{137}$ Cs-contaminated wetlands (Hinton et al. 1999, 2001, 2002). Todd Light is a brand name of illites that can be purchased from a commercial supplier (the Kentucky-Tennessee Clay Company in Nashville, TN). Todd Light Illites, however, come in five different particle sizes with different moisture contents. Particle size and moisture content influence mineral settling rates and could be particularly important to a stream application of the remediation technique. Therefore, three Todd Light Illites (air-floated, semi-dry and crude with moisture contents of $1-3 \%, 8-12 \%$, and $20-22 \%$, respectively) were purchased for further laboratory testing.

Our specific objectives were to:

1) Evaluate longer-term effectiveness of the illite additions on reducing ${ }^{137} \mathrm{Cs}$ concentrations in water. 
2) Examine the settling behavior and ${ }^{137} \mathrm{Cs}$ adsorption capacity of three Todd Light illites in the laboratory.

3) Assess the short-term effects of turbidity, caused from the illite application, on pond environments in R-Canal and Pond A.

4) Conduct artificial stream experiments at AEL to evaluate the effects of an illite application on fish mortality.

5) Choose an illite type based on chemical and physical characteristics of the mineral, effectiveness for ${ }^{137} \mathrm{Cs}$ removal, and environmental impacts.

6) Select a site for a full-sized, flowing stream, field-demonstration of the remediation technique on the SRS, based on ${ }^{137}$ Cs concentrations, stream flow, selected stream dimensions, biodiversity, and stream accessibility.

\subsection{MATERIALS AND METHODS}

\subsection{Settling Behavior and Cs Adsorption Capacity of Todd Light Illites}

We compared the settling rates and flocculation behavior of three Todd Light Illites within beakers of static water ( $3 \mathrm{~g}$ of each clay; $1.5 \mathrm{~L}$ water; duration $24 \mathrm{hrs}$ ). After 19 hours, the water was vigorously stirred with a glass rod for 10 seconds and the re-suspension and flocculation in the water were qualitatively noted.

The Todd Light Illites were also examined for settling characteristics using a batch beaker test. This study was performed in the laboratory by adding the illites to tap water in beakers. This experiment was conducted in a similar manner ( $20 \mathrm{~g}$ illites in $3.5 \mathrm{~L}$ water) to experiments described above except that the water was continuously mixed for $70 \mathrm{~h}$ by a Stir-pak ${ }^{\circledR}$ Laboratory Mixer (overhead stirrer, Cole-Parmer Instrument Company, Vernon Hills, IL) at a speed of 875 rpm. Suspension and flocculation of illites in the water were observed. The experiment was replicated three times.

The principal characteristic of importance to the remediation method is the mineral's ability to adsorb and retain ${ }^{137} \mathrm{Cs}$. Previous experiments had shown that illites were very good in this characteristic (Hinton et al 1999, 2000); however, we were unsure how the three Todd Lights might differ. Therefore, adsorption experiments were conducted in 5-L beakers, each containing $20 \mathrm{~g}$ of minerals and $3.5 \mathrm{~L}$ of ${ }^{137} \mathrm{Cs}$-contaminated water from Pond B. Each of the three Todd Light Illites was considered a separate treatment and each was replicated three times. All water samples were filtered $(<0.45 \mu \mathrm{m})$ immediately after collection from Pond B. The three Todd Light Illites were added to the contaminated Pond B water, and after 70 hours aliquots of water 
were drawn and compared to control samples for ${ }^{137}$ Cs activity. Stable element analysis was carried out on sub-samples.

Physicochemical properties of the different types of Todd Light illites were determined following methods of the Natural Resources Conservation Service (NRCS, 1996). Analyses were performed on air-dried colloid samples that had been crushed and passed through a $0.23-\mathrm{mm}$ sieve. All analyses were conducted in triplicate. Cation exchange capacities (CEC) were determined by summation of exchangeable cations $(\mathrm{Ca}, \mathrm{Mg}, \mathrm{Na}, \mathrm{K}$, and $\mathrm{Al})$ extracted with three overnight extractions of $0.05 \mathrm{M} \mathrm{BaCl}_{2}$. Elemental compositions of the $\mathrm{BaCl}_{2}$ and dithionitereduced extracts were determined by inductively coupled plasma - optical emission spectroscopy (ICP-OES). Organic carbon (OC) was determined using a Leco Carbon Analyzer, Model CR-12 (Leco Corp., St. Joseph, MI). Total sand, silt, and clay concentrations were determined by the micropipette method (Miller and Miller, 1987) in which soil particles were dispersed in a $0.5 \%$ (w/v) sodium metaphosphate and $0.1 \mathrm{M} \mathrm{NaOH}$ solution. Clay $\mathrm{pH}$ was measured in a 1:1 claywater suspension.

\subsection{Turbidity Impact Analyses within Limnocorrals}

A field test was conducted in replicated limnocorrals that had been set-up in 2001. Limnocorrals are field-deployed mesocosms that isolate a column of water and its associated sediments from the surrounding water, but allow exchange between sediments, water, and air. They are made of flexible plastic with a floatation collar at the top that keeps the column's openend floating on the water surface. Retention rings at mid-depth and at the bottom maintain the column's shape. The bottom is weighted down and inserted into the pond's sediments. Three meter diameter limnocorrals were used for this in situ remediation deployment.

Sixteen limnocorrals were randomly placed in R-Canal and Pond A during the second week of April 2001 (Fig. 3). Four of these limnocorrals were designated as controls receiving no clay, six received low-clay treatments of $27 \mathrm{~kg}(60 \mathrm{lbs})$ of illite, enough to cover the sediment with $0.25 \mathrm{~cm}$ illite, and six received high-clay treatments of $270 \mathrm{~kg}(600 \mathrm{lbs})$ of illite, enough to cover the sediment with $2.5 \mathrm{~cm}$ of illite. The application of illite for the first field test of the technique was performed in May of 2001. We re-applied illite to the existing limnocorrals on 3 July 2003. Prior to the second clay application, water samples were taken to characterize the longer-term ability of the clay application to reduce ${ }^{137} \mathrm{Cs}$ concentrations in the water. As was noted after the first application of the illite in 2001, the addition of the illite caused the water to become turbid (Fig. 4) for some two weeks. Indeed, this observation was the motivation for the current study of examining the environmental impacts of the turbidity. 


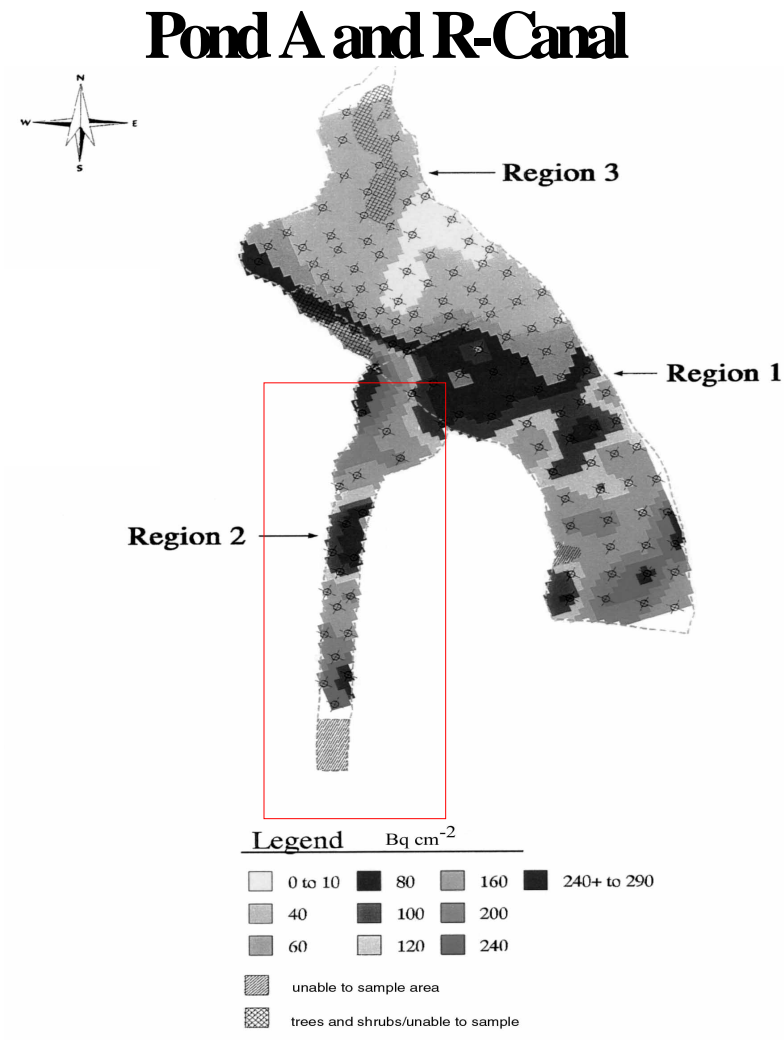

\section{Iimmocorral Locations in R-Canal}

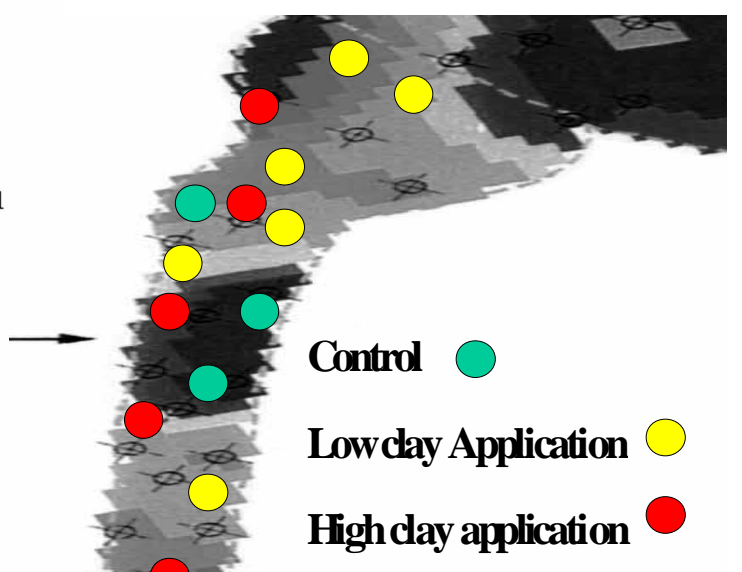

Figure 3. Randomized locations of limnocorrals placed in R-Canal and Pond A on the Savannah River Site. Six limnocorrals were treated with enough clay to cover $0.25 \mathrm{~cm}$ of the sediment surface (Low clay application), six received a treatment 10 times that amount $(2.5 \mathrm{~cm}$ on the sediment surface: High clay application), and four limnocorrals received no clay and served as untreated controls.

\subsubsection{Turbidity and Water Quality}

Turbidity samples were taken 2 days prior to the clay application, and on days $0,1,4,7,12$, 14 , and 18 after the application, by filling $30-\mathrm{mL}$ bottles with water collected at $5 \mathrm{~cm}$ depth. Turbidity values in NTU (Nephelometric Turbidity Units) were measured using a LaMotte 2020 Turbidimeter (LaMotte Co., Chestertown, MD). Water quality measurements were taken with a Quanta Water Quality MultiMeter (HydroLab Co., Austin, TX) two days before clay application and on days $4,7,12,14$, and 18 after clay application. Temperature $\left({ }^{0} \mathrm{C}\right), \mathrm{pH}$, dissolved oxygen (DO, $\left.\mathrm{mg} \mathrm{L}^{-1}\right)$, electrical conductivity $\left(\bullet \mathrm{s} \mathrm{cm}^{-1}\right)$, and oxidation-reduction potential $(\mathrm{ORP}, \mathrm{mV})$ were recorded. 


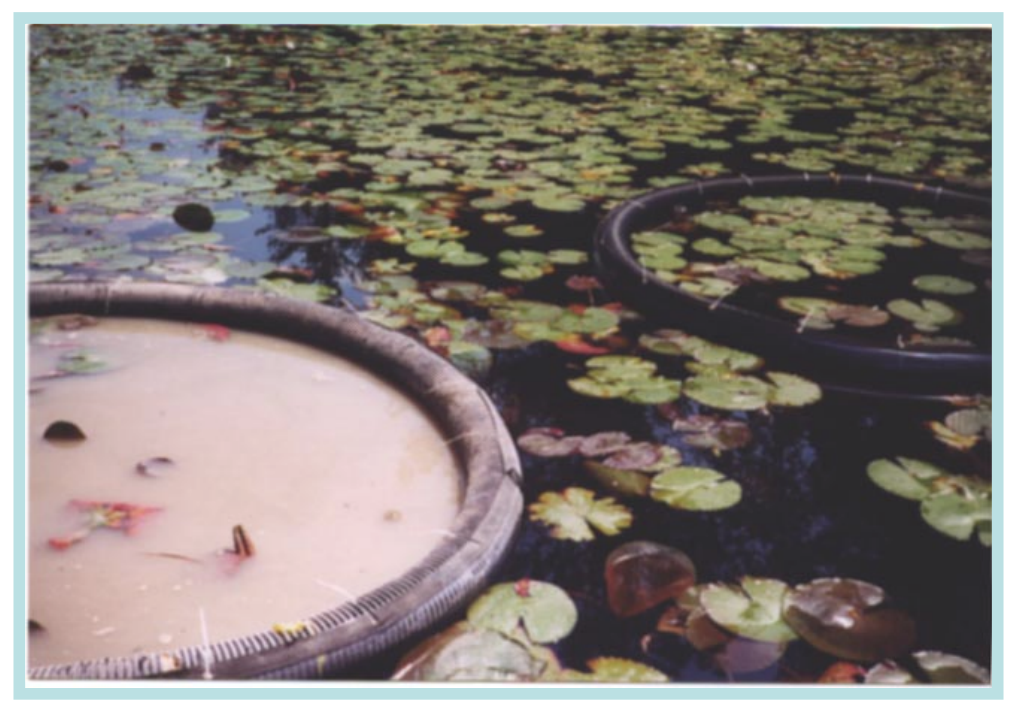

Figure 4. Turbid limnocorral in foreground after receiving a high clay treatment, and a control, untreated limnocorral in the background.

\subsubsection{Macroinvertebrates}

On 9 June, 2003, 24 days prior to the second clay additions, 30 Hester-Dendy (H-D) multiplate samplers (Fig. 5) were placed in 12 of the 16 limnocorrals (4 replicates for each control, low clay, and high clay treatment) located in R-Canal and Pond A. Each sampler consisted of sixteen 7.6-cm square plates separated by approximately $0.3-1.0 \mathrm{~cm}$ (total surface area of $0.205 \mathrm{~m}^{2}$ ). Samplers were tied to the sides of the limnocorrals and hung in the water with their tops approximately $15 \mathrm{~cm}$ below the water surface. Fourteen pre-treatment samplers were collected 4 days prior to illite treatment, 30 June 2003, and sixteen H-D samplers were collected 7 days after clay application, on 10 July 2003. Samplers were collected by placing bags made of $400-\mu \mathrm{m}$ mesh around the sampler in the water, then cutting the string and removing the bag and sampler together. The samplers were stored in coolers and taken to the laboratory until they were sorted for macroinvertebrates. Within three days of collection, the H-D samplers were disassembled, all parts placed in a pan, and all insects found were preserved in $4 \%$ formaldehyde solution. Insects were later identified under microscopic examination with the aid of reference materials (Brigham et al., 1982; Merritt and Cummins, 1984). 


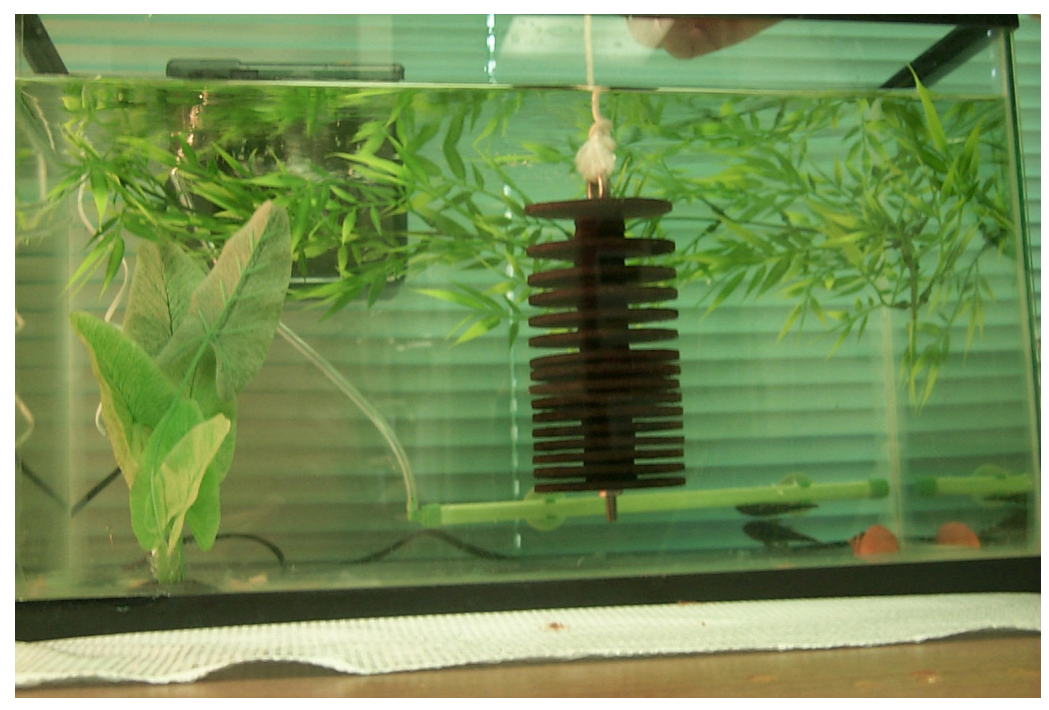

Figure 5. Hester-Dendy (H-D) multiplate samplers were placed in 12 of the 16 limnocorrals (4 replicates for each control, low clay, and high clay treatment) located in R-Canal and Pond A to collect aquatic macroinvertebrates.

Multiple Hester-Dendy samplers were placed in two limnocorrals, one control and one high clay treatment. Comparison of these samplers indicated variation among samplers within a limnocorral. Thus the true community organization would be more accurately characterized by multiple samplers. Though the data may be best viewed as exploratory it does provide valuable incite for the design of a more extensive study. The data for each individual sampler is presented for comparison, but to allow the most accurate characterization of the communities as possible, the multiple samplers were averaged before making comparisons among limnocorrals. This avoids weighting a single corral unduly while allowing use of all of the collected data. Numbers of insects collected in each limnocorral was $\log _{\mathrm{n}}$ transformed prior to analyses. Principal component analysis was employed to summarize the community data. Numbers of components to be examined was determined from their associated eigenvalues and scree plots. Factor scores saved from the PCA were used to assess changes in the species assemblages Because of the small sample sizes that result if the data is dissected into subgroups, we used an ANOVA model that included clay status (BCA vs. ACA), treatment (control, LCA, HCA) and the clay status*treatment interaction term. Graphs comparing factor scores among the clay status or treatments were composed of the least squares means from this model. 


\subsubsection{Phytoplankton Productivity}

Phytoplankton productivity was measured on 4, 12, and 17 days after treatment using the dissolved oxygen method (Wetzel and Likens, 1991; Clesceri et al., 1998). In each limnocorral, water was collected from $10 \mathrm{~cm}$ below the surface in three $300-\mathrm{mL}$ glass bottles with ground glass stoppers. Dissolved oxygen levels in one bottle were recorded using a YSI 5100 dissolved oxygen probe (YSI Inc., Yellow Springs, $\mathrm{OH}$ ), and the two remaining bottles, one clear and one covered in black electrical tape to exclude light, were incubated $10 \mathrm{~cm}$ below water surface for approximately 4 hours. Dissolved oxygen levels in light and dark bottles were recorded, and gross primary productivity, respiration, and net primary productivity calculated (Wetzel and Likens, 1991).

\subsubsection{Chlorophyll-a}

Water samples were taken from twelve limnocorrals for chlorophyll-a analysis 12 and 17 days after illite treatment. These grab samples were taken about $5 \mathrm{~cm}$ below the water surface in 500-mL dark plastic bottles. Samples were immediately stored in an ice cooler and taken to the laboratory. Water was filtered through glass fiber filters, and the filters were frozen until analysis was performed. The filters were then ground in acetone using a glass grinding tube and centrifuged for five minutes. The supernatant was transferred to quartz cuvettes, and absorbances at 665 and $750 \mathrm{~nm}$ were measured with SpectraMax Plus spectrophotometer (Molecular Devices, Sunnyvale, CA). The solution was acidified with 3 drops of $1 \mathrm{~N}-\mathrm{HCl}$, and absorbances were measured again at the same two wavelengths. Phytoplankton cells contain chlorophyll-a and pheophytins, which are degradation products of chlorophyll-a. We were only interested in the amount of chlorophyll-a, thus we corrected for the amount of pheopigments in the sample. The acid turns all of the chlorophyll into pheopigments (it removes the $\mathrm{Mg}$ from the chlorophyll). Calculations based on these absorbances were made to determine the density of chlorophyll-a (Wetzel and Likens, 1991). Calculations were as follows:

$$
\text { - } \mathrm{g} \text { chlorophyll-a } \mathrm{L}^{-1}=\frac{\mathrm{k} * \mathrm{~F} * \mathrm{C} * \mathrm{E}}{\mathrm{V}}
$$

where: $\mathrm{k}=$ absorption coefficient of chlorophyll-a $=11.0$ 
WSRC-TR-2004-00125

SREL-73; UC-66e

$\mathrm{F}=$ factor to equate the reduction in absorbancy to initial chlorophyll concentration = 2.43

$\mathrm{C}=(\mathrm{A} 665 \mathrm{~b}-\mathrm{A} 750 \mathrm{~b}-(\mathrm{A} 665 \mathrm{a}-\mathrm{A} 750 \mathrm{a}) ; \mathrm{b}$ is before acidification, $\mathrm{a}$ is after acidification

$\mathrm{E}=$ extract in $\mathrm{mL}$

$\mathrm{V}=$ volume of water filtered

$$
\text { -g pheophytins }=\frac{\mathrm{k} * \mathrm{~F} * \mathrm{P} * \mathrm{E}}{\mathrm{V}}
$$

where: $\mathrm{P}=1.7(\mathrm{~A} 665 \mathrm{a}-\mathrm{A} 750 \mathrm{a})-(\mathrm{A} 665 \mathrm{~b}-\mathrm{A} 750 \mathrm{~b})$

\subsection{5. ${ }^{137} \mathrm{Cs}$ in Water}

Water samples for ${ }^{137} \mathrm{Cs}$ analyses were collected 2 days before (1 July 2003) and 14 days after (17 July 2003) clay application from each of the 16 limnocorrals. Three-liter samples were taken about $15 \mathrm{~cm}$ below the water surface, filtered with $0.45 \mu \mathrm{m}$ Nitrocellulose filter paper, acidified with nitric acid and stabilized with $\mathrm{CsCl}$. The samples were assayed for ${ }^{137} \mathrm{Cs}$ in $3 \mathrm{~L}$ Marinelli Beakers placed on a 70 X $90 \mathrm{~mm}^{2}$ High-Purity Germanium (HPGE) detector (GAMMA Products Inc., Palos Hills, IL). Subsamples were analyzed for stable elements using ICP-MS. Other parameters, such as $\mathrm{pH}$, electrical conductivity, temperature and dissolved oxygen were determined in the field using a HydroLab instrument.

\subsection{Fish Mortality Study in an Artificial Flowing Stream}

\subsubsection{Study Organisms}

To evaluate effects of the illite application on stream fish, two locally common species found in the middle Savannah River Basin were used, yellowfin shiners (Notropis lutipinnis) and tessellated darters (Etheostoma olmstedi). Yellowfin shiners, a relatively small species, are usually less than 65-mm standard length (SL, the distance from the tip of the snout to the base of the caudal fin). These shiners are often abundant in small to intermediate size tributary streams where sufficient gravel in the sediment is present to allow bluehead chubs (Nocomis leptocephalus) to build pebble mound nests upon which yellowfin shiners also spawn in an obligate spawning relationship (McAuliffe and Bennett, 1981; Wallin, 1989 and 1992). The benthic-spawning behavior of this species makes them susceptible to disturbance of stream sediments and thus a good test of the environmental impacts from the clay applications. Yellowfin shiners feed on insects and a variety of aquatic invertebrates and are an important 
WSRC-TR-2004-00125

SREL-73; UC-66e

insectivorous predator (Sheldon and Meffe, 1983). The number of native insectivorous cyprinid species present at a site is often incorporated into stream environmental assessments (Karr et al., 1986; Paller, 1996).

The tessellated darter is a relatively small fish rarely exceeding 70-mm SL. Males defend nest sites that consist of a cleaned flat undersurface of submerged wood or stone with a saucer swept in the sediments below. Females are attracted to the nest and eggs are attached to the undersurface in a single layer (Gale and Deutsch, 1985; DeWoody et al., 2000). Upon hatching, the embryos drop into the depression. Tessellated darters are benthic feeders preying on a variety of aquatic insects, especially chironomid larvae (Sheldon and Meffe, 1993). Darters (Percidae, Etheostomatinae) are generally sensitive to environmental disturbance due to their benthic habits (Page, 1983). Consequently, darters are often incorporated into stream environmental assessments (Karr et al., 1986), including on the Savannah River Site (Paller, 1996; Paller et al., 2000).

\subsubsection{Study Area and Fish Collection}

Using a backpack electrofisher and a $3 \mathrm{~mm}$ mesh seine, fish were collected on 22-23 July, 1415 August, and 3-5 September 2003. Two backpack electrofishers and two crews, covering opposite sides of the stream and moving upstream simultaneously, were used at all collection sites. Approximately 80 tessellated darters and 200 yellowfin shiners were obtained during each collection period from Fourmile Branch, a tributary of the Savannah River located entirely within the SRS (Fig. 6). Fourmile Branch, originating near the center of the SRS, runs approximately $24 \mathrm{~km}$ to the Savannah River. It is characterized as a blackwater, sandy bottom stream with a channel that alternates between swift runs and pools. Due to thermal effluent releases prior to 1986, Fourmile Branch has an early successional riparian vegetation structure forming a relatively open stream canopy and promoting abundant macrophyte growth (Fletcher et al., 2000). The $57 \mathrm{~km}^{2}$ watershed of Fourmile Branch includes a number of SRS facilities, waste sites, and discharges (WSRC, 1998). Except for the extreme headwaters, most of Fourmile Branch is potentially influenced by SRS operations. A number of radioactive and non-radioactive constituents of concern have been detected in environmental media collected from Fourmile Branch (WSRC, 1998).

\subsubsection{Samplings and Analyses in Artificial Flowing Streams}

Three indoor continuous flow-through raceways (U shape; $35 \mathrm{~cm}$ width, $33 \mathrm{~cm}$ depth, with $10 \mathrm{~m}$ and $8 \mathrm{~m}$ lengths for outside and inside banks, respectively) at SREL's Aquatic Ecology 
Laboratory were used for this study. Stream water was pumped from Upper Three Runs into a reservoir tank and subsequently released into the raceways. A filter system was employed to remove larger litter and organic matter. The filter system was a two-stage process. A screen was attached to the outlet pipe of the reservoir tank and a 3-mm mesh plastic screen was installed in the raceways. Water depths were maintained at 13-14 $\mathrm{cm}$ at the beginning of the raceways and $14-15 \mathrm{~cm}$ at the lower end, with an average velocity of $9 \mathrm{~cm} \mathrm{sec}^{-1}$ in each raceway. Water temperatures did not vary among raceways. Water temperatures varied slightly among replicates due to seasonal temperature changes: $22-23{ }^{\circ} \mathrm{C}$ in August and $20-21{ }^{0} \mathrm{C}$ in September. Turbidity samples were collected at 2, 3, 4, 5, 6, and $7 \mathrm{~m}$ of the raceways.

Upon return to the laboratory, fish were held in a 660-L continuous flow-through raceway until stocked into the experimental raceways. During the first replicate, fish were weighed in a tared beaker of water before being introduced into the experimental raceways (Table 1). This added holding time and handling proved too stressful, particularly to the yellowfin shiners that suffered high mortality. Therefore, the weighing procedure was discontinued for the remaining replicates and instead of all being held for three days as all fish were in the first replicate, tessellated darters and yellowfin shiners were held for approximately 24 hours and one to several hours, respectively, prior to stocking in replicates 2 and 3. 


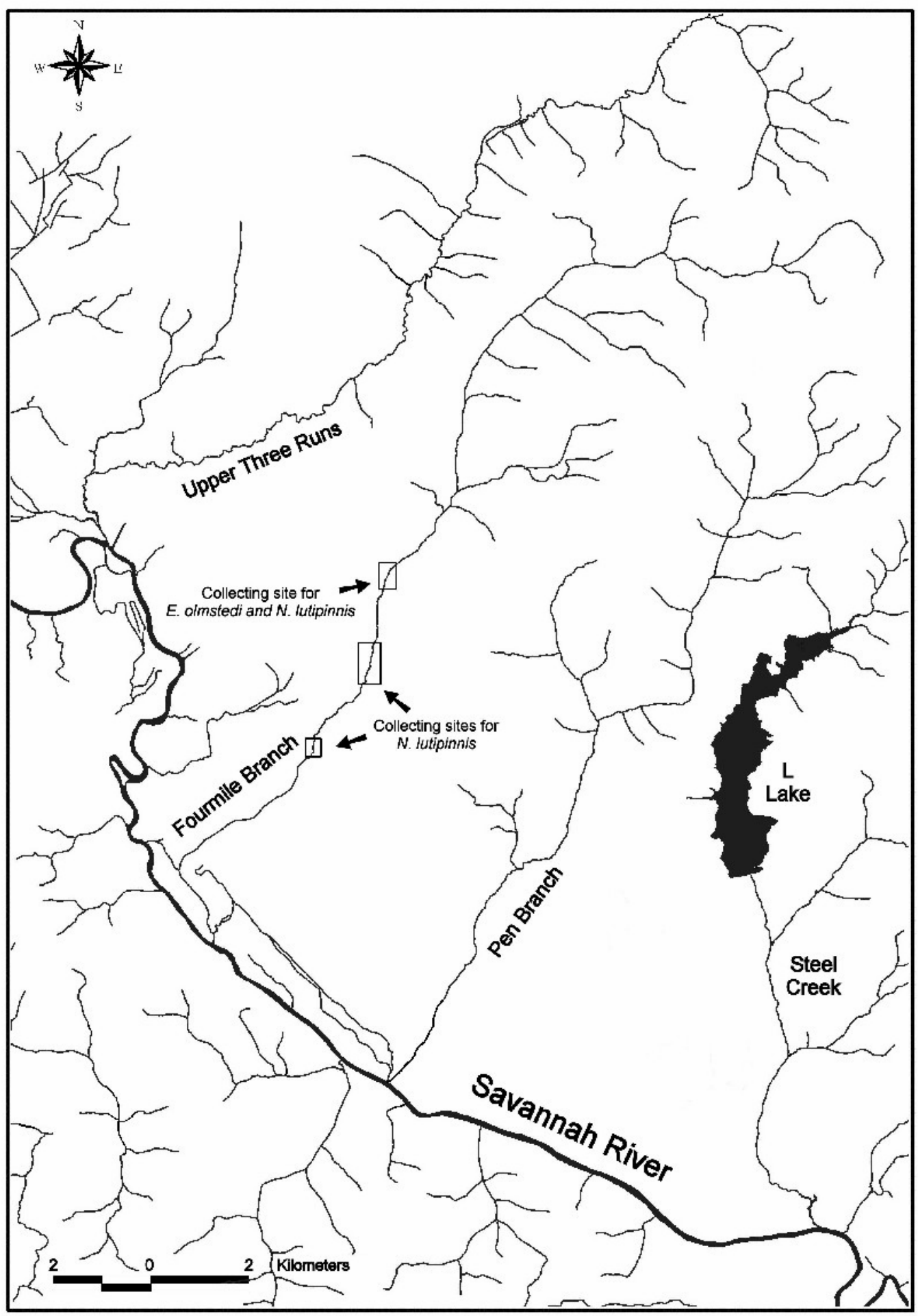

Figure 6. Map of the study area and three fish collection locations on Fourmile Branch. 
Table 1. Combined body weight of 50 yellowfin shiners and 20 tessellated darters measured on 24 July 2003. Fish were weighed in a tared beaker of water before being introduced into the experimental raceways.

\begin{tabular}{lrrrr}
\hline \multirow{2}{*}{ Fish } & \multicolumn{4}{c}{ Total Body Weight (g) } \\
& Raceway 1 & Raceway 2 & Raceway 3 & Avg \pm Stdev \\
\hline Tessellated darter & 53.0 & 48.5 & 50.0 & $50.5 \pm 2.3$ \\
Yellowfin shiner & 96.5 & 106.0 & 95.4 & $99.3 \pm 5.8$ \\
Total & 149.4 & 154.5 & 145.4 & $149.8 \pm 4.5$ \\
\hline
\end{tabular}

Following the holding period, fish were randomly placed into one of the three treatment raceways: untreated control, treated with air-floated illite, or treated with semi-dry illite. For each of the three replicates of the experiment, treatment condition was rotated among raceways. Each raceway was stocked with 50 yellowfin shiners and 20 tessellated darters. Stocked fish were allowed to stabilize in the raceway systems for three days prior to beginning the experiment. Any fish that died in the raceways during this stabilization period were replaced with fish from the holding tank. After the three-day acclimation period, $9.8 \mathrm{~kg}$ of air-floated and semi-dry illites were applied to raceways. The amount of illite applied was equivalent to that which can cover the sediment with $0.25 \mathrm{~cm}$ illite. Each replicate of the experiment was performed for 7 days. Thus, nine trials were conducted ( 2 types of illites and 1 control X 3 replicates). Turbidity was measured on the day clay was applied, and then on the $1^{\text {st }}, 2^{\text {nd }}, 4^{\text {th }}$ and $7^{\text {th }}$ day after application. Fish survival was measured on the $7^{\text {th }}$ day.

To minimize disturbance of fish in the experimental raceways, curtains were hung around each raceway. Habituation to feeding area was avoided by reaching through the curtain and pouring the food into the first $1 / 2$ of the raceway, at locations that varied each day. Raceway and holding tank fish were fed an average of $4.4 \mathrm{~g}$ per day of a $50 \%$ mixture of commercially available frozen brine shrimp and bloodworms (Chironomidae larvae) (San Francisco Bay Brand, Newark, CA). The amount of food provided to each raceway was calculated as approximately three percent of the combined body weight of all fish in the raceway (Table 1).

\subsection{Survey of Potential SRS Locations for Future Field Deployment}

\subsubsection{Site Selection}

The Integrator Operable Unit (IOU) concept represents an effort to understand the cumulative impacts and potential risks of hazardous waste sites within each of the watersheds on the SRS. These watersheds are referred to as Integrator Operable Units because the streams within each 
watershed integrate the effects of all waste sites within the watershed. This integration results from the transport of soluble contaminants such as ${ }^{137} \mathrm{Cs}$ from any or all waste sites and discharges within the watershed to the stream by surface runoff or subsurface discharge. There are six IOUs on the SRS. Five of these correspond to the drainage basins of the five major streams on the SRS (Upper Three Runs, Fourmile Branch, Pen Branch, Steel Creek, and Lower Three Runs). The remaining IOU is the portion of the Savannah River and Savannah River Swamp associated with the SRS. All of these streams discharge into the Savannah River.

Using ArcView GIS (Geographic Information System) and a collection of spatial databases, four of the six IOUs (Lower Three Runs, Fourmile Branch, Steel Creek, and Pen Branch) were selected as potential sites for the clay remediation method based on road accessibility and overflight count rate data of ${ }^{137} \mathrm{Cs}$. Consequently sections of the stream were assessed as potential sites to conduct a larger-scale demonstration of the illite technology.

\subsubsection{Site Assessment}

A Global Positioning System (GPS) unit was used to navigate to a hot spot for ${ }^{137}$ Cs on each stream. Velocity, depth $(\mathrm{cm})$, and width $(\mathrm{m})$ at three locations on each stream were measured for physical characteristic comparison. Each sampling location was separated by $20 \mathrm{~m}$ for a total stream segment length of $40 \mathrm{~m}$ (Fig. 7). Velocity $\left(\mathrm{m} \mathrm{sec}^{-1}\right.$ ), with a flow meter (Model 2035, General Oceanics, Inc., Miami, FL), and depth were measured in the center and at each edge of the stream at each location. Where depth equaled or exceeded $0.6 \mathrm{~m}$, two current velocity measurements were taken, one at 0.2 times the depth and one at 0.8 times the depth. Where the depth was less than $0.6 \mathrm{~m}$, only one measurement was taken at 0.6 times the stream depth. Five replicate sediment samples were collected with a 3.8-cm diameter PVC tube to a depth of $10 \mathrm{~cm}$ at each location. At each location, one in the center of the stream and 4 more samples located $1 \mathrm{~m}$ upstream, $1 \mathrm{~m}$ downstream, $1 \mathrm{~m}$ to the right and $1 \mathrm{~m}$ to the left of the center sample were collected. The sediment samples were characterized for ${ }^{137} \mathrm{Cs}$ concentration and stable elements. For Pen Branch, 3 replicate sediment samples were collected at a side and center of the stream. All sediment samples were oven dried to a constant weight at $105{ }^{\circ} \mathrm{C}$ and sieved at $2 \mathrm{~mm}$.

Analyses of ${ }^{137} \mathrm{Cs}$ in sediments were performed on a Packard Autogamma detector (MINAXI $\gamma$ Auto-Gamma $^{\circledR} 5000$ Series, Packard, Downers Grove, IL) with a well-type NaI (sodium iodine) crystal ( $7.6 \times 8.3 \mathrm{~cm}$ with a $1.5 \%$ relative efficiency). Additional analyses of sediments were performed on a $70 \times 90 \mathrm{~mm}^{2}$ HPGE detector. Cs-137 standards, traceable to the National Institute of Standards and Technology, were assayed in the same physical geometry as the 
samples. Standard QA/QC methods were followed (i.e. use of controls, replicates and blanks for analytical work).

Water samples were also collected in the middle of location 2 in each stream (Fig. 7) and analyzed for water quality and ${ }^{137} \mathrm{Cs}$ concentration in the same way as described in section 4.2.
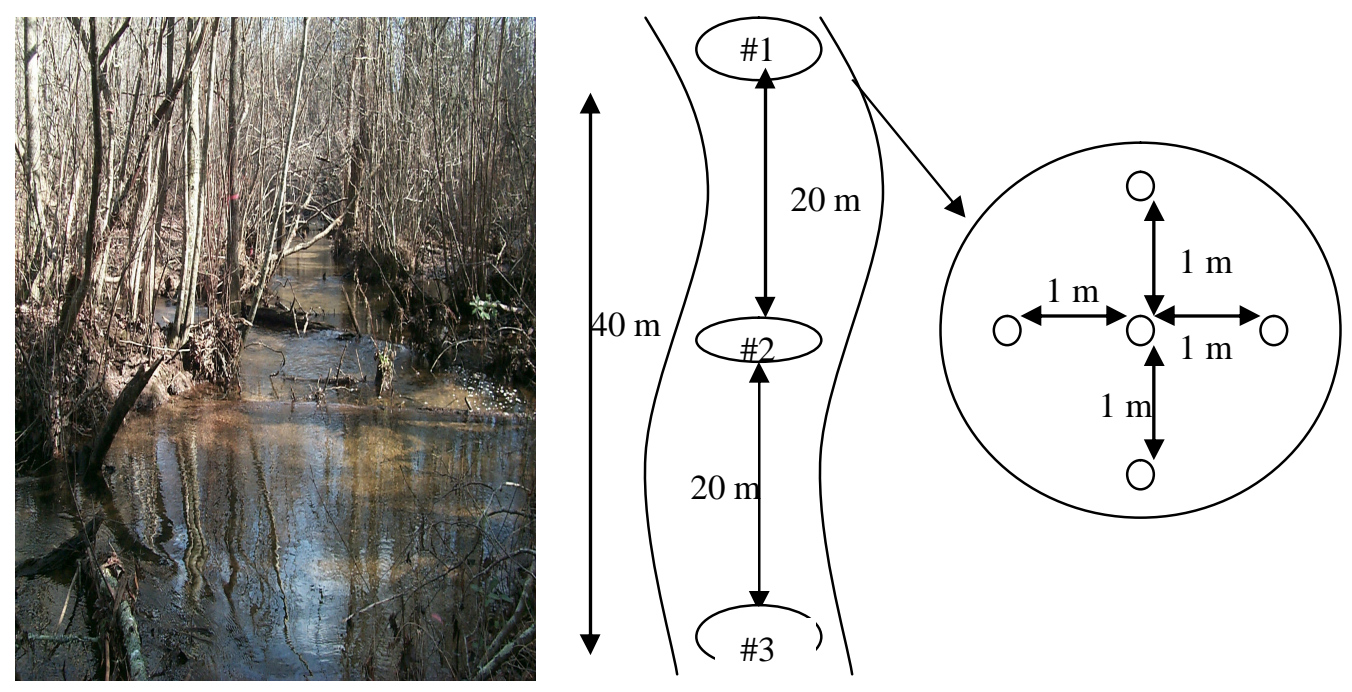

Figure 7. Sampling method for site evaluation of clay application. Five replicate sediment samples were taken at every location, one in the center of the steam, one $1 \mathrm{~m}$ upstream and downstream of the center and $1 \mathrm{~m}$ to each side of the center.

\subsection{Statistical Analyses}

The experimental units in this research were the replicated limnocorrals in R-Canal and Pond $\mathrm{A}$, and the replicated raceways in the artificial stream experiments. Thus sample sizes for statistical analyses were the number of limnocorrals or raceways, not the total number of water, macroinvertebrate, fish, turbidity, productivity, or chlorophyll-a samples taken. Data from samplers were combined prior to analysis for macroinvertebrates. Differences between treatments (controls, low clay, and high clay applications) were compared using Analysis of Variance (ANOVA) and General Linear Models (GLMs) of SAS (SAS Institute, Inc., Cary, NC) (SAS, 1999). Statistical analyses for fish mortality used the same SAS software.

\subsection{RESULTS AND DISCUSSION}

\subsection{Settling Behavior and Cs Adsorption Capacity of Todd Light Illites}

Analyses of the three Todd Light Illites indicated that surface area, $\mathrm{OC}, \mathrm{pH}$, and texture were similar ( $\mathrm{p}>0.05$ ), and that $\mathrm{Al}, \mathrm{Ca}, \mathrm{K}, \mathrm{Mg}$, and CEC differed among them (Table 2). 
Table 2. Selected physicochemical properties of illites used in the study (mean \pm Stdev; $n=3$ ).

\begin{tabular}{|c|c|c|c|}
\hline \multirow{2}{*}{ Property $^{a}$} & \multicolumn{3}{|c|}{ Type of Illite } \\
\hline & Air-floated & Semi-dry & Crude \\
\hline $\mathrm{pH}$ & $4.2 \pm 0.2 \mathrm{a}^{\dagger}$ & $4.7 \pm 0.2 \mathrm{a}$ & $4.4 \pm 0.1 \mathrm{a}$ \\
\hline $\mathrm{OC}(\%)$ & $1.09 \pm 0.01 \mathrm{a}$ & $1.07 \pm 0.02 \mathrm{a}$ & $1.06 \pm 0.02 \mathrm{a}$ \\
\hline CEC (meq $\left.100 \mathrm{~g}^{-1}\right)$ & $7.68 \pm 0.03 a$ & $6.16 \pm 0.07 b$ & $4.92 \pm 0.07 \mathrm{c}$ \\
\hline $\mathrm{EC}\left(\cdot \mathrm{S} \mathrm{cm}^{-1}\right)$ & $155.0 \pm 2.1 \mathrm{a}$ & $111.0 \pm 1.3 \mathrm{a}$ & $119.1 \pm 2.4 \mathrm{a}$ \\
\hline Surface Area $\left(\mathrm{m}^{2} \mathrm{~g}^{-1}\right)$ & $31.3 \pm 0.5 \mathrm{a}$ & $28.6 \pm 0.6 \mathrm{a}$ & $32.2 \pm 1.2 \mathrm{a}$ \\
\hline Clay $(\%)$ & $55.6 \pm 0.1 \mathrm{a}$ & $57.4 \pm 4.3 \mathrm{a}$ & $56.3 \pm 2.0 \mathrm{a}$ \\
\hline Sand $(\%)$ & $34.8 \pm 0.2 \mathrm{a}$ & $30.7 \pm 4.6 \mathrm{a}$ & $35.2 \pm 2.9 \mathrm{a}$ \\
\hline Silt (\%) & $9.6 \pm 0.1 \mathrm{a}$ & $11.9 \pm 0.3 \mathrm{a}$ & $8.5 \pm 0.9 a$ \\
\hline $\mathrm{Ca}\left(\mathrm{mg} \mathrm{kg}^{-1}\right)$ & $599 \pm 6.1 \mathrm{a}$ & $489 \pm 6.4 b$ & $389 \pm 6.2 c$ \\
\hline $\mathrm{K}\left(\mathrm{mg} \mathrm{kg}^{-1}\right)$ & $36.7 \pm 0.5 \mathrm{a}$ & $18.8 \pm 0.1 b$ & $11.0 \pm 0.5 \mathrm{c}$ \\
\hline $\operatorname{Mg}\left(\mathrm{mg} \mathrm{kg}^{-1}\right)$ & $182 \pm 5.8 \mathrm{a}$ & $146 \pm 5.4 b$ & $128 \pm 1.4 \mathrm{c}$ \\
\hline $\mathrm{Na}\left(\mathrm{mg} \mathrm{kg}^{-1}\right)$ & $23.1 \pm 2.5 \mathrm{a}$ & $13.4 \pm 0.3 \mathrm{a}$ & $9.7 \pm 0.3 b$ \\
\hline $\mathrm{Al}\left(\mathrm{mg} \mathrm{kg}^{-1}\right)$ & $40.8 \pm 0.3 \mathrm{a}$ & $32.9 \pm 3.0 \mathrm{~b}$ & $29.2 \pm 1.1 \mathrm{c}$ \\
\hline $\mathrm{Fe}\left(\mathrm{mg} \mathrm{kg}^{-1}\right)$ & $18.9 \pm 0.3 a$ & $17.5 \pm 0.4 a$ & $25.8 \pm 0.9 a$ \\
\hline
\end{tabular}

${ }^{\mathrm{a}} \mathrm{OC}=$ organic carbon, $\mathrm{CEC}=$ cation exchange capacity, EC = electrical conductivity

${ }^{\dagger}$ Within a property, means among the three types of illites followed by the same letter are not significantly different $(\mathrm{p}>0.05)$.

Turbidity was measured at the end of the laboratory settling experiment with readings of 360 $\pm 2.65,208 \pm 7.09$, and $140 \pm 1.53 \mathrm{NTU}$ (mean \pm Stdev.) for air-floated, semi-dry, and crude treatment, respectively. As anticipated, the crude illite produced the lowest turbidity because it had the largest particle size (average size $>2 \mathrm{~cm}$ in diameter) and highest moisture content. Semidry and crude illites immediately flocculated and gradually re-suspended into the water column from the sediment when stirred. The lower CEC of the semi-dry and crude illites may have induced instability by weakening the repulsive forces between particles (Goldberg et al., 1990) and causing colloid flocculation. The water, after suspension, became darker as time increased (Table 3). The suspended particles stayed in the water throughout the experimental period, about 10 days.

Our initial expectation from this experiment was that the results would allow us to recommend a specific Todd Light Illite for use on the SRS. However, the settling characteristics are so different among the three Todd Light Illites examined that they actually add diversity to the remediation tool box, and recommending a single one would likely do disservice to what the 
others offer. In other words, knowing the settling characteristics of these minerals now allows WSRC to choice a Todd Light Illite that best suites the site specific needs of that remediation project. If dispersing the mineral throughout the water column is desired, as might be needed if trying to reduce ${ }^{137} \mathrm{Cs}$ mobility in a lake or a long reach of stream, then the air-floated Todd Light Illite would be the best choice. However, if small localized hot spots are being targeted within a stream, then the large particle size and rapid settling characteristics of the crude Todd Light Illite would allow WSRC to control the application and place the mineral in specific locations.

Knowledge of the different settling behaviors of the illite minerals provides greater flexibility and control during the remediation of diverse types of wetlands.

Table 3. Results of a particle settling and flocculation experiments using different types of Todd Light Illites (air-floated, semi-dry, and crude).

\begin{tabular}{llll}
\hline Characteristic & Air-floated & Semi-Dry & Crude \\
\hline Water Cleared $^{\text {a }}$ & 3 hours & Immediately & Immediately \\
Beaker Bottom Covered (\%) & $100 \%$ & $70 \%$ & $50 \%$ \\
Percolation & Slow & Middle & Fast \\
Water color after suspension & Dark & Light & Medium \\
\hline
\end{tabular}

${ }^{\mathrm{a}}$ Measured by LaMotte 2020 Turbidimeter

Experiments were conducted to compare the three Todd Light Illites' ability to reduce ${ }^{137} \mathrm{Cs}$ concentrations in water. After 70 hours within ${ }^{137}$ Cs-contaminated Pond B water, the air-floated, semi-dry, and crude Todd Light Illites had similar capacities to remove ${ }^{137} \mathrm{Cs}(\mathrm{p}>0.05$; Fig. 8). Thus, choices of which Todd Light Illite to use for a specific remediation project should be based on settling characteristics of the three minerals, as describe above, rather than on their ${ }^{137} \mathrm{Cs}$ absorptive capabilities. 


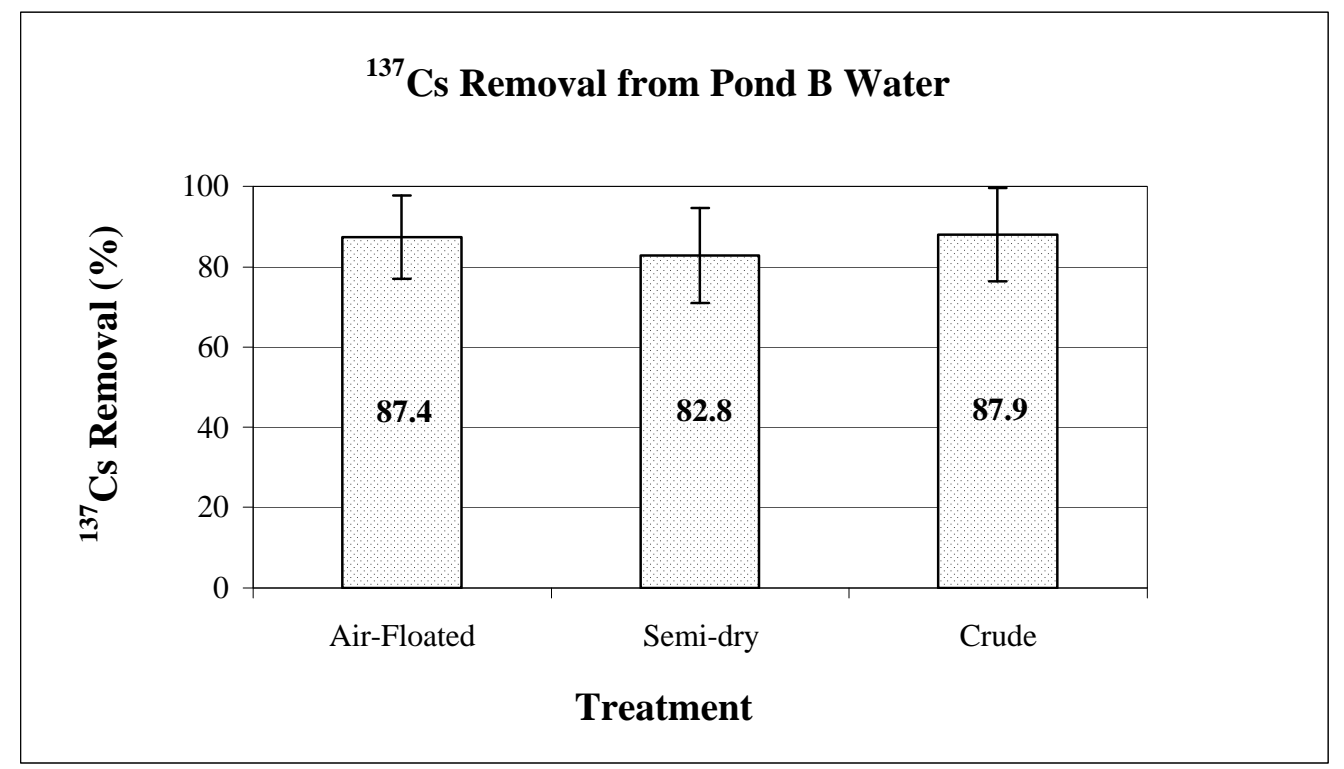

Figure 8. A comparison of mean ( \pm St dev.) ${ }^{137}$ Cs removal efficiencies of contaminated Pond B water samples treated with air-floated, semi-dry, and crude Todd Light Illites.

\subsection{Limnocorral Turbidity Impact Analyses}

\subsection{1. ${ }^{137}$ Cs Concentrations in Water: Short- and Longer-Term Effectiveness}

Water samples were collected from the limnocorrals in Pond A and R-canal 2 days before the second clay application of illite (112 weeks after the first application), and analyzed to evaluate longer-term abilities of the illite application to reduce ${ }^{137} \mathrm{Cs}$ concentrations in the water. During the interim 112 weeks extreme conditions occurred, including both drought and flooding that caused the limnocorrals to dry up, as well as for water to flow over the floatation rings during high water-level conditions. One hundred and twelve weeks after the initial application of illites, average ${ }^{137} \mathrm{Cs}$ concentrations in the water of the limnocorrals that received the high clay application (HCA), low clay application (LCA), and controls were 3.14, 4.15, and $6.07 \mathrm{pCi} \mathrm{L}^{-1}$, respectively. Thus, ${ }^{137} \mathrm{Cs}$ concentrations in the water of the HCA were still significantly lower than that of the controls $(\mathrm{p}<0.05)$. Although mean concentrations of ${ }^{137} \mathrm{Cs}$ in the water of the LCA were lower than controls, the differences were not significant ( $p>0.05$; Fig. 9). The high application rate of illite resulted in reduced ${ }^{137} \mathrm{Cs}$ concentrations in the water for over two years, suggesting that it may be an effective measure for a longer period than previously evaluated. 
WSRC-TR-2004-00125

SREL-73; UC-66e

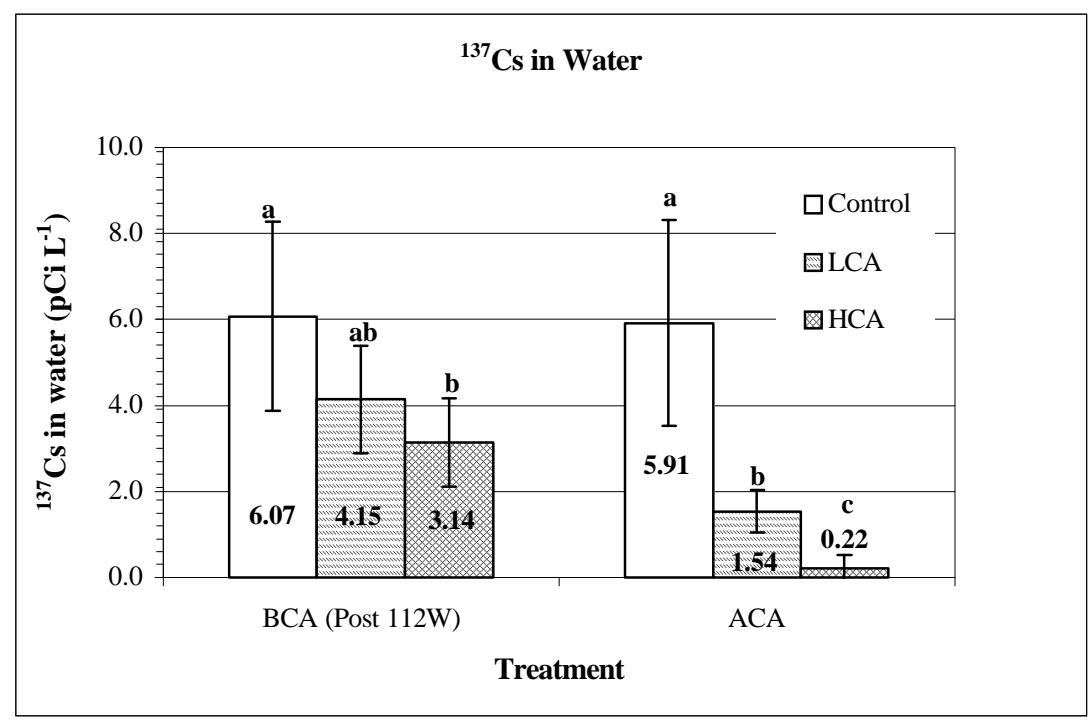

Figure 9. Mean ( \pm Stdev.) activity of ${ }^{137}$ Cs in water samples collected from control and treated limnocorrals (LCA: low clay application; HCA: high clay application). Data show samples taken 112 weeks after the original treatment (BCA; post $112 \mathrm{~W})$ and two weeks after a re-application of the illite treatments (ACA). Within time periods (BCA and ACA), treatment means followed by the same letter are not significantly different at $p>0.05$.

After a second application of the illites to the limnocorrals in Pond A and R-canal, ${ }^{137} \mathrm{Cs}$ concentrations dropped significantly below controls in both treatments (Fig. 9), as was observed after the first application. Water samples were collected before (1 July 2003) and two weeks after air-floated Todd Light illites were added to each of the 16 limnocorrals. The clay material effectively sorbed ${ }^{137} \mathrm{Cs}$ out of the water column. Concentrations of ${ }^{137} \mathrm{Cs}$ were significantly reduced $(\mathrm{p}<0.05)$ in the water column of the low and high clay-amended treatments. Analyses of water quality and stable element concentrations prior to the start of the experiment and after clay application suggested that adding the clay amendments did not significantly $(p>0.05)$ alter the water chemistry in the illite-treated limnocorrals (Table 4). 
Table 4. Water quality measurements were taken once before clay application, July 1, and several times after clay application, on July 7, 10,15, 17, and 21. Temperature, $\mathrm{pH}$, dissolved oxygen (DO), electrical conductivity, and oxidation-reduction potential (ORP) were recorded.

Treatments: Control - no clay application; LCA - low clay application $(0.25 \mathrm{~cm}$ layer of clay on the bottom of the sediment); HCA - high clay application ( $2.5 \mathrm{~cm}$ layer of clay on the bottom of the sediment).

\begin{tabular}{|c|c|c|c|c|c|c|c|}
\hline \multirow{2}{*}{ Treatment } & \multirow{2}{*}{ Sample No. } & \multicolumn{6}{|c|}{ Sampling Date } \\
\hline & & July 1 & July 7 & July 10 & July 15 & July 17 & July 21 \\
\hline & & \multicolumn{6}{|c|}{ Temperature $\left({ }^{0} \mathrm{C}\right)$} \\
\hline \multirow[t]{4}{*}{ Control } & LC1 & 25.47 & 28.06 & 27.60 & 26.16 & 27.03 & 25.24 \\
\hline & LC6 & 25.82 & 28.70 & 28.01 & 26.47 & 27.23 & 25.42 \\
\hline & LC9 & 25.86 & 28.08 & 28.02 & 26.55 & 27.28 & 25.50 \\
\hline & LC10 & 25.76 & 28.49 & 28.19 & 26.69 & 27.38 & 25.67 \\
\hline \multirow{2}{*}{\multicolumn{2}{|c|}{ Treatment Avg \pm Stdev }} & 25.73 & 28.33 & 27.96 & 26.47 & 27.23 & 25.46 \\
\hline & & \pm 0.18 & \pm 0.32 & \pm 0.25 & \pm 0.22 & \pm 0.15 & \pm 0.18 \\
\hline \multirow[t]{6}{*}{ LCA } & LC4 & 25.66 & 28.35 & 27.81 & 26.36 & 27.15 & 25.31 \\
\hline & LC8 & 25.71 & 27.77 & 27.96 & 26.59 & 27.25 & 25.52 \\
\hline & $\mathrm{LC} 12$ & 25.81 & 28.26 & 28.03 & 26.61 & 27.36 & 25.63 \\
\hline & LC13 & 25.78 & 29.20 & 28.20 & 26.76 & 27.36 & 25.63 \\
\hline & $\mathrm{LC} 15$ & 25.97 & 29.27 & 28.79 & 27.16 & 27.80 & 25.88 \\
\hline & LC16 & 25.99 & 28.36 & 28.40 & 26.98 & 27.67 & 25.83 \\
\hline \multirow{2}{*}{\multicolumn{2}{|c|}{ Treatment Avg \pm Stdev }} & 25.82 & 28.54 & 28.20 & 26.74 & 27.43 & 25.63 \\
\hline & & \pm 0.13 & \pm 0.58 & \pm 0.35 & \pm 0.29 & \pm 0.25 & \pm 0.21 \\
\hline \multirow[t]{6}{*}{ HCA } & LC2 & 25.56 & 27.48 & 27.54 & 26.12 & 27.01 & 25.20 \\
\hline & LC3 & 25.56 & 26.66 & 27.50 & 26.09 & 26.92 & 25.23 \\
\hline & LC5 & 25.70 & 27.27 & 27.7 & 26.23 & 27.05 & 25.40 \\
\hline & LC7 & 25.63 & 27.39 & 27.90 & 26.50 & 27.17 & 25.49 \\
\hline & LC11 & 25.82 & 27.41 & 27.81 & 26.46 & 27.24 & 25.56 \\
\hline & LC14 & 25.89 & 27.22 & 27.86 & 26.49 & 27.25 & 25.56 \\
\hline \multirow{2}{*}{\multicolumn{2}{|c|}{ Treatment Avg \pm Stdev }} & 25.69 & 27.24 & 27.72 & 26.32 & 27.11 & 25.41 \\
\hline & & \pm 0.14 & $\pm \mathbf{0 . 3 0}$ & \pm 0.17 & \pm 0.19 & $\pm \mathbf{0 . 1 3}$ & \pm 0.16 \\
\hline
\end{tabular}

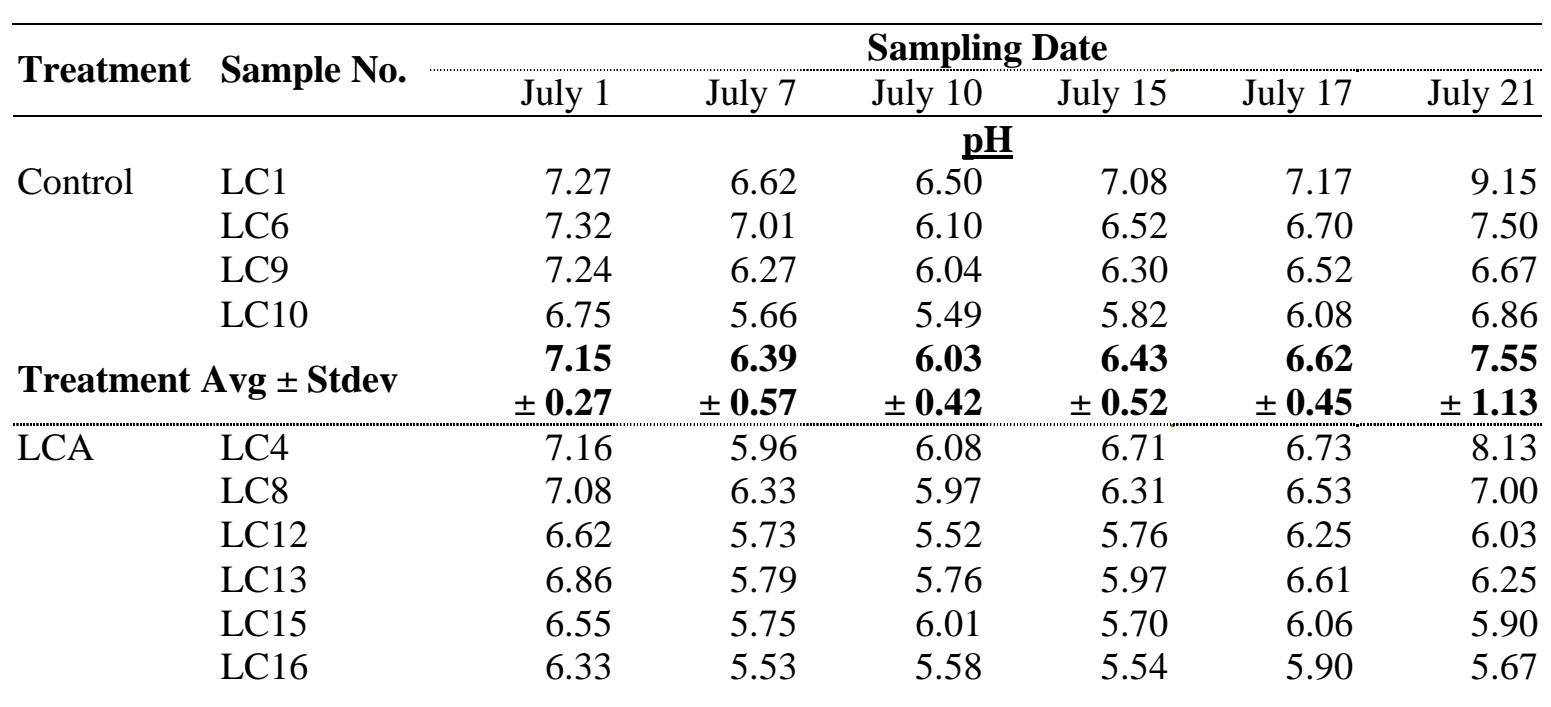


WSRC-TR-2004-00125

SREL-73; UC-66e

\begin{tabular}{|c|c|c|c|c|c|c|c|}
\hline \multicolumn{2}{|c|}{ Treatment Avg \pm Stdev } & 6.77 & 5.85 & 5.82 & 6.00 & 6.35 & 6.50 \\
\hline \multirow{7}{*}{ HCA } & LC2 & -8.92 & \pm 0.21 & \pm 0.24 & $\pm 0.4+$ & 7 & \pm 0.92 \\
\hline & $\begin{array}{l}\mathrm{LC} 2 \\
\mathrm{LC} 3\end{array}$ & $\begin{array}{l}7.43 \\
7.20\end{array}$ & $\begin{array}{l}6.30 \\
5.88\end{array}$ & $\begin{array}{l}6.07 \\
5.60\end{array}$ & $\begin{array}{l}7.20 \\
653\end{array}$ & $\begin{array}{l}7.29 \\
6.27\end{array}$ & $\begin{array}{l}9.69 \\
820\end{array}$ \\
\hline & LC5 & $\begin{array}{l}1.28 \\
7.18\end{array}$ & $\begin{array}{l}5.88 \\
5.9\end{array}$ & $\begin{array}{l}5.00 \\
5.40\end{array}$ & $\begin{array}{l}0.53 \\
6.51\end{array}$ & $\begin{array}{l}0.31 \\
6.31\end{array}$ & $\begin{array}{l}8.29 \\
817\end{array}$ \\
\hline & LC7 & 1.10 & 5.49 & 5.49 & $\begin{array}{l}0.01 \\
5.94\end{array}$ & $\begin{array}{l}0.34 \\
506\end{array}$ & 0.11 \\
\hline & $\mathrm{L} C 11$ & & & & & & \\
\hline & & & & & & & 3.90 \\
\hline \multirow{2}{*}{\multicolumn{2}{|c|}{ Treatment Avg \pm Stdev }} & & 5.99 & 5.50 & 5.51 & 0.13 & 5.97 \\
\hline & & $\begin{array}{r}6.95 \\
\pm 0.42\end{array}$ & $\begin{array}{r}5.89 \\
\pm 0.41\end{array}$ & $\begin{array}{r}5.50 \\
\pm 0.31\end{array}$ & $\begin{array}{r}6.22 \\
\pm 0.64\end{array}$ & $\begin{array}{r}6.37 \\
\pm 0.49\end{array}$ & $\begin{array}{r}7.52 \\
+1.47\end{array}$ \\
\hline & & \multicolumn{6}{|c|}{ DO $\left(\mathrm{mg} \mathrm{L}^{-1}\right)$} \\
\hline \multirow[t]{4}{*}{ Control } & LC1 & 3.78 & 4.87 & 4.27 & 2.04 & 3.31 & 1.09 \\
\hline & LC6 & 6.94 & 8.41 & 6.37 & 4.19 & 5.36 & 2.21 \\
\hline & LC9 & 6.76 & 5.50 & 4.35 & 0.68 & 0.91 & 0.34 \\
\hline & LC10 & 2.11 & 1.80 & 2.29 & 1.03 & 1.67 & 0.37 \\
\hline \multirow{2}{*}{\multicolumn{2}{|c|}{ Treatment Avg \pm Stdev }} & 4.90 & 5.15 & 4.32 & 1.99 & 2.81 & 1.00 \\
\hline & & \pm 2.36 & \pm 2.71 & \pm 1.67 & $\pm \mathbf{1 . 5 8}$ & $\pm \mathbf{1 . 9 7}$ & \pm 0.88 \\
\hline \multirow[t]{6}{*}{ LCA } & LC4 & 2.03 & 4.03 & 3.02 & 1.18 & 2.74 & 0.52 \\
\hline & LC8 & 5.00 & 5.52 & 5.12 & 2.71 & 3.36 & 1.77 \\
\hline & $\mathrm{LC} 12$ & 2.44 & 3.92 & 3.39 & 2.24 & 2.80 & 1.46 \\
\hline & LC13 & 4.64 & 5.88 & 5.24 & 4.27 & 4.79 & 2.81 \\
\hline & LC15 & 4.65 & 3.20 & 2.49 & 1.77 & 2.36 & 1.30 \\
\hline & LC16 & 1.97 & 2.32 & 2.50 & 1.82 & 1.74 & 1.09 \\
\hline \multirow{2}{*}{\multicolumn{2}{|c|}{ Treatment Avg \pm Stdev }} & 3.46 & 4.15 & 3.63 & 2.33 & 2.97 & 1.49 \\
\hline & & \pm 1.45 & $\pm \mathbf{1 . 3 6}$ & \pm 1.25 & $\pm \mathbf{1 . 0 8}$ & \pm 1.04 & \pm 0.77 \\
\hline \multirow[t]{6}{*}{$\mathrm{HCA}$} & LC2 & 1.53 & 0.27 & 1.16 & 0.65 & 2.29 & 1.50 \\
\hline & LC3 & 4.93 & 4.36 & 4.68 & 3.99 & 4.49 & 4.61 \\
\hline & LC5 & 5.97 & 4.30 & 4.49 & 3.62 & 4.26 & 4.53 \\
\hline & LC7 & 4.60 & 3.93 & 4.95 & 3.29 & 4.25 & 3.00 \\
\hline & LC11 & 2.98 & 2.80 & 2.68 & 1.83 & 2.77 & 1.97 \\
\hline & LC14 & 5.09 & 3.85 & 4.72 & 3.40 & 4.61 & 4.70 \\
\hline \multirow{2}{*}{\multicolumn{2}{|c|}{ Treatment Avg \pm Stdev }} & 4.18 & 3.25 & 3.78 & 2.80 & 3.78 & 3.39 \\
\hline & & \pm 1.63 & $\pm \mathbf{1 . 5 6}$ & \pm 1.53 & \pm 1.28 & \pm 0.99 & \pm 1.43 \\
\hline
\end{tabular}

\begin{tabular}{|c|c|c|c|c|c|c|c|}
\hline \multirow{2}{*}{ Treatment } & \multirow{2}{*}{ Sample No. } & \multicolumn{6}{|c|}{ Sampling Date } \\
\hline & & July 1 & July 7 & July 10 & July 15 & July 17 & July 21 \\
\hline & & \multicolumn{6}{|c|}{ Electrical Conductivity $\left(\cdot \mathbf{s ~ c m}^{-1}\right)$} \\
\hline \multirow{4}{*}{ Control } & LC1 & 54 & 40 & 44 & 49 & 19 & 49 \\
\hline & LC6 & 22 & 22 & 22 & 23 & 22 & 24 \\
\hline & LC9 & 26 & 31 & 33 & 37 & 36 & 40 \\
\hline & LC10 & 24 & 27 & 26 & 24 & 23 & 26 \\
\hline \multirow{2}{*}{\multicolumn{2}{|c|}{ Treatment Avg \pm Stdev }} & 31.5 & 30.0 & 31.3 & 33.3 & 25.0 & 34.8 \\
\hline & & \pm 15.1 & \pm 7.6 & \pm 9.6 & \pm 12.3 & \pm 7.5 & \pm 11.9 \\
\hline \multirow[t]{6}{*}{ LCA } & LC4 & 28 & 29 & 30 & 36 & 35 & 37 \\
\hline & LC8 & 27 & 26 & 26 & 29 & 29 & 30 \\
\hline & $\mathrm{LC} 12$ & 24 & 27 & 26 & 26 & 24 & 25 \\
\hline & LC13 & 39 & 25 & 29 & 35 & 35 & 39 \\
\hline & LC15 & 27 & 28 & 31 & 31 & 29 & 27 \\
\hline & LC16 & 29 & 28 & 26 & 29 & 30 & 31 \\
\hline
\end{tabular}


WSRC-TR-2004-00125

SREL-73; UC-66e

\begin{tabular}{|c|c|c|c|c|c|c|c|}
\hline \multicolumn{2}{|c|}{ Treatment Avg \pm Stdev } & $\begin{array}{r}29.0 \\
\pm 5.2\end{array}$ & $\begin{array}{r}27.2 \\
\pm 1.5\end{array}$ & $\begin{array}{r}28.0 \\
\pm 2.3\end{array}$ & $\begin{array}{r}31.0 \\
\pm 3.9\end{array}$ & $\begin{array}{r}30.3 \\
\pm 4.2\end{array}$ & $\begin{array}{r}31.5 \\
\pm 5.5\end{array}$ \\
\hline \multirow[t]{6}{*}{ HCA } & LC2 & 35 & 35 & 36 & 43 & 44 & 46 \\
\hline & LC3 & 24 & 20 & 20 & 21 & 20 & 21 \\
\hline & LC5 & 33 & 30 & 31 & 33 & 33 & 33 \\
\hline & LC7 & 27 & 27 & 26 & 27 & 27 & 27 \\
\hline & LC11 & 25 & 22 & 23 & 23 & 22 & 22 \\
\hline & LC14 & 26 & 23 & 24 & 25 & 25 & 25 \\
\hline \multicolumn{2}{|c|}{ Treatment Avg \pm Stdev } & $\begin{array}{r}28.3 \\
\pm 4.6 \\
\end{array}$ & $\begin{array}{r}26.2 \\
\pm 5.6 \\
\end{array}$ & $\begin{array}{r}26.7 \\
\pm 5.9 \\
\end{array}$ & $\begin{array}{r}28.7 \\
\pm 8.1 \\
\end{array}$ & $\begin{array}{r}28.5 \\
\pm 8.8 \\
\end{array}$ & $\begin{array}{r}29.0 \\
\pm 9.4 \\
\end{array}$ \\
\hline & & \multicolumn{6}{|c|}{ ORP $(\mathrm{mV})$} \\
\hline \multirow[t]{4}{*}{ Control } & LC1 & 371 & 312 & 500 & 540 & 538 & 531 \\
\hline & LC6 & 382 & 356 & 510 & 574 & 558 & 535 \\
\hline & LC9 & 388 & 373 & 436 & 540 & 526 & 534 \\
\hline & LC10 & 390 & 384 & 440 & 548 & 537 & 500 \\
\hline \multirow{2}{*}{\multicolumn{2}{|c|}{ Treatment Avg \pm Stdev }} & 383 & 356 & 472 & 551 & 540 & 525 \\
\hline & & \pm 9 & \pm 32 & \pm 39 & \pm 16 & \pm 13 & \pm 17 \\
\hline \multirow[t]{6}{*}{ LCA } & LC4 & 386 & 350 & 508 & 563 & 550 & 556 \\
\hline & LC8 & 394 & 378 & 427 & 572 & 529 & 552 \\
\hline & $\mathrm{LC} 12$ & 399 & 387 & 458 & 569 & 548 & 552 \\
\hline & LC13 & 379 & 383 & 459 & 564 & 549 & 541 \\
\hline & LC15 & 363 & 387 & 454 & 550 & 533 & 551 \\
\hline & LC16 & 404 & 340 & 441 & 552 & 517 & 528 \\
\hline \multirow{2}{*}{\multicolumn{2}{|c|}{ Treatment Avg \pm Stdev }} & 388 & 371 & 458 & 562 & 538 & 547 \\
\hline & & \pm 15 & \pm 21 & \pm 28 & \pm 14 & \pm 14 & \pm 10 \\
\hline \multirow[t]{6}{*}{$\mathrm{HCA}$} & LC2 & 373 & 151 & 494 & 455 & 528 & 504 \\
\hline & LC3 & 378 & 353 & 525 & 584 & 575 & 572 \\
\hline & LC5 & 386 & 382 & 507 & 562 & 563 & 574 \\
\hline & LC7 & 402 & 399 & 528 & 590 & 566 & 545 \\
\hline & LC11 & 401 & 389 & 455 & 567 & 546 & 547 \\
\hline & LC14 & 385 & 378 & 460 & 572 & 547 & 556 \\
\hline \multirow{2}{*}{\multicolumn{2}{|c|}{ Treatment Avg \pm Stdev }} & 388 & 342 & 495 & 555 & 554 & 550 \\
\hline & & \pm 12 & \pm 95 & \pm 32 & $\pm \mathbf{5 0}$ & \pm 17 & \pm 26 \\
\hline
\end{tabular}

\subsubsection{Turbidity and Water Quality}

Turbidity following the clay application increased two to three orders of magnitude in the low and high clay treated limnocorrals. Initial concentrations of clay averaged approximately 7,700 $\mathrm{mg} \mathrm{L}^{-1}$ and 77,000 $\mathrm{mg} \mathrm{L}^{-1}$ for low- and high-clay treatments, respectively. In spite of these high values, the relatively rapid settling of clay may have lessened its impacts on ecosystem processes. Turbidity in the high and low clay-treatment limnocorrals decreased exponentially after treatment (Fig. 10). The rate of turbidity decrease was modeled with the following equations:

high clay treatment: $\mathrm{y}=3,227\left(\mathrm{e}^{-0.56 \mathrm{x}}\right), \mathrm{R}^{2}=0.95$,

low clay treatment: $\mathrm{y}=184\left(\mathrm{e}^{-0.58 \mathrm{x}}\right), \mathrm{R}^{2}=0.90$,

where $\mathrm{y}=$ turbidity $(\mathrm{NTU}), \mathrm{x}$ days following treatment. 
Turbidity values recorded one day after clay application were less than half of initial values. The model equations presented above agree with the field observations in that the halftime for clearing turbidity is calculated to be 1.2 days. Field observations indicated that the low clay treatments had cleared to levels close to those of the controls after 16 days. Model estimates of the time to reach background turbidity levels in the high clay treatments were 115 days, although field observations from the clay application in 2001 suggest a more rapid clearance rate.

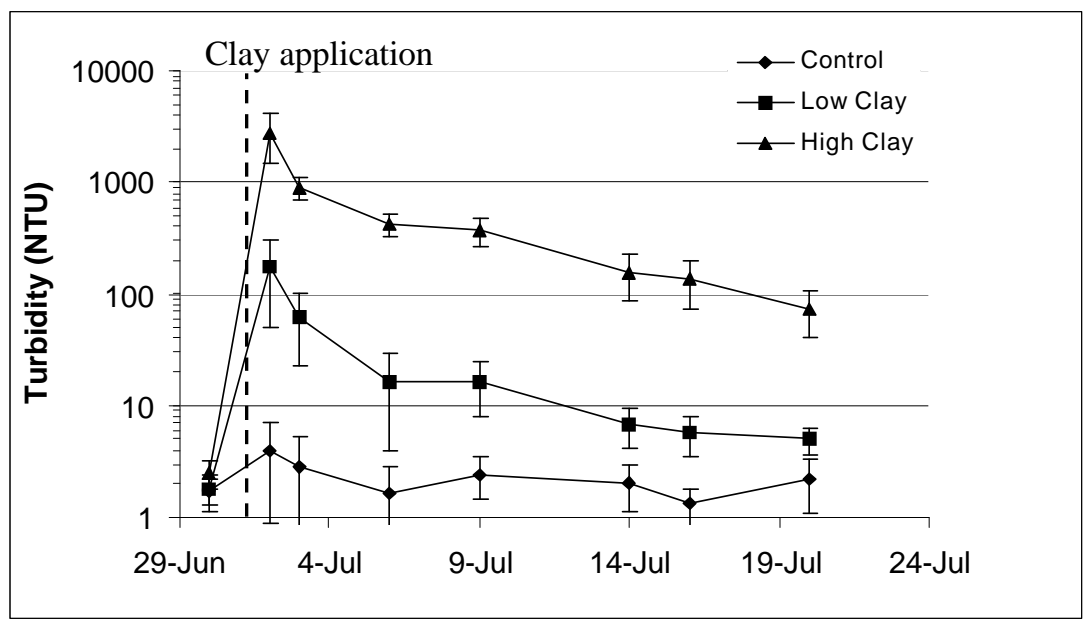

Figure 10. Changes in turbidity (NTU; mean \pm Stdev) are shown from before treatment (29 June, 2003) to nineteen days after treatment. Turbidity decreased exponentially following application.

No significant differences ( $\mathrm{p}>0.05$ ) in $\mathrm{pH}$, electrical conductivity, dissolved oxygen, or oxidation-reduction potential were found among treatments on any sampling date (Table 4). Electrical conductivity values would be expected to decrease if illite were absorbing ionic solutes from the water column in addition to ${ }^{137} \mathrm{Cs}$. Since there is no decrease in electrical conductivity in low or high clay treatments, it seems that clay application will not likely decrease the availability of essential plant nutrients in treated waters, such as $\mathrm{K}^{+}$or $\mathrm{NH}_{4}{ }^{+}$, nor did it increase solute concentrations that may have been contributed from the processed mineral.

The water temperature of high clay limnocorrals was significantly lower $(\mathrm{p}<0.05)$ than the water temperature of both control and low clay treatments on the first sampling date (July 7) after treatment (Fig. 11). On all other sampling dates no significant differences $(p>0.05)$ in water temperature between any treatments were found. A slight decrease in temperature in high clay treated limnocorrals was most likely due to reduced light penetration because of the very turbid water. 


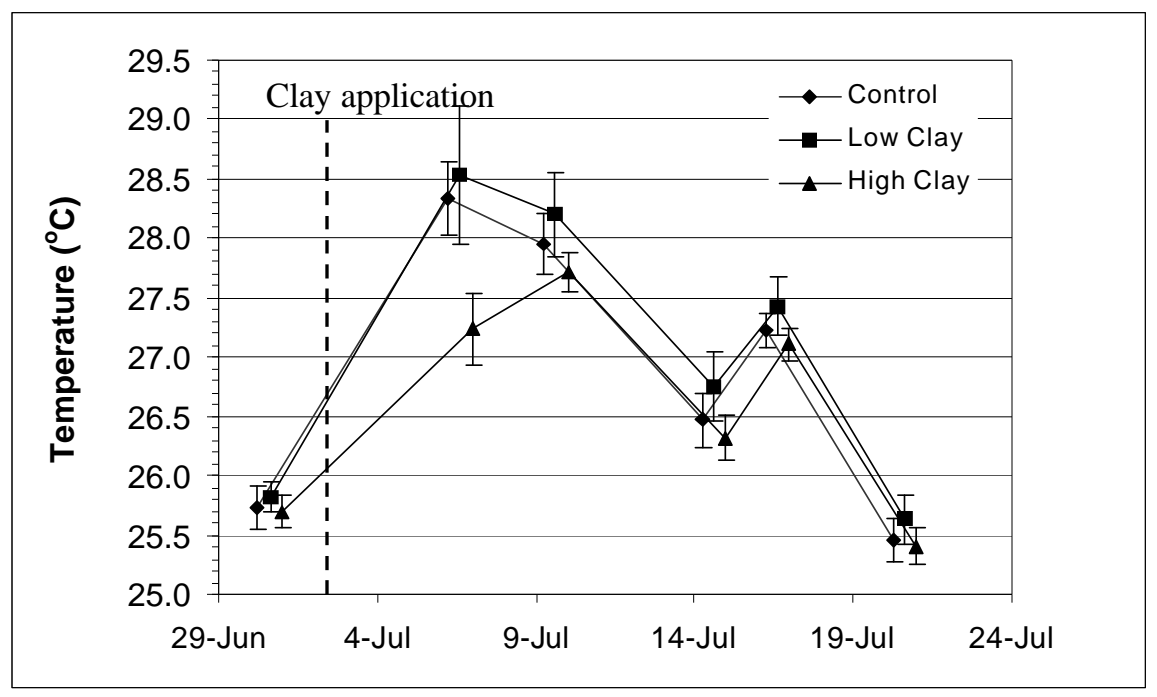

Figure 11. Temperature changes (mean \pm Stdev.) of limnocorrals from June 29 through July 21. Temperature of high clay amended limnocorrals drops below those levels of control and low clay amended limnocorrals briefly after clay application.

\subsubsection{Macroinvertebrates, Phytoplankton Productivity, and Chlorophyll-a}

No significant differences $(\mathrm{p}>0.05)$ in chlorophyll-a levels (Table 5) were found between clay treatments, nor were chlorophyll-a levels correlated with turbidity for any treatment. Phytoplankton productivity and respiration levels were not significantly different $(p>0.05)$ among treatments (Table 6), and productivity levels were not correlated with turbidity. Large variations among replicates within treatments for both chlorophyll-a and productivity measurements complicated interpretation of these data, and suggests that more replicates were needed.

The five most common families of aquatic insects were Coenagrionidae (Odonata, Zygoptera), Libellulidae (Odonata, Anisoptera), Baetidae (Ephemeroptera), Caenidae (Ephemeroptera), and Chironomidae (Diptera) (Fig. 12). Occasional Coleopterans, Megalopterans, and Hemipterans were found, along with other families of Odonates and Dipterans. Total numbers of insects (all families included) found in a Hester-Dendy sampler were analyzed to compare the aquatic insect abundance among treatments (Table 7). No significant difference $(p>0.05)$ in abundances was found among treatments. Although the changes within a treatment are highly variable and not significant, mean changes in insect abundance were higher in the clay application treatments (Table 7). 
Table 5. Water samples were taken for chlorophyll-a analysis on July 21. Treatments: Control no clay application; LCA - low clay application $(0.25 \mathrm{~cm}$ layer of clay on the bottom of the sediments); HCA - high clay application ( $2.5 \mathrm{~cm}$ layer of clay on the bottom of the sediments).

\begin{tabular}{|c|c|c|c|c|}
\hline \multirow[b]{2}{*}{ Treatment } & \multirow{3}{*}{ Sample No. } & \multicolumn{3}{|c|}{ Chlorophyll-a $\left(\bullet \mathrm{g} \mathrm{L}^{-1}\right)$} \\
\hline & & \multirow{2}{*}{ Each Sample } & \multicolumn{2}{|c|}{ Treatment } \\
\hline & & & Average & Stdev \\
\hline \multirow[t]{4}{*}{ Control } & LC1 & 0.00 & 2.51 & 4.58 \\
\hline & LC6 & 9.36 & & \\
\hline & LC9 & 0.67 & & \\
\hline & LC10 & 0.00 & & \\
\hline \multirow[t]{5}{*}{ LCA } & LC4 & 8.69 & 4.01 & 4.55 \\
\hline & LC8 & 9.36 & & \\
\hline & LC13 & 4.01 & & \\
\hline & LC 15 & 0.00 & & \\
\hline & LC16 & 0.67 & & \\
\hline \multirow[t]{4}{*}{$\mathrm{HCA}$} & LC3 & 4.01 & 2.79 & 3.46 \\
\hline & LC5 & 0.00 & & \\
\hline & LC7 & 7.13 & & \\
\hline & LC11 & 0.00 & & \\
\hline
\end{tabular}

Table 6. Gross primary productivity, net primary productivity, and respiration of phytoplankton were measured on July 7, 15, and 21. Treatments: Control - no clay application; LCA - low clay application ( $0.25 \mathrm{~cm}$ layer of clay on the bottom of the sediments); HCA - high clay application ( $2.5 \mathrm{~cm}$ layer of clay on the bottom of the sediments).

\begin{tabular}{|c|c|}
\hline Treatment & Avg. \pm Stdev \\
\hline \multicolumn{2}{|c|}{ Gross Primary Productivity $\left(\mathrm{mg} \mathrm{C} \mathrm{m}^{-3} \mathrm{~h}^{-1}\right)$} \\
\hline Control & $62.6 \pm 46.5$ \\
\hline LCA & $41.2 \pm 23.3$ \\
\hline $\mathrm{HCA}$ & $81.3 \pm 20.4$ \\
\hline \multicolumn{2}{|c|}{ Net Primary Productivity $\left(\mathrm{mg} \mathrm{C} \mathrm{m}^{-3} \mathrm{~h}^{-1}\right)$} \\
\hline Control & $13.2 \pm 53.6$ \\
\hline LCA & $4.13 \pm 46.1$ \\
\hline $\mathrm{HCA}$ & $39.9 \pm 41.3$ \\
\hline \multicolumn{2}{|c|}{$\underline{\text { Respiration }\left(\mathrm{mg} \mathrm{C} \mathrm{m}^{-3} \mathrm{~h}^{-1}\right)}$} \\
\hline Control & $49.3 \pm 17.5$ \\
\hline LCA & $40.2 \pm 28.6$ \\
\hline $\mathrm{HCA}$ & $38.4 \pm 15.4$ \\
\hline
\end{tabular}


Principal component analyses produced 2 components that explained 63 percent of the variance (Table 8). Factor loadings listed in Table 8 indicate which taxa were correlated to each component. Abundance of caenid mayflies and libellulid dragonflies were positively correlated to the first component while baetid mayflies were negatively correlated. Chironomids, coenagrionid damsel flies and to a lesser extent the libellulid dragonflies loaded positively on the second principal component (PC-II; Table 8). In Figure 13 each polygon encloses all of the points for each of the three treatments, before (Fig. 13A) and after (Fig. 13B) the second clay treatment. The position and shape of the polygons illustrate that species assemblages shifted after the second clay treatment and differed among treatments. Analysis of Variance of the factor scores of PC-I confirmed that species assemblages were different before and after the second clay treatment and also differed among treatments (Table 9). The response of the assemblage was consistent in that not only was the relative abundance of caenid mayflies and libellulid dragonflies higher with baetid mayflies lower after the second clay treatment (ACA), but this pattern was enhanced by larger amounts of clay being added (Fig. 14).

Unlike PC-I, mean PC-II factor scores did not differ before and after the second clay treatment or among treatments. The scores for PC-II were generally highly variable resulting in only $17 \%$ of the variance being explained by the ANOVA model (Table 9). It is interesting to note that while means did not differ among treatments, both within the BCA samples and in the ACA, standard deviations where lower in the controls than in the low or high clay treatments respectively (BCA: 0.22, 0.76, 1.20; ACA; 0.54, 0.76, 1.8). The higher variability may indicate reduced stability in the species assemblages after clay treatment. 
WSRC-TR-2004-00125

SREL-73; UC-66e
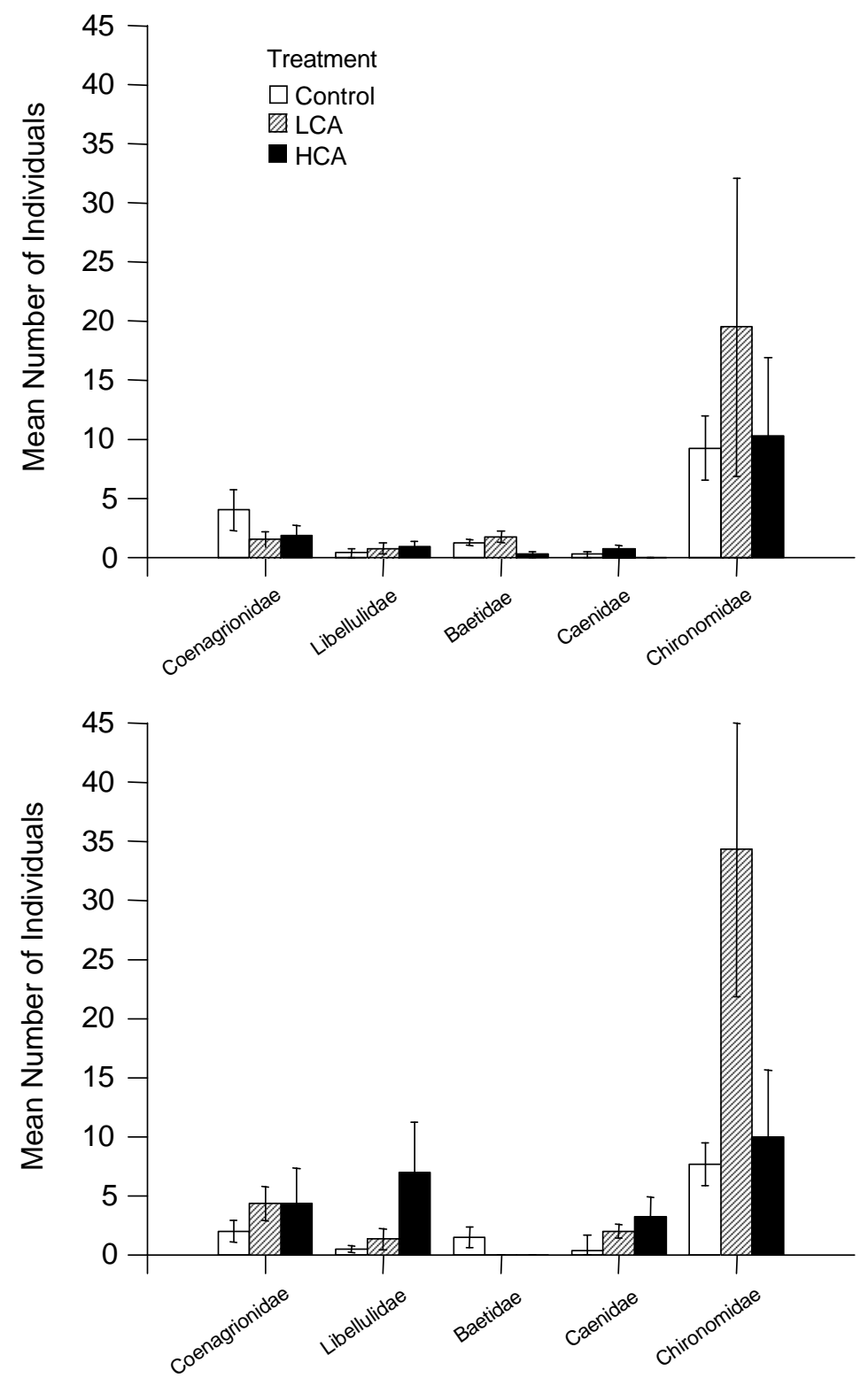

Figure 12. Mean numbers of individuals of the of aquatic insect families most commonly found in the Hester-Dendy samplers. One year after first application (BCA) and seven days after the second application (ACA). Error bars $\pm 1 S E$. 
Table 7. Abundance of aquatic insects was measured before (BCA) and after the second clay application (ACA). Total numbers of insects and number of insects belonging to the most common taxa are presented. Taxonomic richness measured as the total number of families and orders of insects found in the Hester-Dendy samplers. Means and standard deviations are for the samplers; see Figure 12 for limnocoral means.

Treatments: Control - no clay application; LCA - low clay application $(0.25 \mathrm{~cm}$ layer of clay on the bottom of the sediment); HCA - high clay application $(2.5 \mathrm{~cm}$ layer of clay on the bottom of the sediment).

\begin{tabular}{|c|c|c|c|c|c|c|c|c|c|c|c|}
\hline \multirow{2}{*}{\multicolumn{2}{|c|}{ Treatment Sample No. }} & \multicolumn{10}{|c|}{ Number of Insects } \\
\hline & & \multirow[t]{2}{*}{ Family } & \multirow[t]{2}{*}{ Order } & \multirow[t]{2}{*}{ Total Insect } & \multirow[t]{2}{*}{ Coenagrionidae } & \multirow{2}{*}{ Libellulidae } & \multirow{2}{*}{$\frac{\text { Baetidae }}{\text { BCA }}$} & \multirow{2}{*}{ Caenidae } & \multirow{2}{*}{ Chironomidae } & \multirow{2}{*}{ Odonata } & \multirow{2}{*}{ Ephemeroptera } \\
\hline & & & & & & & & & & & \\
\hline \multirow[t]{5}{*}{ Control } & LC1 & 3 & 3 & 16 & 9 & 0 & $\overline{2}$ & 0 & 5 & 9 & 2 \\
\hline & LC6-1 & 3 & 2 & 14 & 5 & 2 & 0 & 0 & 7 & 7 & 0 \\
\hline & LC6-2 & 5 & 4 & 12 & 1 & 1 & 2 & 2 & 5 & 2 & 4 \\
\hline & LC9 & 3 & 3 & 19 & 1 & 0 & 1 & 0 & 17 & 1 & 1 \\
\hline & LC10 & 3 & 3 & 14 & 3 & 0 & 1 & 0 & 9 & 3 & 1 \\
\hline \multicolumn{2}{|c|}{$\begin{array}{l}\text { Treatment Avg } \pm \\
\text { Stdev }\end{array}$} & $\begin{array}{r}3.4 \\
\pm 0.9\end{array}$ & $\begin{array}{c}3.0 \\
\pm 0.7\end{array}$ & $\begin{array}{r}15.0 \\
\pm 2.7\end{array}$ & $\begin{array}{c}3.8 \\
\pm 3.4\end{array}$ & $\begin{array}{c}0.6 \\
\pm 0.9\end{array}$ & $\begin{array}{r}1.2 \\
\pm 0.8\end{array}$ & $\begin{array}{c}0.4 \\
\pm 0.9\end{array}$ & $\begin{array}{c}8.6 \\
\pm \mathbf{5 . 0}\end{array}$ & $\begin{array}{c}4.4 \\
\pm 3.4\end{array}$ & $\begin{array}{r}1.6 \\
\pm 1.5\end{array}$ \\
\hline \multirow[t]{4}{*}{ LCA } & LC4 & 4 & 3 & 13 & 2 & 0 & 1 & 1 & 9 & 2 & 2 \\
\hline & LC8 & 3 & 3 & 60 & 1 & 0 & 2 & 0 & 57 & 1 & 2 \\
\hline & $\mathrm{LC} 12$ & 5 & 4 & 16 & 0 & 1 & 3 & 1 & 10 & 1 & 4 \\
\hline & LC15 & 5 & 4 & 11 & 3 & 2 & 1 & 1 & 2 & 5 & 2 \\
\hline \multicolumn{2}{|c|}{$\begin{array}{l}\text { Treatment Avg } \pm \\
\text { Stdev }\end{array}$} & $\begin{array}{c}4.3 \\
\pm 1.0\end{array}$ & $\begin{array}{c}3.5 \\
\pm 0.6\end{array}$ & $\begin{array}{c}25.0 \\
\pm 23.4\end{array}$ & $\begin{array}{c}1.5 \\
\pm 1.3\end{array}$ & $\begin{array}{c}0.8 \\
\pm 1.0\end{array}$ & $\begin{array}{c}1.8 \\
\pm 1.0\end{array}$ & $\begin{array}{c}0.8 \\
\pm 0.5\end{array}$ & $\begin{array}{r}19.5 \\
\pm 25.3\end{array}$ & $\begin{array}{c}2.3 \\
\pm 1.9\end{array}$ & $\begin{array}{c}2.5 \\
\pm 1.0\end{array}$ \\
\hline \multirow[t]{5}{*}{$\mathrm{HCA}$} & $\mathrm{LC} 2$ & 3 & 2 & 8 & 0 & 0 & 1 & 0 & 6 & 0 & 1 \\
\hline & LC3-1 & 3 & 2 & 39 & 7 & 3 & 0 & 0 & 29 & 10 & 0 \\
\hline & LC3-2 & 2 & 2 & 32 & 0 & 0 & 0 & 0 & 31 & 0 & 0 \\
\hline & LC5 & 3 & 2 & 9 & 3 & 2 & 0 & 0 & 4 & 5 & 0 \\
\hline & LC7 & 2 & 2 & 2 & 1 & 0 & 0 & 0 & 1 & 1 & 0 \\
\hline \multicolumn{2}{|c|}{$\begin{array}{l}\text { Treatment Avg } \pm \\
\text { Stdev }\end{array}$} & $\begin{array}{r}2.6 \\
\pm 0.6 \\
\end{array}$ & $\begin{array}{r}2.0 \\
\pm 0.0 \\
\end{array}$ & $\begin{array}{c}18.0 \\
\pm 16.4 \\
\end{array}$ & $\begin{array}{r}2.2 \\
\pm \mathbf{3 . 0} \\
\end{array}$ & $\begin{array}{r}1.0 \\
\pm 1.4 \\
\end{array}$ & $\begin{array}{r}0.2 \\
\pm 0.5 \\
\end{array}$ & $\begin{array}{c}0.0 \\
\pm \mathbf{0 . 0} \\
\end{array}$ & $\begin{array}{r}14.2 \\
\pm 14.6 \\
\end{array}$ & $\begin{array}{r}3.2 \\
\pm 4.3 \\
\end{array}$ & $\begin{array}{r}0.2 \\
\pm 0.5 \\
\end{array}$ \\
\hline
\end{tabular}




\begin{tabular}{|c|c|c|c|c|c|c|c|c|c|c|c|}
\hline \multirow{2}{*}{\multicolumn{2}{|c|}{ Treatment Sample N }} & \multicolumn{10}{|c|}{ Number of Insects } \\
\hline & & Family & Order & Total Insect & Coenagrionidae & Libellulidae & Baetidae & Caenidae & Chironomidae & Odonata & Ephemeroptera \\
\hline \multirow{7}{*}{ Control } & & & & & & & ACA & & & & \\
\hline & $\mathrm{LC} 1$ & 5 & 5 & 8 & 1 & 0 & $\overline{1}$ & 0 & 4 & 1 & 1 \\
\hline & LC6-1 & 6 & 5 & 38 & 1 & 1 & 0 & 1 & 17 & 2 & 1 \\
\hline & LC6-2 & 5 & 4 & 17 & 4 & 1 & 0 & 3 & 7 & 5 & 3 \\
\hline & LC6-3 & 5 & 4 & 34 & 4 & 1 & 0 & 12 & 14 & 5 & 12 \\
\hline & LC9 & 5 & 4 & 14 & 4 & 1 & 1 & 0 & 7 & 5 & 1 \\
\hline & LC10 & 3 & 3 & 13 & 0 & 0 & 4 & 0 & 7 & 0 & 4 \\
\hline \multicolumn{2}{|c|}{$\begin{array}{l}\text { Treatment Avg } \pm \\
\text { Stdev }\end{array}$} & $\begin{array}{c}4.8 \\
\pm 1.0\end{array}$ & $\begin{array}{c}4.2 \\
\pm 0.8\end{array}$ & $\begin{array}{c}20.7 \\
\pm 12.3\end{array}$ & $\begin{array}{c}2.3 \\
\pm 1.9\end{array}$ & $\begin{array}{c}0.7 \\
\pm 0.5\end{array}$ & $\begin{array}{c}1.0 \\
\pm 1.6\end{array}$ & $\begin{array}{c}2.7 \\
\pm 4.7\end{array}$ & $\begin{array}{c}9.3 \\
\pm \mathbf{5 . 0}\end{array}$ & $\begin{array}{c}3.0 \\
\pm 2.3\end{array}$ & $\begin{array}{c}3.7 \\
\pm 4.3\end{array}$ \\
\hline \multirow[t]{3}{*}{ LCA } & LC4 & 4 & 3 & 24 & 4 & 3 & 0 & 3 & 14 & 7 & 3 \\
\hline & LC8 & 4 & 3 & 69 & 7 & 1 & 0 & 1 & 57 & 8 & 1 \\
\hline & LC15 & 3 & 3 & 36 & 2 & 0 & 0 & 2 & 32 & 2 & 2 \\
\hline \multicolumn{2}{|c|}{$\begin{array}{l}\text { Treatment Avg } \pm \\
\text { Stdev }\end{array}$} & $\begin{array}{r}3.7 \\
\pm 0.6 \\
\end{array}$ & $\begin{array}{r}\mathbf{3 . 0} \\
\pm \mathbf{0 . 0}\end{array}$ & $\begin{array}{r}43.0 \\
\pm 23.3 \\
\end{array}$ & $\begin{array}{c}4.3 \\
\pm 2.5 \\
\end{array}$ & $\begin{array}{r}1.3 \\
\pm 1.5\end{array}$ & $\begin{array}{c}\mathbf{0 . 0} \\
\pm \mathbf{0 . 0}\end{array}$ & $\begin{array}{c}2.0 \\
\pm 1.0\end{array}$ & $\begin{array}{r}34.3 \\
\pm 21.6 \\
\end{array}$ & $\begin{array}{r}5.7 \\
\pm \mathbf{3 . 2} \\
\end{array}$ & $\begin{array}{c}2.0 \\
\pm 1.0\end{array}$ \\
\hline \multirow[t]{6}{*}{$\mathrm{HCA}$} & LC2 & 5 & 4 & 15 & 1 & 0 & 0 & 7 & 5 & 1 & 7 \\
\hline & LC3-1 & 4 & 2 & 46 & 16 & 12 & 0 & 0 & 16 & 28 & 0 \\
\hline & LC3-2 & 4 & 3 & 82 & 8 & 24 & 0 & 3 & 47 & 32 & 3 \\
\hline & LC3-3 & 4 & 3 & 48 & 16 & 15 & 0 & 0 & 15 & 31 & 0 \\
\hline & LC5 & 5 & 4 & 28 & 1 & 11 & 0 & 5 & 9 & 12 & 5 \\
\hline & LC7 & 2 & 2 & 3 & 2 & 0 & 0 & 0 & 0 & 2 & 0 \\
\hline \multirow{2}{*}{\multicolumn{2}{|c|}{$\begin{array}{l}\text { Treatment Avg } \pm \\
\text { Stdev }\end{array}$}} & 4.0 & 3.0 & 37.0 & 7.3 & 10.3 & 0.0 & 2.5 & 15.3 & 17.7 & 2.5 \\
\hline & & \pm 1.1 & \pm 0.9 & \pm 28.1 & \pm 7.2 & \pm 9.2 & \pm 0.0 & $\pm \mathbf{3 . 0}$ & \pm 16.7 & \pm 14.5 & $\pm \mathbf{3 . 0}$ \\
\hline \multirow{4}{*}{\multicolumn{2}{|c|}{$\begin{array}{l}\text { Control } \\
\text { LCA } \\
\text { HCA }\end{array}$}} & & & & Index by $\mathrm{Ch}$ & nges betwee & n BCA & dd ACA (A & CA-BCA) & & \\
\hline & & 1.4 & 1.2 & 5.7 & -1.5 & 0.1 & -0.2 & 2.3 & 0.7 & -1.4 & 2.1 \\
\hline & & -0.6 & -0.5 & 18.0 & 2.8 & 0.6 & -1.8 & 1.3 & 14.8 & 3.4 & -0.5 \\
\hline & & 1.4 & 1.0 & 19.0 & 5.1 & 9.3 & -0.2 & 2.5 & 1.1 & 14.5 & 2.3 \\
\hline
\end{tabular}


WSRC-TR-2004-00125

SREL-73; UC-66e

Table 8. Loadings of abundance of the 5 aquatic insect families collected in the Hester-Dendy samplers on the first 2 principal components.

\begin{tabular}{lcc}
\hline & PC-I & PC-II \\
\hline Baetidae & -0.836 & -0.087 \\
Caenidae & 0.756 & 0.005 \\
Libellulidae & 0.626 & 0.471 \\
Chironomidae & -0.104 & 0.835 \\
Coenagrionidae & 0.363 & 0.662 \\
\hline Eigenvalues & 2.153 & 1.015 \\
Percent total variance & & \\
explained & 36 & 27 \\
\hline
\end{tabular}
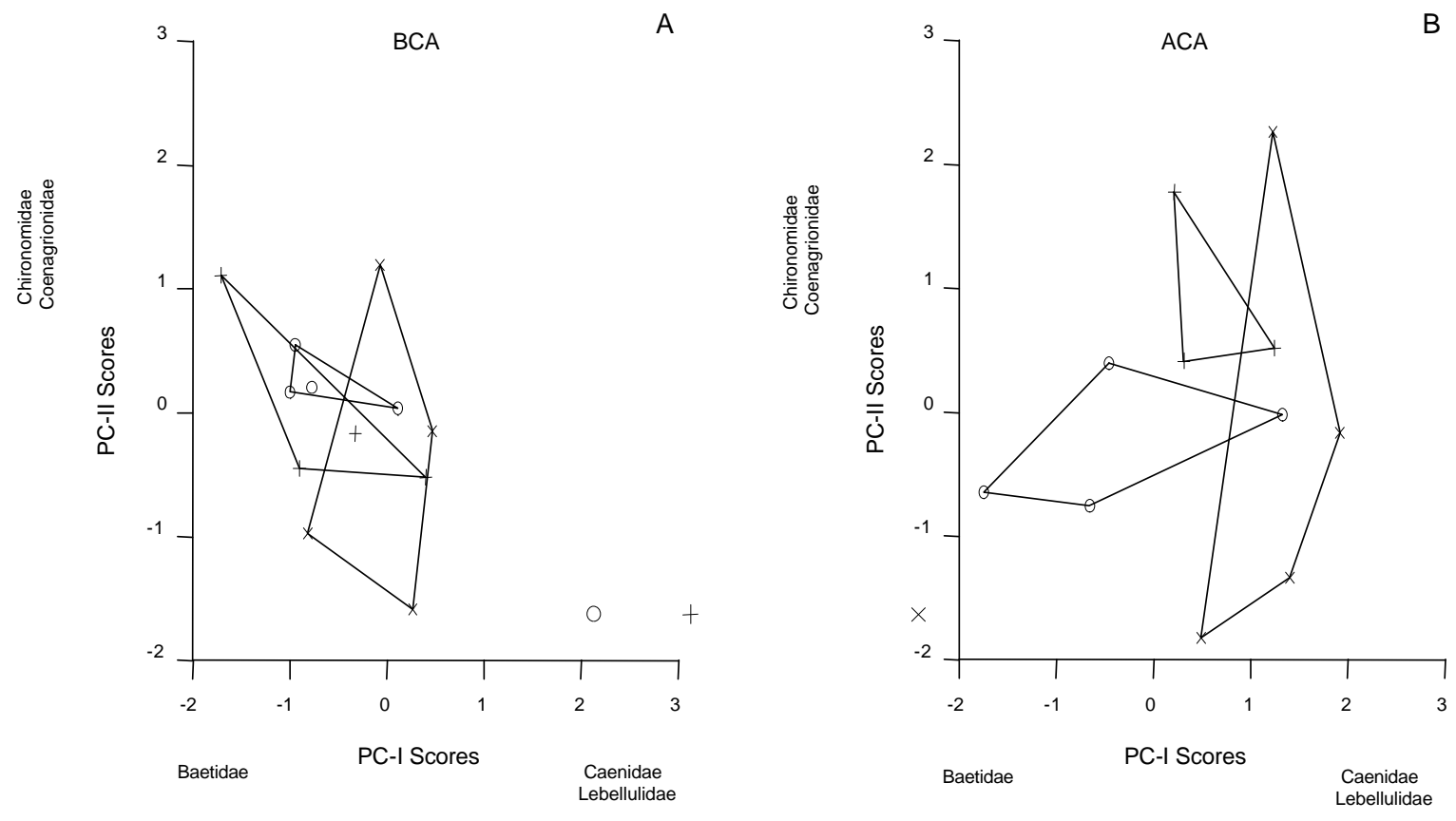

Figure 13. Comparison of factor scores of the first and second principal components. Polygons enclose all points for each treatment: control, low clay application, high clay application. A) BCA-before second clay application; B) ACA-after second clay application. 
Table 9. Results of ANOVA of the effects of clay status (ACA vs. BCA) and treatment on each of the two principle components. Aquatic insect families with loadings of absolute value greater than 0.4 are listed beside the component heading.

\begin{tabular}{lcccl}
\hline Source & $\mathrm{df}$ & $\mathrm{MS}$ & $\mathrm{F}$ & $\mathrm{p}$ \\
\hline PC-I (Caenidae, Libellulidae, & Baetidae) & & & $\mathrm{R}^{2}=0.51$ \\
Clay Status & 1 & 4.924 & 7.825 & 0.01 \\
Treatment & 2 & 2.558 & 4.064 & 0.04 \\
Treatment*Clay Status & 2 & 0.647 & 1.029 & 0.38 \\
Error & 17 & 0.629 & & \\
& & & & \\
PC-II (Chironomidae, Coenagrionidae, Libellulidae & & $\mathrm{R}^{2}=0.17$ \\
Clay Status & 1 & 0.177 & 0.165 & 0.69 \\
Treatment & 2 & 1.102 & 1.029 & 0.38 \\
Treatment*Clay Status & 2 & 0.910 & 0.850 & 0.45 \\
Error & 17 & 1.071 & & \\
& & & & \\
\hline
\end{tabular}

It is important to note that in PC-I, treatments were more similar before the second treatment (Fig. 14B) than after (Fig. 14C). While recovery does not appear complete, the more widely overlapping polygons in Figure 13A (BCA) indicates more similar assemblages than the more separated polygons in Figure 13B (ACA). Thus communities may be on a trajectory to recover from the disturbance.

Caenid mayflies are sprawlers, a functional group that generally lives on top of the substrate, and some taxa (e.g. Caenis) frequently inhabit littoral sediments (Merritt and Cummins 1984). Similarly libeullid dragonflies are sprawlers or climbers and may live on the bottom sediments or climb aquatic vegetation. It is interesting that these two families increased their prevalence on the samplers in response to the clay application. Because the benthos was not sampled during the experiment, we do not know the abundance of these organisms before or after the treatment. However, it is possible that some bottom dwelling caenids and libellulids relocated from the bottom sediments to suspended samplers to avoid clay deposition. This behavior would also be consistent with an increase in abundance on the samplers in the clay application treatments. In streams, behavioral avoidance by aquatic insects of suspended solids has been noted (Ward 1992) so avoidance of sediment deposition when possible seems plausible. Coenagrionid damselflies 
WSRC-TR-2004-00125

SREL-73; UC-66e
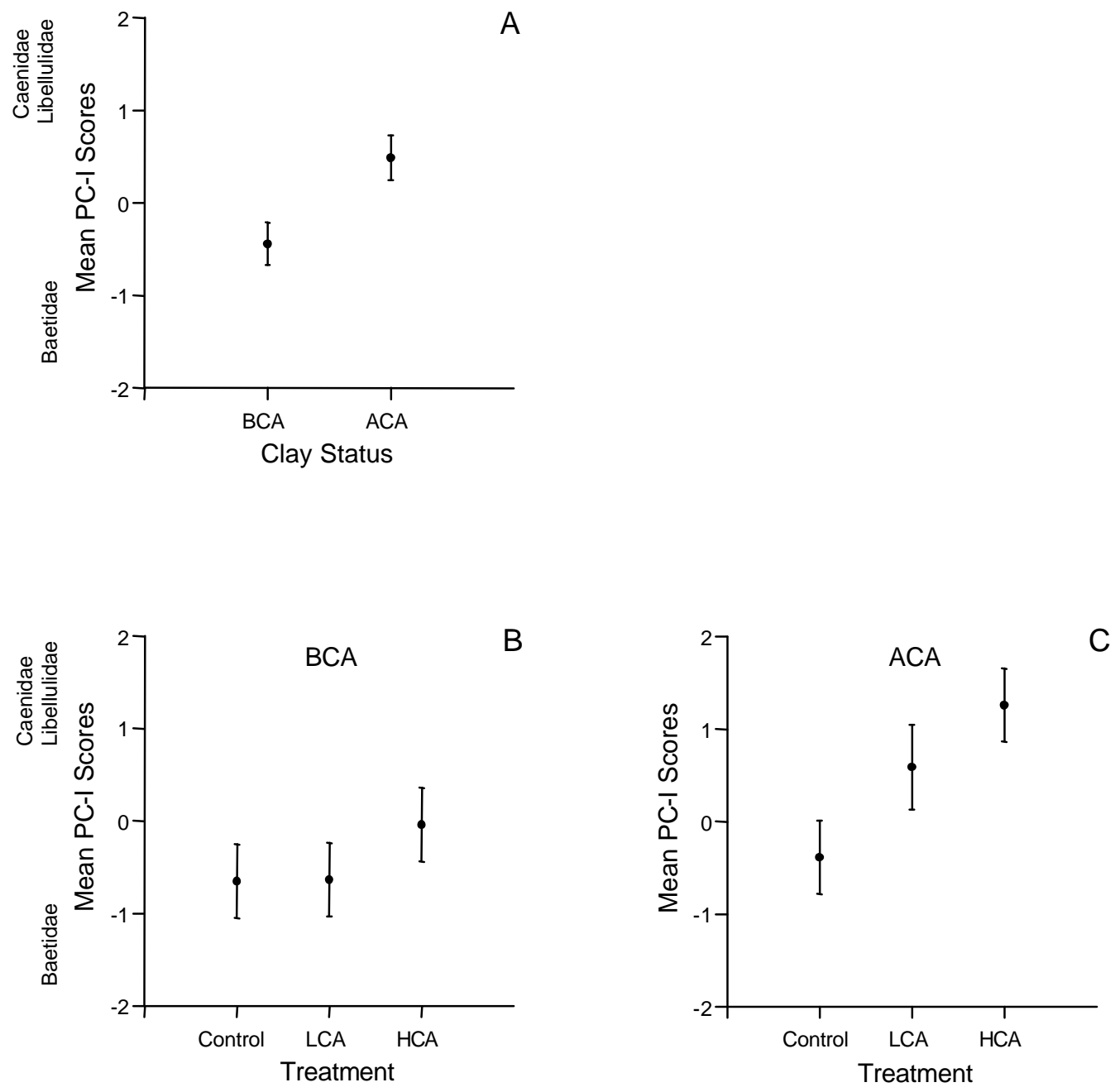

Figure 14. Response of PC-I scores to clay treatment. Least squares means saved from ANOVA 1 standard error. A) mean scores before (BCA) and after (ACA) the second clay application with the effects of treatment controlled. B) Mean scores across treatments before the second clay application: no clay applied (control), low clay application (LCA) and high clay application (HCA). C) Mean scores across treatments after the second clay treatment. 
that are typically climbers and frequently live amongst dense vegetation of still waters (Merritt and Cummins 1984) may have been less affected by the sedimentation. Baetid mayflies swim with fish-like body undulations to submerged objects or aquatic vegetation to which they cling. Baetids were in low numbers prior to disturbance, but decreased or possibly disappeared after clay application. Chironomids as a family are a very diverse group and more difficult to generalize.

In general hanging a single sampler near the water surface may have characterized the phytophyllous insect population better than the benthos. Because of the potential impact of covering the bottom with sediment and possible complex behavioral responses of aquatic insects that may have affected sampling, more extensive sampling of the benthos and multiple water levels will be conducted in future studies.

The lack of impact on dissolved oxygen is consistent with the lack of change in algal abundance or productivity and in future studies this could be confirmed with comprehensive analyses of diel cycles of dissolved oxygen concentrations. Over longer periods of time changes in algal populations are responsible for cascading effects on higher trophic levels in aquatic ecosystems because of resulting decreases in dissolved oxygen and reduced food availability and quality (McCormick and Cairns, 1997). Without changes in algal abundance or productivity, therefore, lack of a more severe impact on water quality and insect community becomes less surprising. Composition of algal populations was not examined, and overall abundance can sometimes mask changes in community structure (Beklioglu and Moss, 1996). High turbidity could shift limitations on algal productivity from nutrients to light availability (Holz et al., 1997), and resultant changes in phytoplankton community structure could be examined as another indicator of the effects of clay treatments. Benthic algae, not examined in this study, is often an important component of freshwater food webs, particularly in shallow clear lakes (Hecky and Hesslein 1995) like Pond A. Siltation of surfaces can limit algal growth and decrease the proportion of its organic content (Graham, 1990). Food quality for consumers of periphyton is reduced even when there is no decrease in total periphyton abundance (Hann et al., 2001). Snails or tadpoles might be good indicators of a reduction in periphyton quality, and filter-feeding bivalves such as freshwater mussels and clams would make good subjects to test whether clay decreases the food quality of phytoplankton. In the current study, snail abundance did decline on the Hester-Dendy samplers in response to clay application.

In undamaged freshwater ecosystems, any given family of insects normally makes up only 3$23 \%$ of the total insect community (Hart and Fuller, 1974). Control and pre-treatment insect samples from the limnocorrals showed that Chironomids and Coenagrionids often constituted 
WSRC-TR-2004-00125

SREL-73; UC-66e

greater percentages of the population than this. In addition, some taxa of the dominant families found in the samplers are known to exhibit high tolerances to low water quality, including low dissolved oxygen. Coenagrionids have been shown to maintain higher populations in low water quality (Brigham et al., 1982); Coenagrionid and Libellulid nymphs both need to hide from prey to be able to hunt, and low levels of increased siltation may help them do this. Chironomids, and Baetid and Caenid mayflies are mostly detrivores or scrapers with a few predaceous chironomids, but some taxa are tolerant to low water quality. Variation in the effects of suspended sediment on macroinvertebrates is also often attributed to the history of the exposed area (Lenat et al., 1981; Gray and Ward, 1982). The initial insect communities in R-Canal may have already been indicative of poor quality waters, and the increased turbidity may have had a weaker effect than it would have had on a more pristine area.

\subsection{Fish Mortality Study in Artificial Flowing Streams}

The effects of turbidity on fish mortality were studied. Effects of turbidity have been previously grouped into three categories: (1) Lethal effects - lethal effects kill individual fish, cause population reductions, or damage the capacity of the ecosystem to produce fish, (2) Sublethal effects - sub-lethal effects injure the tissues or physiology of the organism, but not enough to cause death, (3) Behavioral effects - behavioral effects change activity patterns and/or detrimentally alter fish behavior. In this study, we only examined lethality.

Three continuous water-flowing raceways were used for this study and the turbidity prior to clay application was examined as a background level (Fig. 13). The raceways used pumped water from Upper Three Runs and litter, and organic matter in the stream water caused the pre-treated turbidity. Turbidity values (average value of three raceways) decreased exponentially with time and stabilized between 7-8 NTUs, twelve hours after the system was turned on. Based on this pretreatment characterization of the raceways we turned on the flowing system for 12 hours before fish were introduced.

Turbidity values for air-floated, semi-dry, and control treated raceways were measured before, during and after clay application (Table 8). Samples taken two hours after the application for air-floated treated raceways and one hour after for semi-dry treated raceways showed that turbidity had decreased to levels close to those of the controls $(p>0.05)$. Such a rapid reduction in turbidity would likely have diminished impacts to fish. 


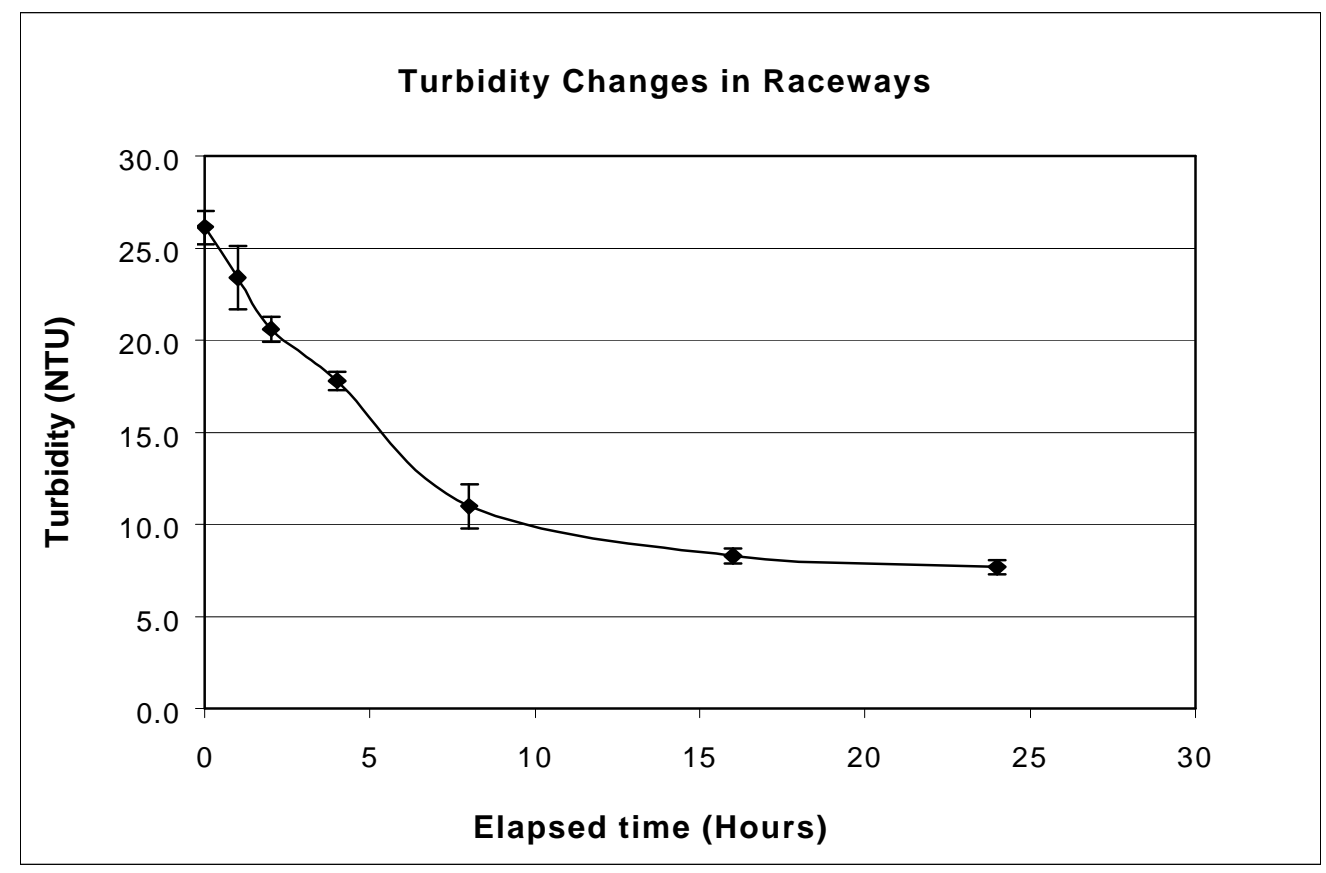

Figure 13. Turbidity (mean \pm Stdev.; $n=3$ ) was measured in the raceways as a function of elapsed time after introducing Upper Three Runs water and prior to clay treatment. Turbidity decreased exponentially with time $\left(y=22\left(e^{-0.05 x}\right) ; R^{2}=0.88\right)$.

Fish mortality was tested by introducing 50 yellowfin shiners and 20 tessellated darters into the control, air-floated, and semi-dry illite treated raceways (Fig. 14). After seven days, no significant $(\mathrm{p}>0.05)$ differences in fish mortality occurred in control and illite treated raceways. Although fish mortality for yellowfin shiners was 4.0 and $2.7 \%$ for air-floated and semi-dry illite treated raceways, respectively, these differences were not statistically significant and fell within the range of mortality observed in the control raceway $(6.7 \%)$. Variables other than illite that likely contributed to fish mortality include stress of handling, life stage, physiological condition, water temperature, and disease. All 20 tessellated darters in each of the three replicates survived throughout the entire seven-day experiments. It is worthy to note that in preliminary experiments, when small refuges from the clay occurred in a raceway, many fish (both dusky shiners and tessellated darters) often remained in these areas, indicating a behavior avoidance of the clay. Such refuges were minimized in the three replicates. In the treatment of a real stream, many fish will likely avoid the clay treatment by migrating upstream, downstream or into any available side channels 
Table 8. Changes in turbidity (mean \pm Stdev.) for air-floated, semi-dry, and control treated raceways were measured before (BCA), during (DCA) and after clay application. Turbidity values were measured $1,2,4,8,24,48,96$, and 168 hours after the clay application and at 2, 3, 4, 5,6 , and $7 \mathrm{~m}$ of raceways.

\begin{tabular}{|c|c|c|c|c|c|c|}
\hline \multirow{2}{*}{ Time } & \multicolumn{6}{|c|}{ Sample Collection } \\
\hline & $2 \mathrm{~m}$ & $3 \mathrm{~m}$ & $4 \mathrm{~m}$ & $5 \mathrm{~m}$ & $6 \mathrm{~m}$ & $7 \mathrm{~m}$ \\
\hline & \multicolumn{6}{|c|}{ Air-floated Clay } \\
\hline $\mathrm{BCA}$ & $4.34 \pm 0.49$ & $4.17 \pm 0.43$ & $3.86 \pm 0.22$ & $4.26 \pm 0.90$ & $4.09 \pm 0.57$ & $4.34 \pm 0.49$ \\
\hline DCA & $525 \pm 250$ & $314 \pm 28.5$ & $232 \pm 38.3$ & $371 \pm 145$ & $364 \pm 68.1$ & $332 \pm 125$ \\
\hline $1 \mathrm{hr}$ & $21.1 \pm 13.8$ & $18.9 \pm 12.0$ & $20.3 \pm 14.1$ & $24.9 \pm 15.2$ & $28.3 \pm 18.1$ & $20.8 \pm 8.9$ \\
\hline $2 \mathrm{hr}$ & $9.57 \pm 2.02$ & $11.0 \pm 1.68$ & $23.4 \pm 5.16$ & $10.2 \pm 4.71$ & $11.2 \pm 2.26$ & $10.7 \pm 2.14$ \\
\hline $4 \mathrm{hr}$ & $5.58 \pm 1.45$ & $5.71 \pm 0.27$ & $6.16 \pm 1.47$ & $6.16 \pm 0.04$ & $7.19 \pm 0.01$ & $7.40 \pm 0.19$ \\
\hline $8 \mathrm{hr}$ & $4.41 \pm 0.02$ & $6.27 \pm 0.87$ & $7.00 \pm 1.40$ & $8.80 \pm 4.01$ & $9.45 \pm 4.32$ & $9.97 \pm 5.22$ \\
\hline $24 \mathrm{hr}$ & $4.26 \pm 0.06$ & $4.63 \pm 0.24$ & $5.56 \pm 0.03$ & $5.07 \pm 0.30$ & $4.58 \pm 0.14$ & $4.93 \pm 0.65$ \\
\hline $48 \mathrm{hr}$ & $4.60 \pm 1.35$ & $5.92 \pm 3.10$ & $5.98 \pm 3.02$ & $6.21 \pm 3.69$ & $6.95 \pm 4.71$ & $6.48 \pm 3.89$ \\
\hline $96 \mathrm{hr}$ & $4.17 \pm 0.36$ & $4.04 \pm 0.06$ & $4.57 \pm 0.21$ & $4.05 \pm 0.18$ & $4.03 \pm 0.20$ & $3.71 \pm 0.29$ \\
\hline \multirow[t]{2}{*}{$168 \mathrm{hr}$} & $5.76 \pm 0.91$ & $5.33 \pm 0.83$ & $5.12 \pm 1.00$ & $5.36 \pm 0.89$ & $5.89 \pm 1.01$ & $5.86 \pm 0.95$ \\
\hline & \multicolumn{6}{|c|}{$\underline{\text { Semi-dry Clay }}$} \\
\hline $\mathrm{BCA}$ & $.90 \pm 2.27$ & $4.50 \pm 0.76$ & $4.52 \pm 0.65$ & $4.66 \pm 0.84$ & $5.55 \pm 1.39$ & $5.22 \pm 0.61$ \\
\hline DCA & $72.1 \pm 49.5$ & $52.3 \pm 32.9$ & $50.7 \pm 19.5$ & $81.3 \pm 56.7$ & $75.2 \pm 53.1$ & $73.7 \pm 48.6$ \\
\hline $1 \mathrm{hr}$ & $5.94 \pm 1.21$ & $5.68 \pm 0.80$ & $5.35 \pm 0.80$ & $7.39 \pm 1.78$ & $10.0 \pm 6.39$ & $6.56 \pm 1.10$ \\
\hline $2 \mathrm{hr}$ & $7.53 \pm 1.62$ & $5.32 \pm 0.47$ & $6.11 \pm 0.31$ & $8.93 \pm 2.44$ & $7.62 \pm 1.59$ & $9.35 \pm 2.78$ \\
\hline $4 \mathrm{hr}$ & $4.87 \pm 1.41$ & $4.43 \pm 0.88$ & $4.66 \pm 1.71$ & $4.69 \pm 1.48$ & $5.22 \pm 2.48$ & $4.75 \pm 1.61$ \\
\hline $8 \mathrm{hr}$ & $4.21 \pm 0.54$ & $4.41 \pm 1.54$ & $3.77 \pm 0.15$ & $5.05 \pm 1.72$ & $5.25 \pm 2.23$ & $4.60 \pm 1.10$ \\
\hline $24 \mathrm{hr}$ & $4.00 \pm 0.57$ & $4.00 \pm 0.67$ & $3.67 \pm 0.05$ & $3.49 \pm 0.41$ & $3.54 \pm 0.26$ & $3.81 \pm 0.90$ \\
\hline $48 \mathrm{hr}$ & $4.28 \pm 0.77$ & $4.12 \pm 0.94$ & $4.45 \pm 1.24$ & $4.45 \pm 1.68$ & $4.96 \pm 2.15$ & $4.33 \pm 1.17$ \\
\hline $96 \mathrm{hr}$ & $3.82 \pm 0.53$ & $3.54 \pm 0.39$ & $3.71 \pm 0.16$ & $3.59 \pm 0.27$ & $3.65 \pm 0.15$ & $3.78 \pm 0.79$ \\
\hline \multirow[t]{2}{*}{$168 \mathrm{hr}$} & $5.14 \pm 1.50$ & $4.51 \pm 1.33$ & $4.36 \pm 0.73$ & $5.24 \pm 1.10$ & $4.58 \pm 0.99$ & $4.57 \pm 1.20$ \\
\hline & \multicolumn{6}{|c|}{ Control } \\
\hline BCA & $4.52 \pm 0.43$ & $4.41 \pm 0.57$ & $4.09 \pm 0.19$ & $4.85 \pm 0.82$ & $4.79 \pm 0.69$ & $4.59 \pm 0.45$ \\
\hline $\mathrm{DCA}$ & $4.12 \pm 0.34$ & $3.94 \pm 0.12$ & $3.87 \pm 0.35$ & $4.01 \pm 0.55$ & $4.18 \pm 0.27$ & $4.10 \pm 0.28$ \\
\hline $1 \mathrm{hr}$ & $3.72 \pm 0.31$ & $3.57 \pm 0.08$ & $3.50 \pm 0.20$ & $3.65 \pm 0.23$ & $3.86 \pm 0.39$ & $3.39 \pm 0.21$ \\
\hline $2 \mathrm{hr}$ & $4.45 \pm 0.18$ & $4.25 \pm 0.27$ & $4.17 \pm 0.40$ & $4.89 \pm 0.50$ & $4.65 \pm 0.39$ & $4.67 \pm 0.59$ \\
\hline $4 \mathrm{hr}$ & $5.89 \pm 0.36$ & $6.26 \pm 0.39$ & $5.93 \pm 0.37$ & $6.21 \pm 0.26$ & $5.53 \pm 0.31$ & $6.12 \pm 0.51$ \\
\hline $8 \mathrm{hr}$ & $4.52 \pm 0.43$ & $4.41 \pm 0.57$ & $4.09 \pm 0.19$ & $4.85 \pm 0.82$ & $4.79 \pm 0.69$ & $4.59 \pm 0.45$ \\
\hline $24 \mathrm{hr}$ & $5.06 \pm 1.18$ & $5.39 \pm 1.58$ & $5.22 \pm 1.49$ & $5.45 \pm 1.56$ & $5.35 \pm 1.41$ & $5.33 \pm 1.70$ \\
\hline $48 \mathrm{hr}$ & $3.72 \pm 0.31$ & $3.57 \pm 0.08$ & $3.50 \pm 0.20$ & $3.65 \pm 0.23$ & $3.86 \pm 0.39$ & $3.39 \pm 0.21$ \\
\hline $96 \mathrm{hr}$ & $4.45 \pm 0.18$ & $4.25 \pm 0.27$ & $4.17 \pm 0.40$ & $4.89 \pm 0.50$ & $4.65 \pm 0.39$ & $4.67 \pm 0.59$ \\
\hline $168 \mathrm{hr}$ & $5.06 \pm 1.18$ & $5.39 \pm 1.58$ & $5.22 \pm 1.49$ & $5.45 \pm 1.56$ & $5.35 \pm 1.41$ & $5.33 \pm 1.70$ \\
\hline
\end{tabular}




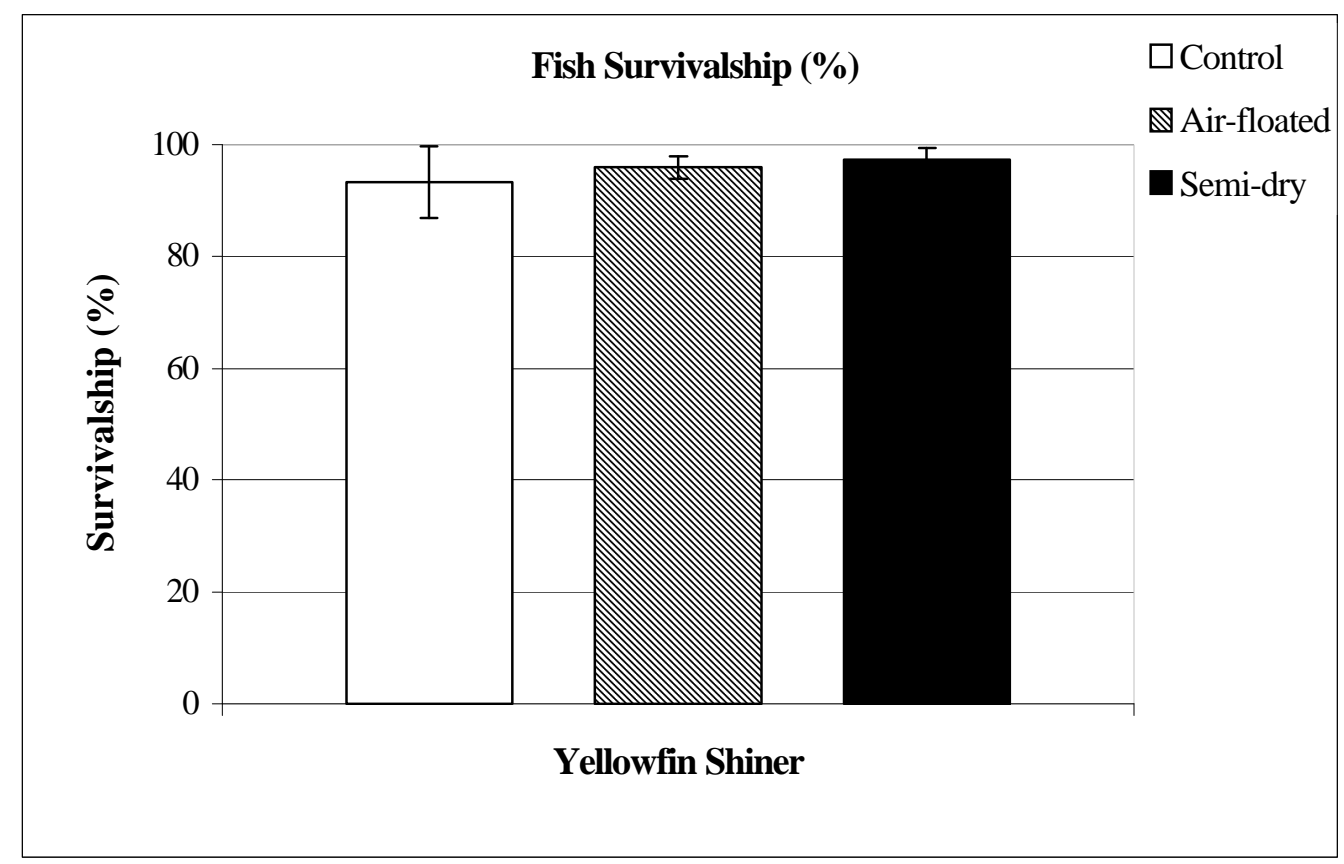

Figure 14. Mean ( \pm Stdev.) survivorship of yellowfin shiners collected from raceways. No significant differences $(p>0.05)$ exist among treatments for the fish survivorship.

\subsection{Survey of Potential SRS Locations for Future Field Deployment}

Selection of the best field site for clay application was based on physical, chemical, and biological characteristics of the streams, as well as accessibility (Table 9). We evaluated these parameters and the results are shown on a scale of 1-4 (1: being the best and 4: being the worst). Physical parameters such as water velocity, depth, and width of streams were measured (Table 10). Bio-abundance was visually monitored and indicated how many fish were in streams with the potential to evaluate the environmental impacts of the illite application.

The ${ }^{137}$ Cs levels in sediment and water represented chemical characteristics (Fig. 15). Since our main objective was to reduce the biological availability of ${ }^{137} \mathrm{Cs}$ in sensitive wetland environments, detectable concentration of ${ }^{137} \mathrm{Cs}$ in streams was critical. Ranking of the streams by their ${ }^{137} \mathrm{Cs}$ concentrations in sediments and water were: Fourmile Branch > Lower Three Runs > Pen Branch • Steel Creek. There were no significant differences ( $p>0.05)$ in ${ }^{137} \mathrm{Cs}$ concentrations in water between the middle and edge of the streams at any single sample location. Based on the results of the site evaluation, Fourmile Branch was suggested as a potential field site for illite remediation. 
Table 9. Evaluation of potential sites for illite application. Results showed on a scale of 1-4 (1: being the best and 4: being the worst).

\begin{tabular}{lcccc}
\hline Parameter & Fourmile Branch & Lower Three Runs & Pen Branch & Steel Creek \\
\hline Accessibility $^{\mathrm{a}}$ & 1 & 3 & 1 & 4 \\
Bio-abundance $^{\mathrm{b}}$ & 2 & 3 & 1 & 3 \\
${ }^{137}$ Cs concentration $^{\mathrm{c}}$ & 1 & 2 & 3 & 3 \\
Velocity/Width/Depth & 1 & 3 & 2 & 3 \\
\hline Total score & 5 & 11 & 7 & 13 \\
\hline Site Selection & 1 & 3 & 2 & 4 \\
\hline
\end{tabular}

abased on relative case to access the site to conduct a field demonstration

based on number of fish

based on ${ }^{137} \mathrm{Cs}$ concentrations in water and sediments of the streams

Table 10. Velocity, depth, and width (mean \pm Stdev.) at 3 locations on each stream were measured for comparison.

\begin{tabular}{lccc}
\hline Potential Site & Velocity $\left(\mathbf{m ~ s e c}^{\mathbf{- 1}}\right)$ & Depth $(\mathbf{c m})$ & Width $(\mathbf{m})$ \\
\hline Fourmile Branch & $0.71 \pm 0.13$ & $22.0 \pm 4.00$ & $3.10 \pm 0.75$ \\
Lower Three Runs & $1.00 \pm 0.37$ & $22.8 \pm 5.23$ & $8.87 \pm 0.40$ \\
Pen Branch & $0.32 \pm 0.12$ & $27.4 \pm 3.21$ & $23.0 \pm 3.21$ \\
Steel Creek & $0.74 \pm 0.22$ & $25.6 \pm 8.55$ & $5.47 \pm 1.45$ \\
\hline
\end{tabular}


WSRC-TR-2004-00125

SREL-73; UC-66e

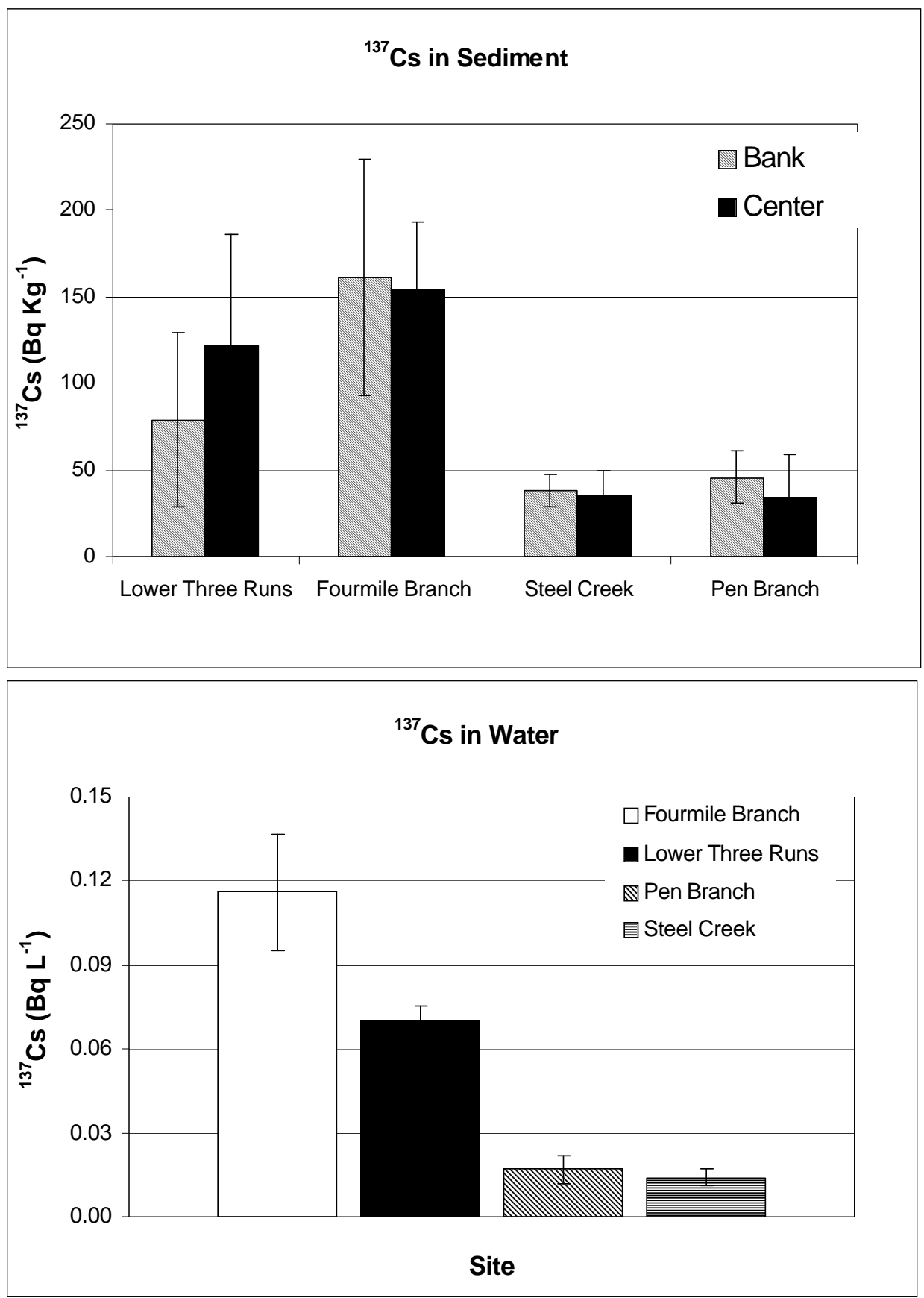

Figure 15. Concentration of ${ }^{137} \mathrm{Cs}$ (mean \pm Stdev.) in sediments and water in streams. A ranking of the ${ }^{137}$ Cs concentrations in sediments and water in streams as chemical characteristics would be Fourmile Branch > Lower Three Runs > Pen Branch • Steel Creek. 
WSRC-TR-2004-00125

SREL-73; UC-66e

\subsection{CONCLUSIONS AND IMPLICATIONS}

During this funding period (FY03) we re-sampled study sites in Pond A and R-Canal that had been treated with illite clays in 2001 . The data revealed that ${ }^{137} \mathrm{Cs}$ concentrations in water are still lower than untreated control sites, some 112 weeks later. This encouraging result indicates that the in situ remediation technique has a longer-term effectiveness that what was previously reported. This positive finding occurred despite the study site experiencing a severe drought, as well as flooded conditions during the two-year period.

Analyses of particle settling and flocculation rates among three commercially available illites (trade name Todd Light) that differed in particle size and moisture content revealed the flexibility of the clay application method and the versatility of the illites to different remediation needs. Air-floated Todd Light Illites were found to disperse quickly throughout the water column and would be ideal for remediating lakes, or possibly long reaches of a contaminated stream. If, however, small localized contaminated hot spots within streams are the target of remediation, then the crude Todd Light Illite's more rapid settling characteristics would allow one to place the mineral specifically where needed, rather than broadly dispersing it within the stream. More work on field deployment methods for various contaminant dispersal scenarios would be useful.

Applying the illite clays caused water turbidity to increase by two to three orders of magnitude. Although water clarity improved at an exponential rate, with a half-time of 1.2 days, some 100 days were required for the high clay treatments to reach the turbidity levels of control sites. The environmental impact of the turbid water was assessed by examining other water quality measurements, phytoplankton productivity, chlorophyll-a production, and the abundance of macro-invertebrates. No significant differences in $\mathrm{pH}$, electrical conductivity, dissolved oxygen or oxidation-reduction potential were found among treatments. Electrical conductivity values would be expected to decrease if the illites were absorbing ionic solutes from the water column, such as $\mathrm{K}_{\text {or }} \mathrm{NH}_{4}$. Thus, the clay application is not likely to decrease the availability of essential plant nutrients in treated waters. No significant differences were observed in phytoplankton productivity, chlorophyll-a, or respiration levels.

No differences in total numbers of macroinvertebrate insects were observed between controls and illite-treated limnocorrals. However, differences in species assemblages of macroinvertebrate insects were apparent between controls and high clay application treatments, two years after the initial clay application. No difference was found between the low clay applications and controls. The divergence in species assemblages among treatments significantly increased after the second clay application. These results are very encouraging in that they suggest that although impacts 
did occur to the macroinvertebrate community, recovery was occurring and that the impacts are not permanent.

When the illite was applied to flowing streams (raceways at the Aquatic Ecology Laboratory), water clarity returned within a matter of hours and fish mortality was not affected. This is an encouraging first approximation at gross effects that might occur in a stream application of the technique. The experiments were acute exposures to turbidity and conducted in artificial raceways, but we know little about the long-term effects to a stream ecosystem.

It is obvious that turbidity from the illite clay applications does much less damage to sensitive wetlands than other ${ }^{137} \mathrm{Cs}$ remediation strategies in which the wetland is totally drained and the contaminated sediments are dredged up and trucked to another locality. In situations were it is deemed absolutely necessary to remediate a ${ }^{137} \mathrm{Cs}$-contamaninate wetland, the use of an in situ illite application would preserve more of the ecosystem function than more destructive remediation methods. Additional measurements are needed to determine the long-term effectiveness of the technique and environmental impacts on parameters not measured in this study. When coupled to the earlier work of Hinton et al. (1999, 2001, 2002), the results reported herein support the use of illite applications to ${ }^{137}$ Cs-contaminated wetlands on the SRS as an alternative to more environmentally destructive remediation methods.

\subsection{ACKNOWLEDGEMENTS}

Authors are appreciative of the technical assistance provided by Jamie Marsh (SREL) and Yi Yi (SREL). This research was supported by WSRS-SGCP and by the Environmental Remediation Sciences Division of the Office of Biological and Environmental Research, U.S. Department of Energy, through Financial Assistance Award No. DE-FC09-96-SR18546 to the University of Georgia Research Foundation. Westinghouse Savannah River Company is operated for the U.S. Department of Energy under contract DE-AC09-96SR18500.

\subsection{REFERENCES}

Brigham, A.R., W.U. Brigham, and A. Gnilka, (ed.). 1982. Aquatic Insects and Oligochaetes of North and South Carolina. Midwest Aquatic Enterprises, Mahomet, IL.

Carlton, W.H., L.R. Bauer, A.G. Evans, L.A. Geary, C.E. Murphy Jr., J.E. Pinder, III, and R.N. Strom. 1992. Cesium in the Savannah River Site environment. Report No. WSRC-RP-92250. Westinghouse Savannah River Company, Aiken, SC. 
Clesceri L.S., A.E. Greenberg, and A.D. Eaton (ed.). 1998. Standard Methods for the Examination of Water and Wastewater. American Public Health Association, Washington, DC.

DeWoody, J.A., D.E. Fletcher, S.D. Wilkins, and J.C. Avise. 2000. Parentage and nest guarding in the tessellated darter (Etheostoma olmstedi) assayed by microsatellite markers (Perciformes : Percidae). Copeia 2000: 740-747.

Dupuis, L., and D. Steventon. 1999. Riparian management and the tailed frog in northern coastal forests. Forest Ecol. Manag. 124: 35-43.

Ellis, J., V. Cummings, J. Hewitt, S. Thrush, and A. Norkko. 2002. Determining the effects of suspended sediment on condition of a suspension feeding bivalve (Atrina zelandica): results of a survey, a laboratory experiment and a field transplant experiment. J. Exp. Mar. Biol. Ecol. 267: 147-174.

ERD. 2002. Environmental Restoration Division. Baseline Change Log 3003 Old R-Area Discharge Canal; May 6, 2002. BSRI, Aiken, SC.

Fletcher, D.E., S.D. Wilkins, J.V. McArthur, and G.K. Meffe. 2000. Influence of riparian alteration on canopy coverage and macrophyte abundance in southeastern USA blackwater streams. Ecol. Eng. 15, Suppl. 1: S67-S78.

Gale, W.F., and W.G. Deutsch. 1985. Fecundity and spawning behavior of captive tessellated darters - fractional spawners. Trans. Am. Fish. Soc. 114: 220-229.

Gillespie, G.R. 2002. Impact of sediment loads, tadpole density, and food type on the growth and development of tadpoles of the spotted tree frog Littoria spenceri: an in-stream experiment. Biol. Conserv. 106: 141-150.

Goldberg, S., B.S. Kapoor, and J.D. Rhoades. 1990. Effect of aluminum and iron oxides and organic matter on flocculation and dispersion of arid zone soils. Soil Sci. 150: 588-593.

Gray, L.J., and J.V. Ward. 1982. Effects of sediment releases from a reservoir on stream macroinvertebrates. Hydrobiologia 96: 177-184.

Grobbelar, J. 1985. Phytoplankton productivity in turbid waters. J. Plankton Res. 7: 653-663.

Hann, B.J., C.J. Mundy, and L.G. Goldsborough. 2001. Snail-periphyton interactions in a prarie lacustrine wetland. Hydobiologia 457: 167-175.

Hart. C., and S. Fuller (ed.). 1974. Pollution Ecology of Freshwater Invertebrates. Academic Press, NY.

Henley, W.F., M.A. Patterson, R.J. Neves, and A.D. Lemly. 2000. Effects of sedimentation and turbidity on lotic food webs: a concise review for natural resource managers. Rev. Fish. Sci. 8: 125-139. 
Hinton, T.G., D.I. Kaplan, A.C. Knox, and S.M. Serkiz. 1999. In situ remediation of ${ }^{137} \mathrm{Cs}$ contaminated wetlands using naturally occurring minerals. Report No. WSRC-TR-9900229. Westinghouse Savannah River Company, Savannah River Site, Aiken, SC.

Hinton, T.G., A. Knox, D.I. Kaplan and S. Serkiz. 2001. An in situ method for remediating ${ }^{137}$ Cs-contaminated wetlands using naturally occurring minerals. J. Radioanal. Nucl. Chem. 249: $197-202$.

Hinton, T.G., A. Knox, and D.I. Kaplan. 2002. Field Deployment of Illite Clay as an In Situ Method for Remediation ${ }^{137}$ Cs-contaminated Wetlands (U). Report No. WSRC-TR-200200516 and SREL-69 (UC-66E). 56 p.

Holz J.C., K.D. Hoagland, R.L. Spawn, A. Popp, and J.L. Andersen. 1997. Phytoplankton community response to reservoir aging, 1968-92. Hydrobiologia 346: 183-192.

Karr, J.R., K.D. Fausch, P.L. Angermeier, P.R. Yant, and I.J. Schlosser. 1986. Assessing biological integrity in running waters: a method and its rationale. Illinois Natural History Survey Special Publication 5.

Lenat D.R., D.L. Penrose, and K.W. Eagleson. 1981. Variable effects of sediment addition on stream benthos. Hydrobiologia 79: 187-194.

McAuliffe, J.R., and D.H. Bennett. 1981. Observations on the spawning habits of the yellowfin shiner, Notropis lutipinnis. J. Elisha Mitchell Sci. Soc. 97: 200-203.

Merritt, R.W., and K.W. Cummins. 1984. An Introduction to the Aquatic Insects of North America, $2^{\text {nd }}$ edition. Kendall/Hunt Publishing Co., Dubuque, IO.

Miller, W.P., and D.M. Miller. 1987. A micro-pipette method for soil mechanical analysis. Commun. Soil Sci. Plant Anal. 18: 1-15.

Newcombe C.P., and D.D. MacDonald. 1991. Effects of suspended sediments on aquatic ecosystems. North Am. J. Fish. Manag. 11: 72-82.

NRCS, Natural Resources Conservation Service. 1996. Soil Survey Laboratory Methods Manual. Soil Survey Investigations. Report No. 42. United States Department of Agriculture, Washington, DC, U.S.A.

Page, L.M. 1983. Handbook of darters. T. F. H. Publications Inc., Neptune City, NJ.

Paller, M.H., M.J.M. Reichert, and J.M. Dean. 1996. The use of fish communities to assess environmental impacts in South Carolina coastal plain streams. Trans. Am. Fish. Soc. 125: 633-644.

Paller, M.H., M.J.M. Reichert, J.M. Dean, and J.C. Seigle. 2000. Use of fish community data to evaluate restoration success in a riparian stream. Ecol. Eng. 15, Suppl. 1: S171-187.

RAC, Risk Assessment Corporation. 1999. Draft Final Report Savannah River Site Dose Reconstruction Project. Phase II: Source term Calculation and Ingestion Pathway Data 
Retrieval, Evaluation of Material Released from the Savannah River Site. RAC Report No.1-CDC-SRS-1999-Draft Final, Neeses, SC.

Ruhe, R.V., and E.A. Matney. 1980. Clay mineralogy of Selected Sediments and Soils. Report prepared by the Savannah River Laboratory. E. I. dePont de Nemours and Company, Aiken, SC.

SAS. 1999. SAS procedure guide. Version 8.01. SAS Inst. Inc. Cary, NC.

Seaman, J.C., T. Meehan, and P.M Bertsch. 2001. Immobilization of cesium-137 and uranium in contaminated sediments using soil amendments. J. Environ. Qual. 30: 1206-1213.

Sheldon, A.L., and G.K. Meffe. 1993. Multivariate analysis of feeding relationships of fishes in blackwater streams. Environ. Biol. Fish. 37: 161-171.

Sobral, P., and J. Widdows. 2000. Effects of increasing current velocity, turbidity, and particlesize selection of the feeding activity and scope for growth of Rudiitapes decussatus from Ria Formosa, southern Portugal. J. Exp. Mar. Biol. Ecol. 245: 111-125.

Wallin, J. E. 1989. Bluehead chub (Nocomis leptocephalus) nests used by yellowfin shiners (Notropis lutipinnis). Copeia 4: 1077-1080.

Wallin, J.E. 1992. The symbiotic nest association of yellowfin shiners, Notropis lutipinnis, and bluehead chubs, Nocomis leptocephalus. Environ. Biol. Fish. 33: 287-292.

Wetzel, R.G., and G.E. Likens. 1991. Limnological Analyses. W.B. Saunders Company, Philadelphia, PA.

Whicker, F.W., J.E. Pinder, J.W. Bowling, J.J. Alberts, and I.L. Brisbin. 1990. Distribution of long-lived radionuclides in an abandoned reactor cooling reservoir. Ecol. Monogr. 60: 471496.

Whicker, F.W., D.J. Niquett, and T.G. Hinton. 1993. To remediate or not: a case history p. 473485. In R.L. Kathren, D.H. Denham, and K. Salmon (ed.) Proceedings of the Twenty Sixth Mid Year Topical Meeting of the Health Physics Society: Environmental Health Physics. Columbia Chapter, Health Physics Society. Coeur d'Alene, ID.

Whicker, F.W., T.G. Hinton, M.M. MacDonnell, J.E. Pinder, III, and L.J. Habegger. (in press) Avoiding destructive remediation at DOE sites. Science. 12 March 2004

WSRC, 1998. Integrator operable unit work plan for the Fourmile Branch (U). WSRC-RP-97448, Rev.0. Westinghouse Savannah River Company, Aiken, SC. 


\subsection{APPENDIX A: TIMELINE OF ACTIVITY}

Nov.25, 2002

Jan. 2003

Feb. 3, 2003

Jan.-Feb, 2003

Feb. 12-29, 2003

Feb. 2003

March 5, 2003

March-April, 2003
The following final report was published on work done in FY02:

Hinton, T.G., A. Knox, and D.I. Kaplan. 2002. Field Deployment of Illite Clay as an In Situ Method for Remediation ${ }^{137}$ Cs-contaminated Wetlands (U). Report No. WSRC-TR-2002-00516 and SREL-69 (UC-66E). 56 p. Water samples were taken from each of the 16 limnocorrals in R-Canal and Pond $\mathrm{A}$ and assayed for ${ }^{137} \mathrm{Cs}$ and a suite of stable elements. These data are valuable for longer-term effectiveness of the remediation method.

Bonjun Koo, a postdoctoral researcher started to help on the project. $\mathrm{He}$ completed his radiation worker training (RW-II)

We spent considerable time looking at WSRC databases for IOUs such as Fourmile Branch, Steel Creek, Upper Three Runs, Pen Branch, and Lower Three Runs.

Sediment and water samples were taken from each IOUs for baseline data. They were counted for ${ }^{137} \mathrm{Cs}$. Took water quality measurements on each IOUs (table below). Physical parameters such as depth, width, and velocity were recorded for selecting the best field site for clay application.

\begin{tabular}{lcccc}
\hline Parameter & $\begin{array}{c}\text { Fourmile } \\
\text { Branch }\end{array}$ & $\begin{array}{l}\text { Lower } \\
\text { Three Runs }\end{array}$ & Pen Branch & Steel Creek \\
\hline DO $\left(\mathrm{mg} \mathrm{L}^{-1}\right)$ & 9.25 & 9.01 & 9.67 & 9.80 \\
EC $\left(\cdot \mathrm{S} \mathrm{cm}^{-1}\right)$ & 56 & 74 & 79 & 66 \\
ORP $(\mathrm{mV})$ & 316 & 256 & 279 & 304 \\
pH & 6.62 & 7.47 & 8.30 & 7.05 \\
Temp. $\left({ }^{0} \mathrm{C}\right)$ & 14.8 & 13.1 & 7.85 & 13.7 \\
TDS $\left(\mathrm{g} \mathrm{L}^{-1}\right)$ & 0.00 & 0.10 & 0.11 & 0.00 \\
\hline
\end{tabular}

$90.7 \mathrm{~kg}$ of each three different Illite clays (air-floated, semi-dry, and crude) from Kentucky-Tennessee Clay Company were ordered for laboratory and AEL experiments.

Hester-Dendy samplers were deployed in the 16 limnocorrals in R-Canal and Pond A for pre-testing. Two H-D samplers in each limnocorrals (4 control; no clay application, 5 LCA, and 6 HCA) were introduced except for limnocorral ${ }^{\#} 13$ (LCA) that had a huge hole.

Lab experiments to determine which type of illite clays will be the best for field application. Settling velocities, removal of ${ }^{137} \mathrm{Cs}$ in static water 
and dynamic water systems of Todd Light Illites were examined.

Physicochemical properties of the illites were also determined.

March 10,2003

StowAway TidbiT Temperature Loggers were deployed in limnocorrals

\#1 (control), 12 (LCA), 14 (HCA), and R-canal.

March 25, 2003

Pre-turbidity was checked for 24 hours in 3 raceways at AEL (data in table below). The pipes of raceway ${ }^{\#} 2$ and 3 were plugged (indicated as N/A) and the data was not available.

\begin{tabular}{lllccc}
\hline \multirow{2}{*}{ Raceway } & \multirow{2}{*}{ Date } & \multirow{2}{*}{ Time } & \multicolumn{3}{c}{ Turbidity (NTU) } \\
\cline { 5 - 6 } & & & Rep. 1 & Rep. 2 & Rep. 3 \\
\hline${ }^{\#} 1$ & $3 / 24 / 03$ & $8: 30 \mathrm{am}$ & 26.6 & 25.1 & 26.7 \\
${ }^{\#} 2$ & $3 / 24 / 03$ & $8: 30 \mathrm{am}$ & 34.6 & 31.3 & 33.8 \\
${ }_{3} 3$ & $3 / 24 / 03$ & $8: 30 \mathrm{am}$ & 12.2 & 12.1 & 12.2 \\
Blank (DI water) & $3 / 24 / 03$ & $8: 30 \mathrm{am}$ & 0.00 & 0.00 & 0.00 \\
\#1 $^{\#}$ & $3 / 25 / 03$ & $8: 30 \mathrm{am}$ & 7.70 & 7.14 & 7.30 \\
${ }_{2} 2$ & $3 / 25 / 03$ & $8: 30 \mathrm{am}$ & N/A & N/A & N/A \\
${ }_{3} 3$ & $3 / 25 / 03$ & $8: 30 \mathrm{am}$ & N/A & N/A & N/A \\
Blank (DI water) & $3 / 25 / 03$ & $8: 30 \mathrm{am}$ & 0.00 & 0.00 & 0.00 \\
\hline
\end{tabular}

April 2, 2003

Hester-Dendy samplers were collected for pre-testing. Insects were isolated, sorted, and identified for counting. Results indicated that there was no significance for number of insects at $p>0.05$ among treatments (table below).

\begin{tabular}{lll}
\hline Treatment & Sample No. & $\begin{array}{l}\text { Number of Individual } \\
\text { Invertebrates }\end{array}$ \\
\hline Control & LC1 & 12 \\
& LC6 & 27 \\
& LC9 & 37 \\
Treatment Avg \pm Stdev & LC10 & 23 \\
\hline LCA & LC4 & $24.8 \pm 10.3$ \\
& LC8 & 7 \\
& LC12 & 0 \\
& LC13 & 22 \\
& LC15 & 56 \\
Treatment Avg \pm Stdev & LC16 & 14 \\
HCA & LC2 & 17 \\
& LC3 & 3 \\
& LC5 & 20 \\
& LC7 & 14 \\
& LC11 & 14 \\
Treatment Avg \pm Stdev & LC14 & 17 \\
\hline
\end{tabular}


April-May, 2003

April 3, 2003

May 29-June 5, 2003

June 6, 2003

June 9, 2003

June 10-15, 2003
Prepared AEL experiments. We cleaned the raceways and modified the filtering system. Continued analyses for sediment and water samples produced by laboratory experiments.

Water samples were also taken from 16 limnocorrals in R-canal for chlorophyll-a analysis. No significant differences existed at $\mathrm{p}>0.05$ (table below).

\begin{tabular}{|c|c|c|}
\hline Treatment & Sample No. & Chlorophyll-a (ug L $\left.{ }^{-1}\right)$ \\
\hline \multirow[t]{3}{*}{ Control } & LC1 & 4.81 \\
\hline & LC9 & 8.02 \\
\hline & LC10 & 1.60 \\
\hline Treatment Avg \pm Stdev & & $4.81 \pm 3.21$ \\
\hline \multirow[t]{5}{*}{ LCA } & LC4 & 0.89 \\
\hline & LC12 & 2.67 \\
\hline & LC13 & 3.56 \\
\hline & LC15 & 0.00 \\
\hline & LC16 & 1.60 \\
\hline Treatment Avg \pm Stdev & & $1.75 \pm 1.41$ \\
\hline \multirow[t]{6}{*}{$\mathrm{HCA}$} & $\mathrm{LC} 2$ & 0.00 \\
\hline & LC3 & 2.14 \\
\hline & LC5 & 5.35 \\
\hline & LC7 & 2.14 \\
\hline & LC11 & 2.14 \\
\hline & LC14 & 2.67 \\
\hline Treatment Avg \pm Stdev & & $2.41 \pm 1.72$ \\
\hline
\end{tabular}

Raceways were examined for water velocity, depth and clay movement at AEL.

We fixed limnocorrals in R-canal for clay application that examined the environmental impacts.

Ordered 1.95 Mg (tonnes; 4,300 Ibs) of air-floated illites for applying clay into the limnocorrals. $30 \mathrm{H}-\mathrm{D}$ multiplate samplers were placed in twelve of the 16 limnocorrals located in R-Canal and Pond A.

Collected 5 fish species such as mosquito fish (Gambusia affinis), dusky shiner (Notropis cummingsae), yellowfin shiner (Notropis lutipinnis), tesellated darter (Etheostoma olmstedi), and blackbaned darter (Percina nigrofasciata) in the Fourmile Branch and introduced them into a raceway for selecting two species for clay experiments. Based on the result of survival (table below) and literature review, we selected tessellated darters for a bottom-feeder and yellowfin shiners for a topfeeder as study organisms. 
WSRC-TR-2004-00125

SREL-73; UC-66e

\begin{tabular}{lcc}
\hline Fish & No. of Fish Introduced & No. of Fish Survived \\
\hline Mosquito & 12 & 9 \\
Dusky shiner & 12 & 11 \\
Yellowfin shiner & 12 & 12 \\
Tesellated darter & 12 & 12 \\
Blackbaned darter & 7 & 7 \\
\hline
\end{tabular}

June 16, 2003

Collected 50 tessellated darters and 50 yellowfin shiner in Fourmile

Branch. Started AEL experiments to evaluate the effect of clay

application on fish mortality and sedimentation in continuous flowing

raceways and static fish tanks. Twelve yellowfin shiners and 9 tessellated

darters were introduced into a raceway. Those were collected on 16 July, 2003 (1 month after) for fish mortality. We also put 12 yellowfin shiner and 2 tessellated darters into $125.4 \mathrm{~L}$ static fish tanks $(56.5 \mathrm{~cm} \mathrm{X} 48 \mathrm{~cm})$ and fish were collected on 16 September, 2003 (3 months after) for fish mortality. Results indicated that there are no significant differences between air-floated clay treatment and control ( $p>0.05)$. During the experiment, turbidity was also checked.

June 20, 2003

$0.76 \mathrm{~kg}$ of air-floated illite was applied into static fish tanks and measured turbidity and fish mortality. The applied amount of illite was equivalent amount, which we applied into limnocorrals can cover the sediment with $0.25 \mathrm{~cm}$ illite.

June 27, 2003 $1.95 \mathrm{Mg}(4,300 \mathrm{Ibs})$ of air-floated air-floated were arrived.

June 30, 2003

July-Sep., 2003 14 pre-treated H-D samplers were collected.

Performed AEL experiments and limnocorral experiments in R-Canal and Pond A for evaluating environmental impacts of clay application.

July 1, 2003 Turbidity and water quality measurement were taken from limnocorrals for BCA baseline data. 3-liter water samples were also taken.

July 3-4, 2003 Turbidity samples were taken.

July 3, 2003 Clay amendments were added to the limnocorrals in R-Canal and Pond A. The limnocorrals were randomly chosen for low clay application, high clay application, and controls (no clay application). $27.22 \mathrm{~kg}$ of clay was added to the low application limnocorrals. $272.2 \mathrm{~kg}$ of clay was added to the high application limnocorrals.

July 10, 2003 15 H-D samplers were collected one week after clay application. 
July $7,10,15,17$, Water quality was done on each limnocorral with the hydrolab. Also,

and 21, 2003

July 7, 15, 21, 2003

July 15, 21, 2003

July 22-23, 2003

July 24-Aug. 4, 2003

July 28, 2003

Aug. 4, 2003

Aug. 11, 2003

Aug. 14-15, 2003

Aug. 19, 2003

Aug. 26, 2003

Sep. 3-5, 2003

Sep. 9, 2003

Sep. 16, 2003

Sep. 22, 2003 turbidity samples were collected.

Phytoplankton productivity was measured using the dissolved oxygen method.

Water samples were taken from 14 limnocorrals for chlorophyll-a analyses. Samples were taken about $5 \mathrm{~cm}$ below the water surface. $1^{\text {st }}$ replicate for fish mortality and sedimentation experiment: Using backpack electrofishers and a 3-mm mesh seine, fish were collected.

50 yellowfin shiners and 20 tessellated darters introduced into raceways for clay experiment.

$9.78 \mathrm{~kg}$ of air-floated and semi-dry illites was applied into raceways and measured turbidity on 28, 29, 30 July, and 1, 4 August, 2003. The applied amount of illite was equivalent amount, can cover the sediment with $0.25 \mathrm{~cm}$ illite.

$1^{\text {st }}$ fish collection from raceways for fish mortality and sedimentation was also measured for clay movement.

38 days after the clay application, 15 H-D samplers were deployed to evaluate longer-term effect of clay application on macroinvertebrates. Final turbidity samples were taken from all 16 limnocorrals. $2^{\text {nd }}$ replicate for fish mortality and sedimentation experiment. Air-floated and semi-dry illites was applied into raceways and measured turbidity on 19, 20, 21, 23, and 26 August, 2003.

$2^{\text {nd }}$ fish collection from raceways.

$3^{\text {rd }}$ replicate for fish mortality and sedimentation experiment.

Illite were introduced and measured turbidity on 9, 10, 11, 13, and 16 September, 2003.

$3^{\text {rd }}$ fish collection from raceways and

$15 \mathrm{H}$-D samplers were collected from the limnocorrals. 